\title{
Cochrane
}

Library

Cochrane Database of Systematic Reviews

\section{Direct oral anticoagulants versus warfarin for preventing stroke and systemic embolic events among atrial fibrillation patients with chronic kidney disease (Review)}

Kimachi M, Furukawa TA, Kimachi K, Goto Y, Fukuma S, Fukuhara S

Kimachi M, Furukawa TA, Kimachi K, Goto Y, Fukuma S, Fukuhara S.

Direct oral anticoagulants versus warfarin for preventing stroke and systemic embolic events among atrial fibrillation patients with chronic kidney disease.

Cochrane Database of Systematic Reviews 2017, Issue 11. Art. No.: CD011373.

DOI: 10.1002/14651858.CD011373.pub2.

www.cochranelibrary.com

Direct oral anticoagulants versus warfarin for preventing stroke and systemic embolic events among atrial fibrillation patients with chronic kidney disease (Review)

Copyright @ 2017 The Cochrane Collaboration. Published by John Wiley \& Sons, Ltd. 
TABLE OF CONTENTS

HEADER

ABSTRACT

PLAIN LANGUAGE SUMMARY

SUMMARY OF FINDINGS

2

BACKGROUND

OBJECTIVES

METHODS

RESULTS

Figure 1.

Figure 2.

Figure 3.

DISCUSSION

AUTHORS' CONCLUSIONS

ACKNOWLEDGEMENTS

REFERENCES

CHARACTERISTICS OF STUDIES

DATA AND ANALYSES

Analysis 1.1. Comparison 1 Direct oral anticoagulants versus warfarin, Outcome 1 All strokes and systemic embolic events. ...

Analysis 1.2. Comparison 1 Direct oral anticoagulants versus warfarin, Outcome 2 Ischaemic stroke.

Analysis 1.3. Comparison 1 Direct oral anticoagulants versus warfarin, Outcome 3 Haemorrhagic stroke.

Analysis 1.4. Comparison 1 Direct oral anticoagulants versus warfarin, Outcome 4 Major bleeding.

Analysis 1.5. Comparison 1 Direct oral anticoagulants versus warfarin, Outcome 5 Myocardial infarction.

Analysis 1.6. Comparison 1 Direct oral anticoagulants versus warfarin, Outcome 6 Minor bleeding.

Analysis 1.7. Comparison 1 Direct oral anticoagulants versus warfarin, Outcome 7 Gastrointestinal bleeding.

Analysis 1.8. Comparison 1 Direct oral anticoagulants versus warfarin, Outcome 8 Intracranial haemorrhage.

Analysis 1.9. Comparison 1 Direct oral anticoagulants versus warfarin, Outcome 9 All-cause mortality.

Analysis 2.1. Comparison 2 Direct oral anticoagulants versus warfarin: subgroup analysis for participants with $\mathrm{CrCl} 30$ to $50 \mathrm{~mL} /$ min, Outcome 1 All strokes and systemic embolic events.

Analysis 2.2. Comparison 2 Direct oral anticoagulants versus warfarin: subgroup analysis for participants with $\mathrm{CrCl} 30$ to $50 \mathrm{~mL} /$ min, Outcome 2 Major bleeding.

Analysis 3.1. Comparison 3 Direct oral anticoagulants versus warfarin: subgroup analysis for participants with $\mathrm{CrCl} 15$ to $30 \mathrm{~mL} /$ min, Outcome 1 All strokes and systemic embolic events.

Analysis 3.2. Comparison 3 Direct oral anticoagulants versus warfarin: subgroup analysis for participants with $\mathrm{CrCl} 15$ to $30 \mathrm{~mL} /$ min, Outcome 2 Major bleeding.

Analysis 4.1. Comparison 4 Direct oral anticoagulants versus warfarin: subgroup analysis for different doses of DOAC, Outcome 1 All strokes and systemic embolic events.

Analysis 4.2. Comparison 4 Direct oral anticoagulants versus warfarin: subgroup analysis for different doses of DOAC, Outcome 2 Major bleeding.

Analysis 4.3. Comparison 4 Direct oral anticoagulants versus warfarin: subgroup analysis for different doses of DOAC, Outcome 3 All-cause mortality.

Analysis 5.1. Comparison 5 Direct oral anticoagulants versus warfarin: adverse events, Outcome 1 Epistaxis.

Analysis 5.2. Comparison 5 Direct oral anticoagulants versus warfarin: adverse events, Outcome 2 Nasopharyngitis.

Analysis 5.3. Comparison 5 Direct oral anticoagulants versus warfarin: adverse events, Outcome 3 Diarrhoea.

Analysis 5.4. Comparison 5 Direct oral anticoagulants versus warfarin: adverse events, Outcome 4 Upper respiratory tract inflammation.

Analysis 5.5. Comparison 5 Direct oral anticoagulants versus warfarin: adverse events, Outcome 5 Back pain.

Analysis 5.6. Comparison 5 Direct oral anticoagulants versus warfarin: adverse events, Outcome 6 Cardiac failure.

Analysis 6.1. Comparison 6 Direct oral anticoagulants versus warfarin: fixed-effect model, Outcome 1 All strokes and systemic embolic events.

Analysis 6.2. Comparison 6 Direct oral anticoagulants versus warfarin: fixed-effect model, Outcome 2 Major bleeding. ........... ADDITIONAL TABLES 
[Intervention Review]

\title{
Direct oral anticoagulants versus warfarin for preventing stroke and systemic embolic events among atrial fibrillation patients with chronic kidney disease
}

\author{
Miho Kimachi ${ }^{1}$, Toshi A Furukawa², Kimihiko Kimachi ${ }^{1}$, Yoshihito Goto ${ }^{3}$, Shingo Fukuma1 ${ }^{1}$, Shunichi Fukuhara1,4 \\ 1Department of Healthcare Epidemiology, School of Public Health in the Graduate School of Medicine, Kyoto University, Kyoto, Japan. \\ 2Department of Health Promotion and Human Behavior, Kyoto University Graduate School of Medicine/School of Public Health, Kyoto, \\ Japan. ${ }^{3}$ Department of Health Informatics, Kyoto University School of Public Health, Kyoto, Japan. ${ }^{4}$ Center for Innovative Research for \\ Communities and Clinical Excellence, Fukushima Medical University, Fukushima, Japan
}

Contact address: Miho Kimachi, Department of Healthcare Epidemiology, School of Public Health in the Graduate School of Medicine, Kyoto University, Yoshida Konoe-cho, Sakyo-ku, Kyoto, Kyoto, 606-8501, Japan. kimachi.miho.5c@kyoto-u.ac.jp.

Editorial group: Cochrane Kidney and Transplant Group.

Publication status and date: New, published in Issue 11, 2017.

Citation: Kimachi M, Furukawa TA, Kimachi K, Goto Y, Fukuma S, Fukuhara S. Direct oral anticoagulants versus warfarin for preventing stroke and systemic embolic events among atrial fibrillation patients with chronic kidney disease. Cochrane Database of Systematic Reviews 2017, Issue 11. Art. No.: CD011373. DOI: 10.1002/14651858.CD011373.pub2.

Copyright @ 2017 The Cochrane Collaboration. Published by John Wiley \& Sons, Ltd.

\section{A B S T R A C T}

\section{Background}

Chronic kidney disease (CKD) is an independent risk factor for atrial fibrillation (AF), which is more prevalent among CKD patients than the general population. AF causes stroke or systemic embolism, leading to increased mortality. The conventional antithrombotic prophylaxis agent warfarin is often prescribed for the prevention of stroke, but risk of bleeding necessitates regular therapeutic monitoring. Recently developed direct oral anticoagulants (DOAC) are expected to be useful as alternatives to warfarin.

\section{Objectives}

To assess the efficacy and safety of DOAC including apixaban, dabigatran, edoxaban, and rivaroxaban versus warfarin among AF patients with CKD.

\section{Search methods}

We searched the Cochrane Kidney and Transplant Specialised Register (up to 1 August 2017) through contact with the Information Specialist using search terms relevant to this review. Studies in the Specialised Register are identified through searches of CENTRAL, MEDLINE, and EMBASE, conference proceedings, the International Clinical Trials Register (ICTRP) Search Portal, and ClinicalTrials.gov.

\section{Selection criteria}

We included all randomised controlled trials (RCTs) which directly compared the efficacy and safety of direct oral anticoagulants (direct thrombin inhibitors or factor Xa inhibitors) with dose-adjusted warfarin for preventing stroke and systemic embolic events in non-valvular AF patients with CKD, defined as creatinine clearance ( $\mathrm{CrCl}$ ) or eGFR between 15 and $60 \mathrm{~mL} / \mathrm{min}$ (CKD stage G3 and G4).

\section{Data collection and analysis}

Two review authors independently selected studies, assessed quality, and extracted data. We calculated the risk ratio (RR) and 95\% confidence intervals $(95 \% \mathrm{Cl})$ for the association between anticoagulant therapy and all strokes and systemic embolic events as the primary efficacy outcome and major bleeding events as the primary safety outcome. Confidence in the evidence was assessing using GRADE. 


\section{Main results}

Our review included 12,545 AF participants with CKD from five studies. All participants were randomised to either DOAC (apixaban, dabigatran, edoxaban, and rivaroxaban) or dose-adjusted warfarin. Four studies used a central, interactive, automated response system for allocation concealment while the other did not specify concealment methods. Four studies were blinded while the other was partially open-label. However, given that all studies involved blinded evaluation of outcome events, we considered the risk of bias to be low. We were unable to create funnel plots due to the small number of studies, thwarting assessment of publication bias. Study duration ranged from 1.8 to 2.8 years. The large majority of participants included in this study were CKD stage G3 $(12,155)$, and a small number were stage G4 (390). Of 12,545 participants from five studies, a total of 321 cases (2.56\%) of the primary efficacy outcome occurred per year. Further, of 12,521 participants from five studies, a total of 617 cases $(4.93 \%)$ of the primary safety outcome occurred per year. DOAC appeared to probably reduce the incidence of stroke and systemic embolism events (5 studies, 12,545 participants: $\mathrm{RR} 0.81,95 \% \mathrm{Cl} 0.65$ to 1.00 ; moderate certainty evidence) and to slightly reduce the incidence of major bleeding events (5 studies, 12,521 participants: RR 0.79 , 95\% $\mathrm{Cl} 0.59$ to 1.04 ; low certainty evidence) in comparison with warfarin.

\section{Authors' conclusions}

Our findings indicate that DOAC are as likely as warfarin to prevent all strokes and systemic embolic events without increasing risk of major bleeding events among AF patients with kidney impairment. These findings should encourage physicians to prescribe DOAC in AF patients with CKD without fear of bleeding. The major limitation is that the results of this study chiefly reflect CKD stage G3. Application of the results to CKD stage G4 patients requires additional investigation. Furthermore, we could not assess CKD stage G5 patients. Future reviews should assess participants at more advanced CKD stages. Additionally, we could not conduct detailed analyses of subgroups and sensitivity analyses due to lack of data.

\section{PLAIN LANGUAGE SUMMARY}

\section{Direct oral anticoagulants for prevention of stroke in atrial fibrillation patients with chronic kidney disease}

\section{What is the issue?}

Chronic kidney disease (CKD) patients have an increased risk of atrial fibrillation (AF), which can often lead to stroke or systemic embolism. The conventional therapy for preventive AF is dose-adjusted warfarin, but this can increase the risk of bleeding, which necessitates regular therapeutic monitoring. Recently, direct oral anticoagulants (DOAC) have been developed as alternatives to warfarin. We reviewed the evidence on DOAC compared to warfarin for preventing stroke and systemic embolic events in AF patients with CKD.

\section{What did we do?}

We found five studies that compared the effects of DOAC (apixaban, dabigatran, edoxaban, and rivaroxaban) and dose-adjusted warfarin. The 12,545 participants in these five studies had non-valvular AF and moderate kidney impairment. These studies presented data on all composite outcomes of stroke and systematic embolic events as the primary efficacy outcome, with major bleeding events as the primary safety outcome. The median follow-up period ranged from 1.8 to 2.8 years. The evidence is accurate as of August 2017.

\section{What did we find?}

DOAC probably reduced the incidence of stroke and systemic embolic events as a primary efficacy outcome, compared to warfarin. Further, DOAC might slightly reduce the incidence of major bleeding events as a primary safety outcome, compared to warfarin.

\section{Conclusions}

This review demonstrated that DOAC are as likely as warfarin to prevent all strokes and systemic embolic events without increasing major bleeding events among AF patients with CKD. According to GRADE, the quality of the evidence was moderate for the primary efficacy outcome because of concerns with imprecision and low for the primary safety outcome because of concerns with inconsistency and imprecision. The results of this study chiefly apply to CKD stage G3 patients, since we could not assess those with CKD stage G4 or G5. 


\begin{tabular}{|c|c|c|c|c|c|c|}
\hline \multirow{12}{*}{ 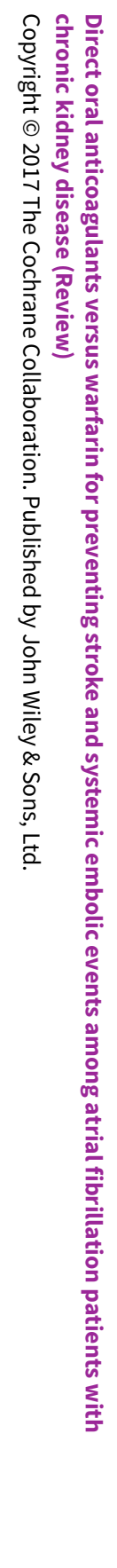 } & \multicolumn{6}{|c|}{$\begin{array}{l}\text { S U M M A R Y O F F I N D I N G S } \\
\text { Summary of findings for the main comparison. Direct oral anticoagulants (DOAC) versus warfarin for preventing stroke and systemic embolic events } \\
\text { among atrial fibrillation patients with chronic kidney disease (CKD) }\end{array}$} \\
\hline & \multicolumn{6}{|c|}{ DOAC versus warfarin for preventing stroke and systemic embolic events among atrial fibrillation patients with CKD } \\
\hline & \multicolumn{6}{|c|}{$\begin{array}{l}\text { Patient or population: atrial fibrillation patients with CKD } \\
\text { Setting: Hospital-based setting } \\
\text { Intervention: DOAC } \\
\text { Comparison: Dose-adjusted warfarin }\end{array}$} \\
\hline & \multirow[t]{3}{*}{ Outcomes } & \multicolumn{2}{|c|}{ Illustrative comparative risks* $(95 \% \mathrm{CI})$} & \multirow{3}{*}{$\begin{array}{l}\text { Relative effect } \\
(95 \% \mathrm{CI})\end{array}$} & \multirow{3}{*}{$\begin{array}{l}\text { No. of partici- } \\
\text { pants } \\
\text { (studies) }\end{array}$} & \multirow{3}{*}{$\begin{array}{l}\text { Quality of the evi- } \\
\text { dence } \\
\text { (GRADE) }\end{array}$} \\
\hline & & Assumed risk & Corresponding risk & & & \\
\hline & & Warfarin & DOAC & & & \\
\hline & $\begin{array}{l}\text { All strokes and } \\
\text { systemic embolic events } \\
\text { Follow up: } 1.8 \text { years to } 2.8 \text { years }\end{array}$ & 29 per 1,000 & $\begin{array}{l}23 \text { per } 1,000 \\
\text { (19 to } 29)\end{array}$ & RR 0.81 (0.65 to 1.00$)$ & $12,545(5)$ & $\begin{array}{l}\oplus \oplus \oplus \ominus^{1} \\
\text { MODERATE }\end{array}$ \\
\hline & $\begin{array}{l}\text { Major bleeding } \\
\text { Follow up: } 1.8 \text { years to } 2.8 \text { years }\end{array}$ & 55 per 1,000 & $\begin{array}{l}43 \text { per } 1,000 \\
\text { (32 to } 57)\end{array}$ & RR 0.79 (0.59 to 1.04$)$ & $12,521(5)$ & $\begin{array}{l}\oplus \oplus \Theta \Theta^{12} \\
\mathrm{LOW}\end{array}$ \\
\hline & $\begin{array}{l}\text { Myocardial infarction } \\
\text { Follow up: } 2.8 \text { years }\end{array}$ & 11 per 1,000 & $\begin{array}{l}10 \text { per } 1,000 \\
(5 \text { to } 21)\end{array}$ & RR 0.92 (0.45 to 1.90$)$ & $2,740(1)$ & - \\
\hline & $\begin{array}{l}\text { Minor bleeding } \\
\text { Follow up: } 2.5 \text { years to } 2.8 \text { years }\end{array}$ & 74 per 1,000 & $\begin{array}{l}72 \text { per } 1,000 \\
\text { (43 to } 119 \text { ) }\end{array}$ & $\begin{array}{l}\text { RR } 0.97 \\
\text { (0.58 to } 1.61)\end{array}$ & $3,012(2)$ & $\begin{array}{l}\oplus \oplus \Theta \Theta^{12} \\
\mathrm{LOW}\end{array}$ \\
\hline & $\begin{array}{l}\text { Gastrointestinal bleeding } \\
\text { Follow up: } 1.9 \text { years to } 2.8 \text { years }\end{array}$ & 17 per 1,000 & $\begin{array}{l}24 \text { per } 1,000 \\
\text { (17 to } 35)\end{array}$ & $\begin{array}{l}\text { RR } 1.40 \\
\text { (0.97 to } 2.01 \text { ) }\end{array}$ & $5,678(2)$ & $\begin{array}{l}\oplus \oplus \oplus \Theta^{1} \\
\text { MODERATE }\end{array}$ \\
\hline & $\begin{array}{l}\text { Intracranial haemorrhage } \\
\text { Follow up: } 1.8 \text { years to } 2.8 \text { years }\end{array}$ & 14 per 1,000 & $\begin{array}{l}6 \text { per } 1,000 \\
(4 \text { to } 9)\end{array}$ & RR 0.43 (0.27 to 0.69$)$ & $12,521(5)$ & $\begin{array}{l}\oplus \oplus \oplus \Theta^{1} \\
\text { MODERATE }\end{array}$ \\
\hline
\end{tabular}




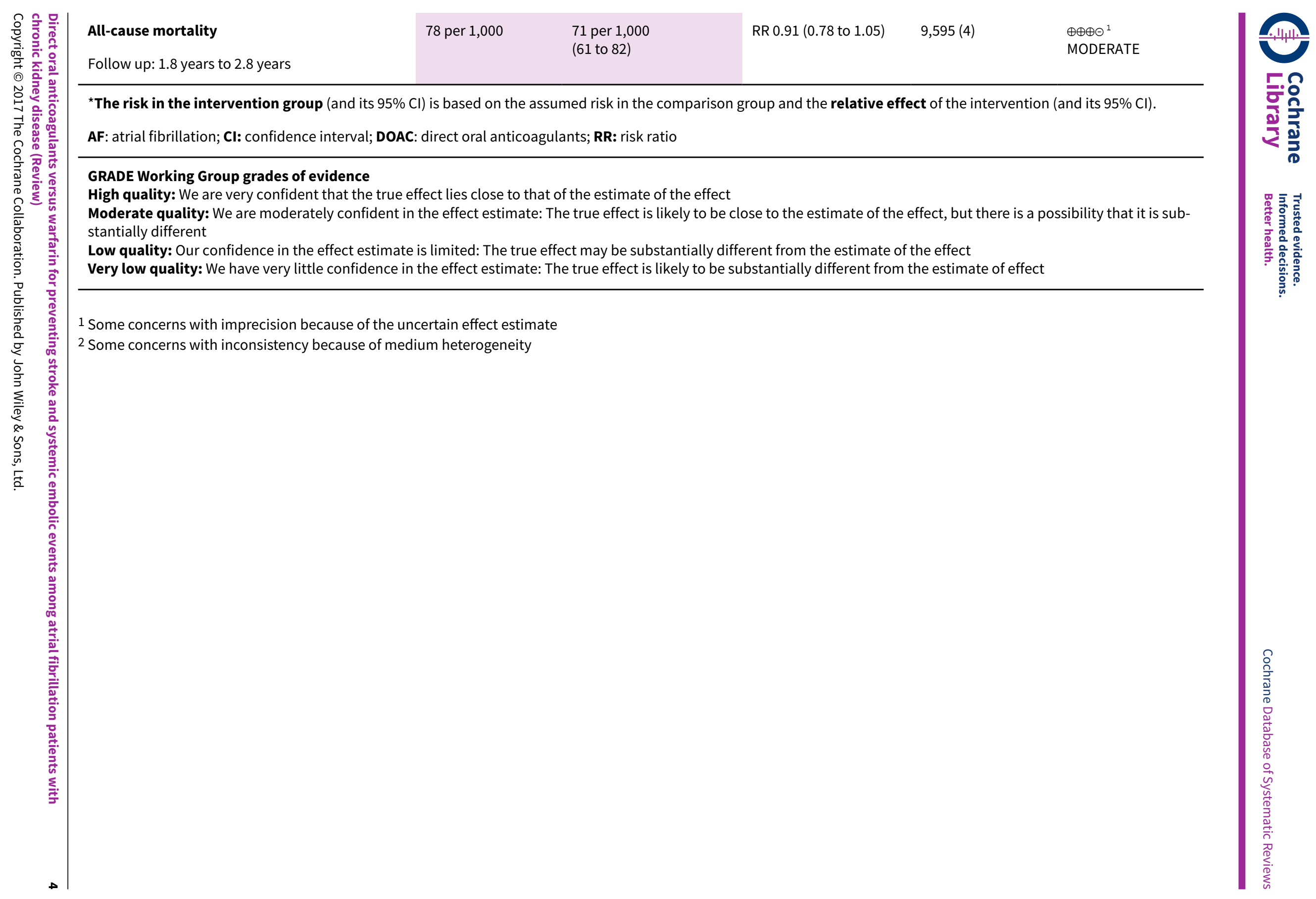




\section{B A C K G R O U N D}

\section{Description of the condition}

Atrial fibrillation (AF) is the most common form of sustained arrhythmia and causes irregular and rapid heart rate. Common symptoms are palpitation and chest pain; some people also experience fainting spells.

Chronic kidney disease (CKD) is an independent risk factor for AF (Go 2009). It has been reported that AF prevalence among CKD patients is much higher than the $1 \%$ to $2 \%$ prevalence in the general population (Alonso 2011; Go 2001; Nelson 2012; Stewart 2001). A recent study demonstrated AF prevalence of $16 \%$ for patients with estimated glomerular filtration rate (eGFR) of $45 \mathrm{~mL} / \mathrm{min}$ or more and $20.4 \%$ prevalence for those with eGFR $<45 \mathrm{~mL} / \mathrm{min}$ (Soliman 2010). CKD is defined as kidney structure or function abnormality present for more than three months, with health implications. CKD is classified into stage 1 (eGFR $\geq 90 \mathrm{~mL} / \mathrm{min}$ ); stage 2 (60 to $89 \mathrm{~mL}$ ) min); stage $3 a$ ( 45 to $59 \mathrm{~mL} / \mathrm{min}$ ); stage $3 \mathrm{~b}$ (30 to $44 \mathrm{~mL} / \mathrm{min}$ ); stage 4 (15 to $29 \mathrm{~mL} / \mathrm{min}$ ); and stage 5 (<15 mL/min) (KDIGO 2012).

CKD and AF have several risk factors in common, such as increasing age, hypertension, diabetes mellitus and other pre-existing heart diseases. Once people suffer from CKD, further multiple factors are associated with AF such as activation of the renin-angiotensinaldosterone system, chronic inflammation, vascular calcification, and left ventricular hypertrophy (Ng 2013). AF is associated with stroke or systemic embolism, leading to increased morbidity or mortality. Stroke due to AF are attributed to the poor contractile status of the left atrium and blood stasis in the atrium that leads to thrombus formation (Watson 2009). It has been shown that reduced eGFR and proteinuria were independently associated with the incidence of thromboembolism in patients with $\mathrm{AF}$ after adjusting for other stroke risk factors (Go 2009).

\section{Description of the intervention}

It has been reported that anticoagulation therapy reduces the risk of thromboembolic events in AF patients with normal kidney function. The conventional antithrombotic prophylaxis agent is a vitamin $\mathrm{K}$ antagonist such as warfarin. Efficacy of dose-adjusted warfarin for preventing AF-related stroke has been reported to be better (risk reduction of $60 \%$ ) than aspirin (20\% risk reduction) (Hart 2007). However, warfarin has some limitations: it has multiple dietary interactions, especially with vitamin $\mathrm{K}$, and concomitant drugs; and takes two to three days to begin working. Because warfarin has a narrow therapeutic window, and inadequate control results in haemorrhage, guidelines suggest that warfarin levels should be controlled within the range of the international normalised ratio (INR) of 2.0 to 3.0 (EHRA-EACTS 2010). In people with CKD, further warfarin-related complications may arise because risk of haemorrhage is increased (Olsen 2012). Warfarin use for people with end-stage kidney disease is particularly challenging because of the risk of serious bleeding; however, people with CKD patients in earlier stages with AF may benefit from warfarin.

Recently, direct oral anticoagulants (DOAC) have been developed as alternatives to vitamin $\mathrm{K}$ agonists. It has been reported that DOAC such as direct thrombin inhibitors and factor Xa inhibitors are associated with lower risks of stroke and bleeding than vitamin $\mathrm{K}$ agonists in people with normal kidney function (Bruins Slot 2013;
Miller 2012; Mitchell 2013). DOAC provide rapid onset of action and do not need regular monitoring because they do not interact with foods or other drugs (Eriksson 2011). Currently, major regulatory agencies (EMA 2014; FDA 2014; Health Canada 2017) have approved the DOAC for AF patients with CKD stage G3 or G4 (creatinine clearance $(\mathrm{CrCl})$ or eGFR between 15 and $60 \mathrm{~mL} / \mathrm{min}$ ) (Table 1), but evidence supporting their use is limited (Reinecke 2013).

\section{How the intervention might work}

Warfarin indirectly interrupts the extrinsic coagulation cascade by inhibiting the synthesis of vitamin K-dependent clotting factors II, VII, IX, and X. In contrast, factor Xa inhibitors including apixaban, edoxaban and rivaroxaban directly interrupt the activity of clotting factor $\mathrm{Xa}$, which converts prothrombin to thrombin. In addition, direct thrombin inhibitors such as dabigatran also act by directly inhibiting thrombin.

Bruins Slot 2013 showed that DOAC significantly decreased the number of stroke and other systemic embolic events compared with dose-adjusted warfarin in AF patients regardless of kidney function (odds ratio (OR) $0.81,95 \%$ confidence interval $(\mathrm{Cl}) 0.72$ to 0.91 ) and reduced major bleeding (OR $0.89,95 \% \mathrm{Cl} 0.81$ to 0.98 ).

\section{Why it is important to do this review}

The number of people with CKD and AF is rising annually. The risk for stroke or systemic thromboembolism due to AF in people with CKD is significantly higher than in those with normal kidney function (hazard ratio (HR) $1.49,95 \% \mathrm{Cl} 1.38$ to 1.59). All-cause mortality is also significantly higher among people with CKD (HR $2.37,95 \% \mathrm{Cl} 2.30$ to 2.44 ) (Olsen 2012) than the general population.

Although anticoagulants are frequently prescribed for CKD patients with $A F$ to reduce the risk for stroke or systemic thromboembolic events, these agents tend to be used less often for this population than for people who do not have CKD (Olsen 2012). This finding is attributed to the fact that results of large clinical studies of anticoagulant therapy for $\mathrm{AF}$ among moderate to severe CKD patients are lacking, and clinicians are wary of risks of bleeding.

DOAC may be more effective and safer for people with CKD than warfarin; they show promise to reduce prevalence of stroke and systemic embolic events, and may reduce risk of bleeding.

\section{O B J E C T IVES}

To assess the efficacy and safety of DOAC including apixaban, dabigatran, edoxaban, and rivaroxaban versus warfarin among AF patients with CKD.

\section{METHODS}

\section{Criteria for considering studies for this review}

\section{Types of studies}

All randomised controlled trials (RCTs) and quasi-RCTs (RCTs in which allocation to treatment was obtained by alternation, use of alternate medical records, date of birth or other predictable methods) comparing DOAC with warfarin were obtained. Cluster RCTs were also included if the intra-cluster correlation coefficient was reported. Cross-over studies were not included to avoid carryover effects. 


\section{Types of participants}

Eligible participants were diagnosed with non-valvular $\mathrm{AF}$ and moderate kidney impairment, defined as $\mathrm{CrCl}$ or eGFR between 15 and $60 \mathrm{~mL} / \mathrm{min}$ (CKD stage G3 and G4). Non-valvular AF was diagnosed with electrocardiography. Patients were excluded if they had valvular AF, recent stroke, and conditions associated with an increased risk for bleeding.

\section{Types of interventions}

We included studies that investigated DOAC. These include apixaban, dabigatran, edoxaban, and rivaroxaban as well as any other intervention classified as DOAC. We included any dose or regimen compared with warfarin. Warfarin was to be dose-adjusted using INR.

\section{Types of outcome measures}

\section{Primary outcomes}

- Composite of all strokes and systemic embolic events

* All strokes: sudden focal neurologic deficit caused by cerebrovascular thrombosis, and categorised as ischaemic, haemorrhagic, or unspecific

* Systemic embolic events: acute vascular occlusion of an extremity or organ

- Major bleeding: reduction in haemoglobin of at least $20 \mathrm{~g} / \mathrm{L}$, and transfusion of at least two units of blood, or symptomatic bleeding in a critical area or organ.

In our protocol, we intended to distinguish the effect of DOAC on two efficacy primary outcomes: all strokes and systemic embolic events. However, all included studies reported composite outcomes for all strokes, including ischaemic and haemorrhagic stroke and systemic embolic events; we therefore assessed these as one composite outcome.

\section{Secondary outcomes}

- Myocardial infarction (MI): diagnosis based on electrocardiographic changes, elevation of enzymes or confirmed during post-mortem examination

- Minor bleeding: non-major clinically relevant bleeding

- Gastrointestinal (GI) bleeding

- Intracranial haemorrhage: all intracerebral, subdural, epidural and subarachnoid haemorrhage

- All-cause mortality: death from any cause (vascular and nonvascular)

- Vascular death: death due to stroke (both ischaemic and haemorrhagic), heart disease, haemorrhage and sudden deaths of unknown causes.

\section{Search methods for identification of studies}

\section{Electronic searches}

We searched the Cochrane Kidney and Transplant Specialised Register (up to 1 August 2017) through contact with the Information Specialist using search terms relevant to this review. The Cochrane kidney and Transplant Specialised Register contains studies identified from the following sources.

1. Monthly searches of the Cochrane Central Register of Controlled Trials CENTRAL
2. Weekly searches of MEDLINE OVID SP

3. Handsearching of kidney-related journals and the proceedings of major kidney conferences

4. Searching of the current year of EMBASE OVID SP

5. Weekly current awareness alerts for selected kidney journals

6. Searches of the International Clinical Trials Register (ICTRP) Search Portal and ClinicalTrials.gov.

Studies contained in the Specialised Register were identified through search strategies for CENTRAL, MEDLINE, and EMBASE based on the scope of Cochrane Kidney and Transplant. Details of these strategies, as well as a list of handsearched journals, conference proceedings and current awareness alerts, were available in the Specialised Register section of information about Cochrane Kidney and Transplant.

See Appendix 1 for search terms used in strategies for this review.

\section{Searching other resources}

1. Reference lists of review articles, relevant studies, and clinical practice guidelines.

2. Letters seeking information about unpublished or incomplete studies to investigators known to be involved in previous studies.

3. We also searched reference lists of the identified studies and contacted the pharmaceutical companies.

\section{Data collection and analysis}

\section{Selection of studies}

The search strategy described was used to obtain titles and abstracts of studies that might be relevant to the review. The titles and abstracts were screened independently by two authors, who discarded studies that were not applicable; however, studies and reviews that might include relevant data or information on studies were retained initially. Two authors independently assessed retrieved abstracts, and if necessary, the full text of these studies to determine which satisfy our inclusion criteria.

\section{Data extraction and management}

Data extraction was carried out independently by two authors using standard data extraction forms. Studies reported in nonEnglish or non-Japanese language journals was translated before assessment. Where more than one publication of one study exists, reports were grouped together and the publication with the most complete data was used in the analyses. Where relevant outcomes were only published in earlier versions, these data were used. Any discrepancy between published versions was highlighted.

\section{Assessment of risk of bias in included studies}

The following items were independently assessed by two authors using the risk of bias assessment tool (Higgins 2011) (see Appendix 2).

- Was there adequate sequence generation (selection bias)?

- Was allocation adequately concealed (selection bias)?

- Was knowledge of the allocated interventions adequately prevented during the study?

* Participants and personnel (detection bias)

* Outcome assessors (performance bias)

Direct oral anticoagulants versus warfarin for preventing stroke and systemic embolic events among atrial fibrillation patients with 
- Were incomplete outcome data adequately addressed (attrition bias)?

- Were reports of the study free of suggestion of selective outcome reporting (reporting bias)?

- Was the study apparently free of other problems that could put it at a risk of bias?

\section{Measures of treatment effect}

For dichotomous outcomes (e.g. stroke, bleeding), results were expressed as risk ratio (RR) with $95 \% \mathrm{Cl}$. Where continuous scales of measurement were used to assess the effects of treatment, the mean difference (MD) were used, or the standardised mean difference (SMD) if different scales had been used.

\section{Unit of analysis issues}

RCTs with multiple intervention groups were included. Each intervention group was compared to the single control group.

\section{Dealing with missing data}

Any further information required from the original author was requested by written correspondence (e.g. emailing to corresponding authors) and any relevant information obtained in this manner was included in the review. Evaluation of important numerical data such as screened, randomised patients as well as intention-to-treat (ITT), as-treated and per-protocol (PP) population were carefully performed. Attrition rates, for example drop-outs, losses to follow-up and withdrawals were investigated. Issues of missing data and imputation methods (for example, lastobservation-carried-forward) were critically appraised (Higgins 2011).

\section{Assessment of heterogeneity}

Heterogeneity was analysed using a $\mathrm{Chi}^{2}$ test on $\mathrm{N}-1$ degrees of freedom, with an alpha of 0.05 used for statistical significance and with the $I^{2}$ test (Higgins 2003). $I^{2}$ values of $25 \%, 50 \%$ and $75 \%$ correspond to low, medium and high levels of heterogeneity.

\section{Assessment of reporting biases}

If possible, funnel plots were used to assess for the potential existence of small study bias (Higgins 2011).

\section{Data synthesis}

Data were pooled using the random-effects model but the fixedeffects model was also be used to ensure robustness of the model chosen and susceptibility to outliers.

\section{Subgroup analysis and investigation of heterogeneity}

Subgroup analysis was used to explore possible sources of heterogeneity (e.g. participants, interventions and study quality). Heterogeneity among participants could be related to age, history of previous stroke and baseline stroke risk factors (assessed by CHADS $_{2}$ score) (Gage 2001). CKD stages were also assessed.

Heterogeneity in treatments could be related to dose and duration of therapy, subtype of DOAC, and concomitant use of antiplatelet therapy.

Where a variety of agents were used, adverse effects were tabulated and assessed with descriptive techniques, as they were likely to differ for the various agents. Where possible, the risk difference with $95 \% \mathrm{Cl}$ was calculated for each adverse effect.

\section{Sensitivity analysis}

We performed sensitivity analyses to explore the influence of the following factors on effect size.

- Repeating the analysis excluding unpublished studies

- Repeating the analysis taking account of risk of bias, as specified

- Repeating the analysis excluding any very long or large studies to establish how much they dominate the results

- Repeating the analysis excluding studies using the following filters: diagnostic criteria, language of publication, source of funding (industry versus other), and country.

\section{'Summary of findings' tables}

We presented the main results of the review in 'Summary of findings' tables. These tables present key information concerning the quality of the evidence, the magnitude of the effects of the interventions examined, and the sum of the available data for the main outcomes (Schünemann 2011a). The 'Summary of findings' tables also include an overall grading of the evidence related to each of the main outcomes using the GRADE (Grades of Recommendation, Assessment, Development and Evaluation) approach (GRADE 2008). The GRADE approach defines the quality of a body of evidence as the extent to which one can be confident that an estimate of effect or association is close to the true quantity of specific interest. The quality of a body of evidence involves consideration of within-trial risk of bias (methodological quality), directness of evidence, heterogeneity, precision of effect estimates and risk of publication bias (Schünemann 2011b). We presented the following outcomes in the 'Summary of findings' tables.

- All strokes and systemic embolic events

- Major bleeding

- Ischaemic stroke

- Haemorrhagic stroke

- MI

- Minor bleeding

- Gl bleeding

- Intracranial haemorrhage

- All-cause mortality

- Vascular death

\section{RE S U L T S}

\section{Description of studies}

For detailed descriptions of the studies covered in this review, please see the following tables: Characteristics of included studies; Characteristics of excluded studies; Characteristics of ongoing studies.

\section{Results of the search}

After searching the Specialised Register, contacting pharmaceutical companies, and an additional web search, we identified 177 records. After full-text review, five studies (172 records) were included (ARISTOTLE Study 2010; ENGAGE AF-TIMI 48 Study 2013; J-ROCKET AF Study 2012; RE-LY Study 2009; ROCKET AF Study 2010) and four studies (four records) were excluded (Caluwé 2016; 
Figure 1. Study flow diagram.

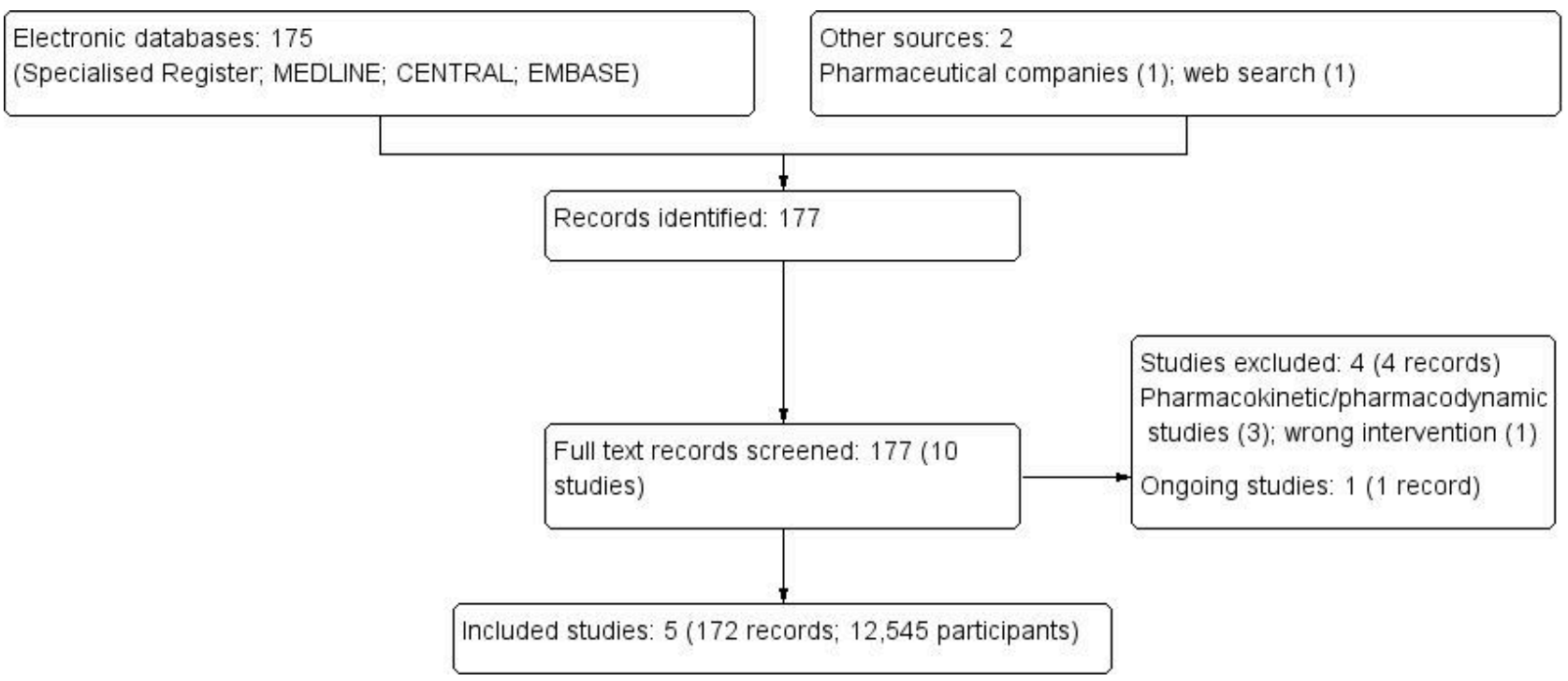

\section{Included studies}

We identified a total of 172 records representing five large studies (ARISTOTLE Study 2010; ENGAGE AF-TIMI 48 Study 2013; J-ROCKET AF Study 2012; RE-LY Study 2009; ROCKET AF Study 2010). We sent enquiry requests to the relevant pharmaceutical companies about how they dealt with missing data (the ITT analysis or modified ITT analysis). All companies responded but only one provided additional unpublished information (ARISTOTLE Study 2010).

These five studies enrolled 12,545 G3 and G4 participants. The participants had non-valvular AF and moderate kidney impairment. All five studies used the Cockcroft-Gault equation to define $\mathrm{CrCl}$ as a marker of kidney function. ARISTOTLE Study 2010 defined moderate kidney impairment as $\mathrm{CrCl}$ of 25 to $50 \mathrm{~mL} / \mathrm{min}$, while the other studies defined it as $\mathrm{CrCl}$ of 30 to $50 \mathrm{~mL} / \mathrm{min}$. Although participants with severe kidney impairment were exclusionary in ENGAGE AF-TIMI 48 Study 2013, a few participants with $\mathrm{CrCl}<30$ $\mathrm{mL} / \mathrm{min}$ were randomised and analysed as having moderate kidney impairment.

- ARISTOTLE Study 2010 included 2747 participants (91.1\%) with CKD stage $\mathrm{G} 3$ and 270 participants (8.9\%) with CKD stage G4

- ENGAGE AF-TIMI 48 Study 2013 included 2620 participants $(95.6 \%)$ with CKD stage $\mathrm{G} 3$ and 120 participants (4.4\%) with CKD stage $\mathrm{G} 4$

- J-ROCKET AF Study 2012 included 284 participants with CKD stage $\mathrm{G} 3$

- RE-LY Study 2009 included 3554 participants with CKD stage G3

- ROCKET AF Study 2010 included 2950 participants with CKD stage G3.

Therefore, the large majority of participants included in this review were CKD stage G3 rather than stage G4 (CKD stage G3: 12,155 participants; stage G4: 390 participants).
Of 172 records, ARISTOTLE Study 2010 had 43 records, ENGAGE AFTIMI 48 Study 2013 had 27 records, J-ROCKET AF Study 2012 had 15 records, RE-LY Study 2009 had 25 records, and ROCKET AF Study 2010 had 62 records. They included original studies and various sub studies such as different research questions, different population focused on specific conditions (e.g. elderly patients, patients with high $\mathrm{CHADS}_{2}$ score), and conference proceedings.

We used a subset of data from these five studies, which enrolled primarily AF patients with normal kidney function. The number of patients with CKD in each study was:

- ARISTOTLE Study 2010: 3,017/18,122 (17\%)

- ENGAGE AF-TIMI 48 Study 2013: 2,740/14,071 (19.5\%)

- J-ROCKET AF Study 2012: 284/1,278 (22.2\%)

- RE-LY Study 2009: 3,554/17,951 (19.8\%)

- ROCKET AF Study 2010: 2,950/14,264 (20.7\%).

The extracted participants from each study were of an acceptable sample size. We determined that the patients with CKD represented a predefined subgroup in each of the original studies, because the balance of the allocated groups had been maintained.

All five studies were RCTs. We summarized the baseline characteristics of four studies that estimated kidney function by the Cockcroft-Gault equation (ARISTOTLE Study 2010; ENGAGE AF-TIMI 48 Study 2013; J-ROCKET AF Study 2012; ROCKET AF Study 2010). RE-LY Study 2009 estimated kidney function by CKD-EPI and while the characteristics of these patients were not likely to differ from the other four studies, the results of this study were excluded from the summary of the baseline characteristics.

Mean and median age of participants ranged between 78 and 79 years, and $53.5 \%$ were female. Previous stroke history was $35.6 \%$, mean $\mathrm{CHADS}_{2}$ score ranged between 2.6 and 3.7, prior vitamin K use was $56.1 \%$, and prevalence of aspirin use was $33.6 \%$. 
Patients excluded from the included studies had: reversible AF or AF due to heart valve disorder; experienced a stroke in the past seven days; a condition associated with an increased risk of bleeding; were contraindicated for warfarin treatment; severe anaemia; received an investigational drug or medical device within 30 days before the planned clinical trial; active liver disease; severe comorbidity and whose life expectancy fell within the planned study period; were pregnant; and were unfit or unwilling to comply with the study-related procedures, such as subjects with alcohol dependence or those who refused to supply written informed consent. All studies allowed participants to use concomitant antiplatelet agents containing less than $100 \mathrm{mg}$ of acetylsalicylic acid and thienopyridine, but this was restricted to a single use.

The included studies compared warfarin against the following DOAC: apixaban 2.5 or $5.0 \mathrm{mg}$ (ARISTOTLE Study 2010), dabigatran 110 or $150 \mathrm{mg}$ (RE-LY Study 2009), edoxaban 30 mg (ENGAGE AFTIMI 48 Study 2013), rivaroxaban 10 mg (J-ROCKET AF Study 2012) or $15 \mathrm{mg}$ (ROCKET AF Study 2010). Apixaban and dabigatran are usually administered twice a day while edoxaban and rivaroxaban were administered once daily. All studies compared DOAC with dose-adjusted warfarin using INR. The target INR for four studies, excluding J-ROCKET AF Study 2012, was between 2.0 and 3.0 among all participants. In J-ROCKET AF Study 2012, the target INR in participants younger than 70 years was between 2.0 and 3.0, while that in those aged 70 years and older was between 1.6 and 2.5.

All five studies presented data on all composite outcomes of stroke and systematic thromboembolism as the primary efficacy outcome, with major bleeding events as the primary safety outcome. The median follow-up period ranged from 1.8 to 2.8 years.

\section{Excluded studies}

Four studies were excluded. Three studies where pharmacokinetic/ pharmacodynamic studies of ximelagatran and metagatran (Eriksson 2003a), edoxaban (Koretsune 2015), and argatroban (Murray 2004), and one study compared rivaroxaban plus vitamin $\mathrm{K} 2$ versus vitamin $\mathrm{K}$ antagonist (Caluwé 2016).

\section{Risk of bias in included studies}

Figure 2 and Figure 3 summarize our assessment of risk of bias for the five included studies. Two authors independently assessed the included studies for each checklist item as having high, low, or unclear risk of bias.

\section{Figure 2. Risk of bias graph: review authors' judgements about each risk of bias item presented as percentages} across all included studies.

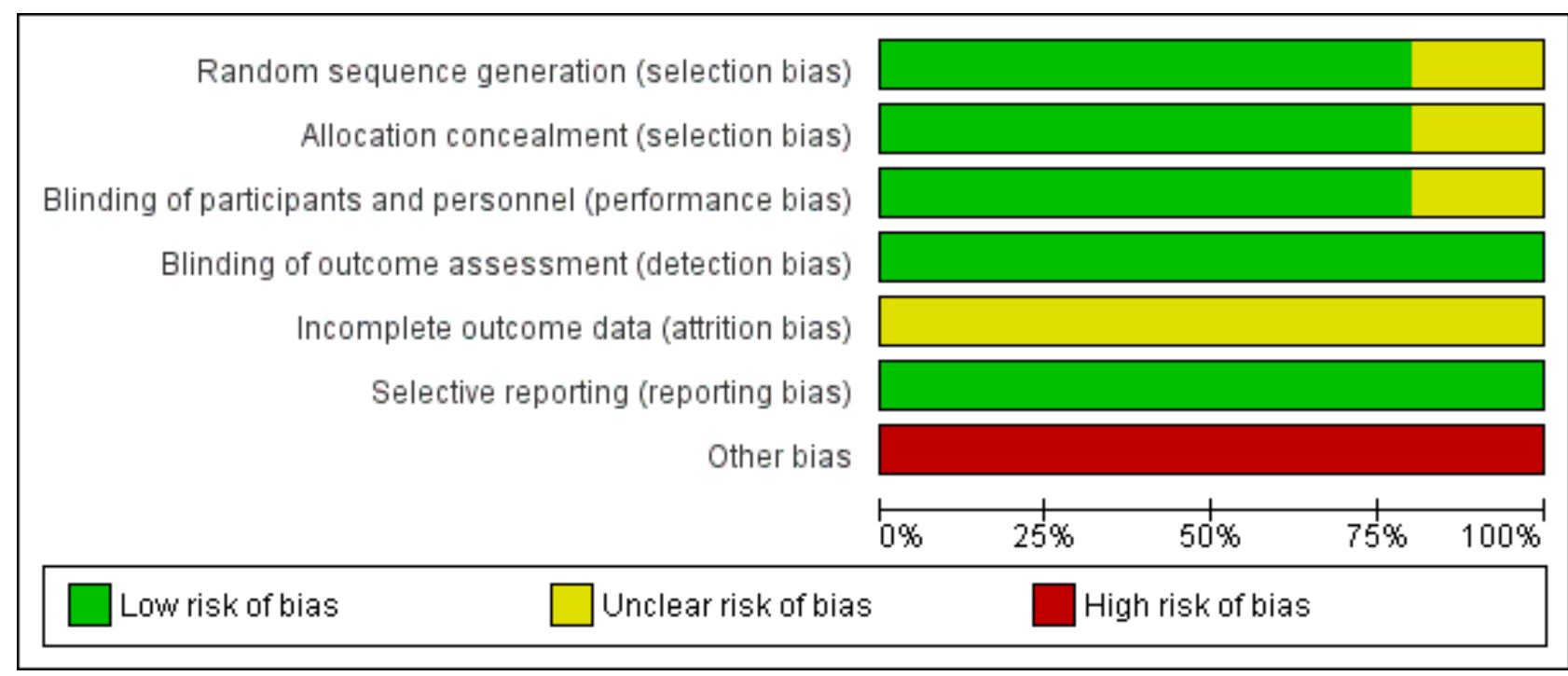


Figure 3. Risk of bias summary: review authors' judgements about each risk of bias item for each included study.

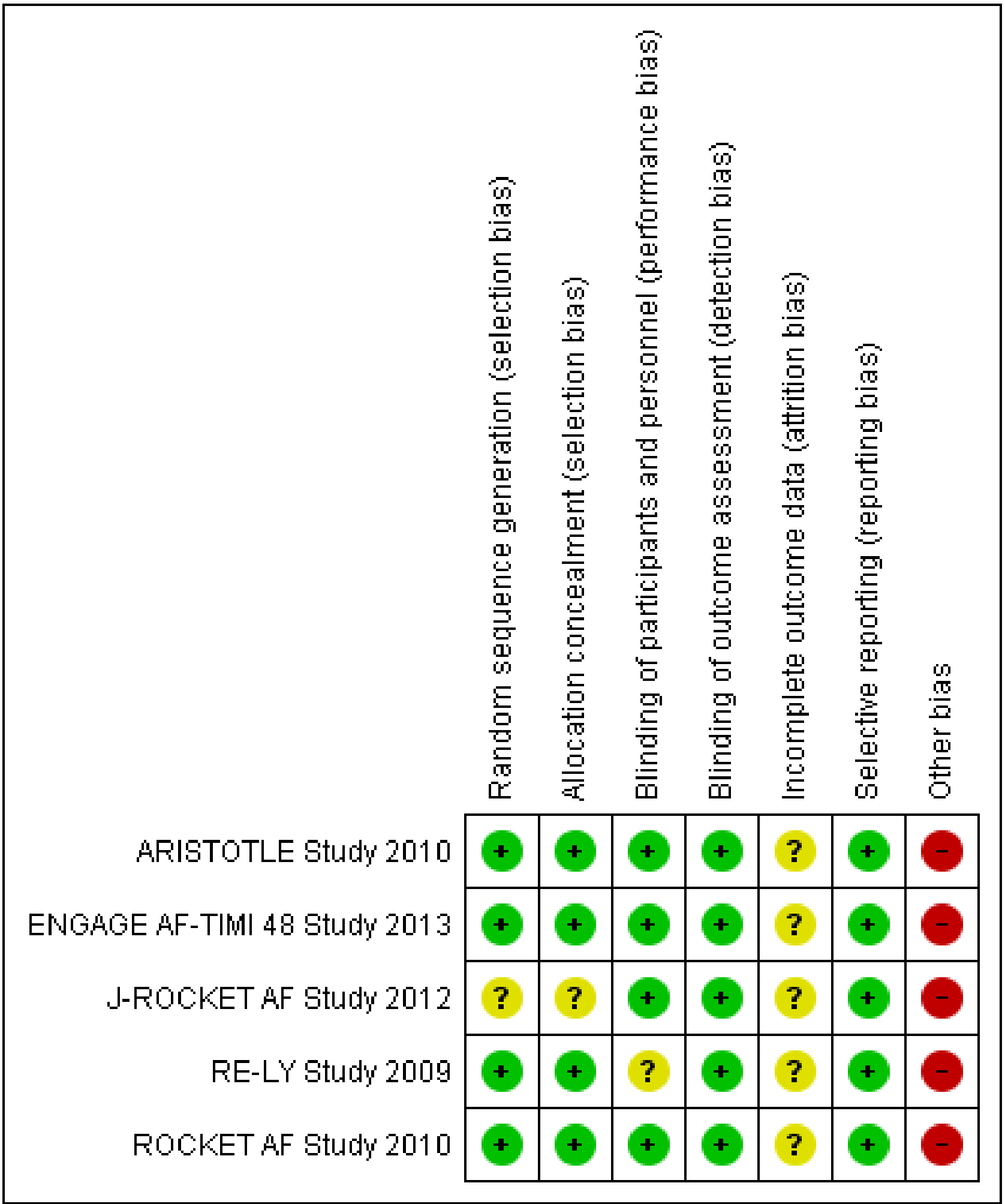

\section{Allocation}

Four studies used a central, interactive, automated response system for allocation concealment (ARISTOTLE Study 2010; ENGAGE AF-TIMI 48 Study 2013; RE-LY Study 2009; ROCKET AF Study 2010), while J-ROCKET AF Study 2012 did not specify randomisation or concealment methods. Therefore, we assessed the four studies to have a low risk of bias and J-ROCKET AF Study 2012 to have unclear risk of bias. We used subgroup analysis results from each large study but determined that the balance of the allocated groups

Direct oral anticoagulants versus warfarin for preventing stroke and systemic embolic events among atrial fibrillation patients with 10 chronic kidney disease (Review)

Copyright (c) 2017 The Cochrane Collaboration. Published by John Wiley \& Sons, Ltd. 
had been maintained because the extracted participants from each study were of an acceptable sample size.

\section{Blinding}

Four studies had adequate double-blinding procedures (ARISTOTLE Study 2010; ENGAGE AF-TIMI 48 Study 2013; J-ROCKET AF Study 2012; ROCKET AF Study 2010). Further, independent, centralized clinical end-point committees who were blind to treatment assessed outcomes based on agreed-upon definitions. RE-LY Study 2009 had incomplete blinding, as while dabigatran was administered in a blinded fashion, warfarin was administered in an open-label fashion, and INR was adjusted at least monthly. This incomplete blinding may have led to performance bias. However, we considered that any risk of performance bias would be reduced by a predetermined equal interval of follow-up. Further, we assessed the risk of detection bias to be low because the outcomes were objective measures and outcome assessors were blinded.

\section{Incomplete outcome data}

For the primary efficacy outcome of all strokes and systematic thromboembolic events, two studies (ARISTOTLE Study 2010; RELY Study 2009) reported results from ITT analyses; ENGAGE AF-TIMI 48 Study 2013 reported results based on both ITT and modified ITT analyses; ROCKET AF Study 2010 reported results based on ITT, modified ITT, and PP analyses; and J-ROCKET AF Study 2012 reported results from modified ITT and PP analyses. For the primary safety outcome of major bleeding events, only RE-LY Study 2009 reported results from ITT analyses, while the other four provided results from modified ITT analyses, which included all randomised participants who had received at least one dose of the study drug during the follow-up period.

\section{Selective reporting}

We found no evidence of selective reporting bias in any of the five studies, and all predefined primary efficacy and safety outcomes in the protocols were reported in the published manuscripts.

\section{Other potential sources of bias}

All of the studies examined were sponsored by pharmaceutical companies.

\section{Effects of interventions}

See: Summary of findings for the main comparison Direct oral anticoagulants (DOAC) versus warfarin for preventing stroke and systemic embolic events among atrial fibrillation patients with chronic kidney disease (CKD)

See: Summary of findings for the main comparison for the main comparisons.

In the original protocol, we aimed to distinguish two primary efficacy outcomes: all strokes and systemic embolic events. However, all included studies reported composite outcomes of all strokes, including both ischaemic and haemorrhagic stroke and systemic embolic events; therefore we examined them as one composite outcome.

For both primary and secondary efficacy outcomes, including all strokes and systemic embolic events, MI, and all-cause mortality, we included the results that used the conventional ITT analyses for the four studies (ARISTOTLE Study 2010; ENGAGE AF-TIMI 48 Study
2013; RE-LY Study 2009; ROCKET AF Study 2010) and the results that used the modified ITT analyses for one study (J-ROCKET AF Study 2012). Vascular death was not reported in any of the included studies.

For primary and secondary safety outcomes, including major bleeding, minor bleeding, Gl bleeding, and intracranial haemorrhage, we included the results that used modified ITT analyses for four studies (ARISTOTLE Study 2010; ENGAGE AF-TIMI 48 Study 2013; J-ROCKET AF Study 2012; ROCKET AF Study 2010) and the result that used the conventional ITT analyses for one study (RE-LY Study 2009).

\section{Primary outcomes}

\section{All strokes and systemic embolic events}

A total of 12,545 participants from all five studies were included in this analysis. We used the random-effects model to assess the association between anticoagulants and the primary efficacy outcome. DOAC probably reduced the incidence of composite outcomes in comparison with warfarin (Analysis 1.1 (5 studies, 12,545 participants): RR $0.81,95 \% \mathrm{Cl} 0.65$ to 1.00 ; moderate certainty evidence). There was no heterogeneity $\left(1^{2}=0 \%\right)$. We assessed the quality of evidence for the primary efficacy outcome to be moderate by GRADE because of concerns with imprecision. In addition, four studies (ARISTOTLE Study 2010; ENGAGE AFTIMI 48 Study 2013; J-ROCKET AF Study 2012; ROCKET AF Study 2010) reported the RR of ischaemic stroke or haemorrhagic stroke. DOAC probably made little difference to the incidence of ischaemic stroke in comparison with warfarin (Analysis 1.2 (4 studies, 8,991 participants): RR 1.01, 95\% Cl 0.75 to 1.36 ; moderate certainty evidence). There was no heterogeneity $\left(\mathrm{I}^{2}=0 \%\right)$. In contrast, DOAC probably reduced the incidence of haemorrhagic stroke in comparison with warfarin (Analysis 1.3 (4 studies, 8,991 participants): RR $0.52,95 \% \mathrm{Cl} 0.28$ to 0.97 ; moderate certainty evidence). There was no heterogeneity $(12=0 \%)$. We assessed the quality of evidence concerning both ischaemic and haemorrhagic strokes to be moderate because of concerns with imprecision.

\section{Major bleeding}

A total of 12,521 participants from all five studies reported major bleeding events, defined as a reduction in at least $20 \mathrm{~g} /$ $L$ of haemoglobin, transfusion of at least two units of blood, symptomatic bleeding in a critical area or organ, or death due to major bleeding, according to the ISTH criteria. DOAC might slightly reduce the incidence of major bleeding events in comparison with warfarin (Analysis 1.4 (5 studies, 12,521 participants): RR 0.79, $95 \% \mathrm{Cl} 0.59$ to 1.04 ; low certainty evidence). There was medium heterogeneity $\left(1^{2}=63 \%\right)$. We assessed the quality of evidence for the primary safety outcome to be low by GRADE because of concerns with inconsistency and imprecision.

\section{Secondary outcomes}

\section{Myocardial infarction}

ENGAGE AF-TIMI 48 Study 2013 reported no difference in the incidence of $\mathrm{MI}$ between DOAC compared to warfarin (Analysis 1.5 (1 study, 2,740 participants): RR $0.92,95 \% \mathrm{Cl} 0.45$ to 1.90 ). Although the other four studies (ARISTOTLE Study 2010; J-ROCKET AF Study 2012; RE-LY Study 2009; ROCKET AF Study 2010) indicated that they would assess the incidence of MI in their protocol, ARISTOTLE Study 2010 and J-ROCKET AF Study 2012 did not report on the results,

Direct oral anticoagulants versus warfarin for preventing stroke and systemic embolic events among atrial fibrillation patients with 
while RE-LY Study 2009 and ROCKET AF Study 2010 reported the composite outcomes for stroke, systemic embolic events, MI and others, but not separately for these items.

\section{Minor bleeding}

Two studies (ENGAGE AF-TIMI 48 Study 2013; J-ROCKET AF Study 2012) reported that DOAC might make little difference to minor bleeding events in comparison with warfarin (Analysis 1.6 (2 studies, 3,012 participants): RR $0.97,95 \% \mathrm{Cl} 0.58$ to 1.61 ; low certainty evidence). There was substantial heterogeneity $\left(1^{2}=70 \%\right)$. We assessed the quality of evidence to be low because of concerns with inconsistency and imprecision. No data was available for the other three studies (ARISTOTLE Study 2010; RE-LY Study 2009; ROCKET AF Study 2010).

\section{Gastrointestinal bleeding}

Two studies (ENGAGE AF-TIMI 48 Study 2013; ROCKET AF Study 2010) reported that DOAC probably leaded to slightly more $\mathrm{GI}$ bleeding events in comparison with warfarin (Analysis 1.7 (2 studies, 5,678 participants): RR $1.40,95 \% \mathrm{Cl} 0.97$ to 2.01 ; moderate certainty evidence). There was no heterogeneity $\left(1^{2}=0 \%\right)$. We assessed the quality of evidence to be moderate because of concerns with imprecision. No data was available for the other three studies (ARISTOTLE Study 2010; J-ROCKET AF Study 2012; RELY Study 2009).

\section{Intracranial haemorrhage}

All five studies reported that DOAC probably reduced intracranial haemorrhage events in comparison with warfarin (Analysis 1.8 (5 studies, 12,521 participants): RR $0.43,95 \% \mathrm{Cl} 0.27$ to 0.69 ; moderate certainty evidence). There was low heterogeneity $\left(1^{2}=\right.$ $25 \%)$. We assessed the quality of evidence to be moderate because of concerns with imprecision.

\section{All-cause mortality}

Four studies (ARISTOTLE Study 2010; ENGAGE AF-TIMI 48 Study 2013; J-ROCKET AF Study 2012; RE-LY Study 2009) reported that DOAC probably make little difference to all-cause mortality in comparison with warfarin (Analysis 1.9 (4 studies, 9,595 participants): RR $0.91,95 \% \mathrm{Cl} 0.78$ to 1.05 ; moderate certainty evidence). There was no heterogeneity $(12=0 \%)$. We assessed the quality of evidence to be moderate because of concerns with imprecision. Although ROCKET AF Study 2010 also indicated the assessment of all-cause mortality in their protocol, the results were not reported.

\section{Vascular death}

We could not obtain the results for vascular death from any of the included studies.

\section{Subgroup analyses}

We conducted several pre-defined subgroup analyses for both the primary efficacy outcome and primary safety outcome to explore the heterogeneity of treatment effects.

\section{CKD stages}

ARISTOTLE Study 2010 and ENGAGE AF-TIMI 48 Study 2013 included several participants with $\mathrm{CrCl}<30 \mathrm{~mL} / \mathrm{min}$. In the original articles, these participants were analysed as having moderate kidney impairment. However, an FDA report for ENGAGE AF-TIMI 48 Study 2013 and a report from the pharmaceutical company for ARISTOTLE Study 2010 categorised the data differently, as CKD stage $3(\mathrm{CrCl} 30$ to $50 \mathrm{~mL} / \mathrm{min}$ ) and CKD stage $4(\mathrm{CrCl} 15$ to $30 \mathrm{~mL} / \mathrm{min})$, respectively. Therefore, we re-analysed the primary outcomes according to CKD stage, categorising 12,155 participants as CKD stage G3 and 390 participants as stage G4.

DOAC probably slightly reduced the composite efficacy outcomes of all strokes and systemic embolic events in comparison with warfarin for participants with CKD stage 3 (Analysis 2.1 (5 studies, 12,155 participants): RR $0.82,95 \% \mathrm{Cl} 0.66$ to 1.02 ; moderate certainty evidence). There was no heterogeneity $(12=0 \%)$. Likewise, DOAC might slightly reduce the composite efficacy outcomes in comparison with warfarin for participants with CKD stage G4 (Analysis 3.1 (2 studies, 390 participants): RR $0.68,95 \% \mathrm{Cl} 0.23$ to 2.00; low certainty evidence). There was no heterogeneity $\left(I^{2}=0 \%\right)$. These results were consistent with the overall results.

DOAC probably slightly reduced major bleeding events in comparison with warfarin for participants with CKD stage $G 3$ (Analysis 2.2 (5 studies, 12,132 participants): RR $0.80,95 \% \mathrm{Cl}$ 0.62 to 1.03; moderate certainty evidence). There was moderate heterogeneity $(12=53 \%)$. Only one study (ARISTOTLE Study 2010) of 268 participants with CKD stage G4 reported that DOAC might improve major bleeding events in comparison with warfarin (Analysis 3.2 (1 studies, 268 participants): RR $0.30,95 \% \mathrm{Cl} 0.11$ to 0.80).

\section{Other baseline characteristics}

No data were available for subgroup analyses of other participant characteristics such as age, history of stroke and risk factors of baseline stroke ( $\mathrm{CHADS}_{2}$ score). Additional assessments are required once more information is published.

\section{How to prescribe anticoagulants}

\section{Dose and duration of therapy per day}

Participants in RE-LY Study 2009 were randomly assigned to receive either $110 \mathrm{mg}$ or $150 \mathrm{mg}$ of dabigatran twice a day. Participants in ARISTOTLE Study 2010 were prescribed either $2.5 \mathrm{mg}$ or $5 \mathrm{mg}$ of apixaban twice a day, with dosage determined according to whether participants satisfied two or more of the following criteria: (i) age $\geq 80$ years; (ii) body weight $\leq 60 \mathrm{~kg}$; or (iii) $\mathrm{SCr} \geq 1.5 \mathrm{mg} / \mathrm{dL}$ (133 $\mu \mathrm{mol} / \mathrm{L}$ ). Participants in the other three studies were administered single doses (ENGAGE AF-TIMI 48 Study 2013: 30 mg edoxaban once a day; ROCKET AF Study 2010: 15 mg rivaroxaban once a day; JROCKET AF Study 2012: $10 \mathrm{mg}$ rivaroxaban once a day).

We conducted subgroup analyses to assess the different dosages of DOAC. In RE-LY Study 2009, the patients were randomised in a 1:1:1 fashion, $110 \mathrm{mg}$ of dabigatran, $150 \mathrm{mg}$ of dabigatran or dose-adjusted warfarin, and the results of analyses were separately shown for dabigatran $110 \mathrm{mg}$ versus warfarin and for dabigatran $150 \mathrm{mg}$ versus warfarin. However, we could not obtain the results for different dosages of apixaban (ARISTOTLE Study 2010). We entered two comparisons of dabigatran (dabigatran $110 \mathrm{mg}$ versus warfarin, and dabigatran $150 \mathrm{mg}$ versus warfarin) into the metaanalysis. Participants on DOAC probably reduced the composite primary efficacy outcomes of all strokes and systemic embolic events in comparison with warfarin (Analysis 4.1 ( 5 studies, 12,545 participants): RR $0.81,95 \% \mathrm{Cl} 0.65$ to 1.00 ; moderate certainty 
evidence). There was no heterogeneity $\left(I^{2}=0 \%\right)$. Likewise, DOAC probably made little difference to all-cause mortality as the secondary efficacy outcome in comparison with warfarin (Analysis 4.3 (4 studies, 9,595 participants): RR $0.91,95 \% \mathrm{Cl} 0.78$ to 1.05 ; moderate certainty evidence). There was no heterogeneity $\left(\mathrm{I}^{2}=\right.$ $0 \%)$. Further, DOAC might slightly reduce the incidence of major bleeding in comparison with warfarin (Analysis 4.2 (5 studies, 12,521 participants): RR $0.81,95 \% \mathrm{Cl} 0.63$ to 1.03 ; low certainty evidence). There was moderate heterogeneity $\left(I^{2}=54 \%\right)$. These results were mostly consistent with the original results.

No data were available for the comparison of the duration of each therapy.

\section{Subtype of DOAC}

Rivaroxaban was studied in two studies (ROCKET AF Study 2010; J-ROCKET AF Study 2012). However, the sample size of J-ROCKET AF Study 2012 was smaller than ROCKET AF Study 2010, and the prescribed doses were different between the studies. Therefore, it was difficult to perform subtype analysis. All other drugs were examined by a single study respectively, so we could not assess differences in DOAC subtypes.

\section{Concomitant use of antiplatelet therapy}

All studies allowed the use of less than $100 \mathrm{mg}$ or $165 \mathrm{mg}$ of aspirin, and all but one study (ENGAGE AF-TIMI 48 Study 2013) permitted the use of antiplatelet agents such as thienopyridine. However, no data were available for subgroup analysis.

\section{Adverse events}

Several adverse events were assessed for rivaroxaban (ROCKET AF Study 2010; J-ROCKET AF Study 2012). Rivaroxaban might make little difference to any adverse effects in comparison with warfarin (see results; Analysis 5).

\section{Sensitivity analysis}

We planned several pre-defined sensitivity analyses for both the primary efficacy outcome and primary safety outcome to explore the influence on effect size.

We did not carry out the sensitivity analysis for repeating the analysis excluding unpublished studies, because our study did not include unpublished studies. We did not carry out the sensitivity analysis for repeating the analysis taking into account risk of bias, because we considered the risk of bias to be low. We did not carry out the sensitivity analysis for repeating the analysis excluding any very long or large studies to establish how much they dominate the results, because the sample size of J-ROCKET AF Study 2012 was small, and other studies had similar weight. We also did not the sensitivity analysis for repeating the analysis excluding studies using the following filters: diagnostic criteria, language of publication, source of funding (industry versus other), and country. The criteria for kidney impairment and warfarin dosage were previously described and similar, and other criteria were similar. All included publications were written in English. All studies were supported by pharmaceutical research companies. Various western or Asian countries were involved in all studies except for J-ROCKET AF Study 2012, which targeted Japanese participants only.

\section{Analysis using fixed effects model}

We performed sensitivity analyses using the fixed-effect model. DOAC probably slightly reduced the incidence of composite outcomes in comparison with warfarin (Analysis 6.1 (5 studies, 12,545 participants): RR $0.81,95 \% \mathrm{Cl} 0.65$ to 1.01 ; moderate certainty evidence). There was no heterogeneity $\left(\mathrm{I}^{2}=0 \%\right)$. Further, DOAC probably reduced the incidence of major bleeding in comparison with warfarin (Analysis 6.2 (5 studies, 12,521 participants): RR $0.79,95 \% \mathrm{Cl} 0.67$ to 0.92 ; low certainty evidence). There was medium heterogeneity $\left(1^{2}=63 \%\right)$. The results obtained using the fixed-effects model were mostly consistent with those obtained using the random-effects model even though the point estimates and $95 \% \mathrm{Cls}$ were slightly different.

\section{DISCUSSION}

\section{Summary of main results}

We analysed $12,545 \mathrm{AF}$ patients with moderate to severe kidney impairment in five RCTs that examined the efficacy and safety of four DOAC: apixaban, dabigatran, edoxaban, and rivaroxaban.

Included studies directly compared the association between DOAC and dose-adjusted warfarin for the composite outcomes of all strokes and systemic embolic events as the primary efficacy outcome, and major bleeding as the primary safety outcome. AF patients with CKD on DOAC probably reduced the incidence of all strokes and systemic embolic events in comparison with warfarin. Further, participants on DOAC might slightly reduce the incidence of major bleeding events.

This was the subset of data from five large studies, which enrolled primarily AF patients regardless of kidney function. The incidence of all strokes and systemic embolic events among patients with CKD was probably slightly consistent with among all participants from the original studies (Bruins Slot 2013). Further, the point estimates for the incidence of major bleeding among participants with CKD were lower than those among patients without kidney impairment, although $95 \% \mathrm{Cl}$ was larger because of the smaller sample size.

The results of subgroup analyses according to CKD stage $G 3$ and $\mathrm{G} 4$ were mostly consistent with the overall results. The only point of difference was that CKD stage G4 (ARISTOTLE Study 2010) DOAC might reduce major bleeding events in comparison with warfarin, but the number of participants categorised into CKD stage G4 was small, so we could not assess the association with sufficient power.

These findings indicate that DOAC are more or similarly effective and similarly safe for AF patients with CKD as dose-adjusted warfarin, at least in stage 3 CKD. Physicians can therefore feel more confident in prescribing DOAC to AF patients with CKD without the burden of regular monitoring that is necessary for warfarin.

\section{Overall completeness and applicability of evidence}

Currently, major regulatory agencies (EMA 2014; FDA 2014; Health Canada 2017) have approved DOAC for use by AF patients with CKD stage $\mathrm{G} 3$ or $\mathrm{G} 4$, but evidence supporting their use is limited (Reinecke 2013).

We systematically reviewed the studies that re-analysed the subgroups; that is, participants with kidney impairment, of the five large RCTs targeting AF participants. The sample size of each 
subgroup study was large and the balance and comparability of randomised baseline characteristics was retained in these subgroups.

All participants in the intervention and control groups had nonvalvular AF and CKD, and other baseline characteristics were similar across the studies. Warfarin was controlled within the range of the INR of 2.0 to 3.0 for four studies, excluding J-ROCKET AF Study 2012, and the conditions for comparisons were consistent across studies. In J-ROCKET AF Study 2012, the target INR range was 2.0 to 3.0 for participants younger than 70 years and 1.6 to 2.5 for those aged 70 years and older.

Each study also included participants from western and Asian countries, indicating that the data were higher generalizable.

This systematic review had several limitations. First, ARISTOTLE Study 2010 and ENGAGE AF-TIMI 48 Study 2013 included participants with severe kidney impairment $(\mathrm{CrCl}<30 \mathrm{~mL} / \mathrm{min})$. However, as shown in the subgroup analyses, our results chiefly apply to CKD stage G3 patients, so further studies are required to determine the efficacy and safety of DOAC on patients with CKD stage G4. Additionally, we could not examine the effects on CKD stage G5 patients. Although recent meta-analyses showed that warfarin may not be beneficial for patients with end-stage kidney disease, the effect of DOAC on these patients is unclear (Dahal 2016; Liu 2015). Future reviews should assess participants with more advanced CKD stages. Second, kidney function can be measured using several parameters and equations, such as $\mathrm{CrCl}$, estimated by Cockcroft-Gault equation; and eGFR, estimated by the Modification of Diet in Renal Disease (MDRD) equation or CKDEPI. GFR as estimated by MDRD or CKD-EPI may be more precise than $\mathrm{CrCl}$ (Levey 2006; Levey 2009). However, we could not estimate GFR using MDRD or CKD-EPI because the number of participants within each group were not indicated. We used $\mathrm{CrCl}$ estimated by the Cockcroft-Gault equation because it is widely used and all RCTs included in this review estimated kidney function using this method. Third, we could not perform some subgroup or sensitivity analyses due to lack of available data. In particular, it is important to assess subtypes or different dosages of DOAC to explore possible sources of heterogeneity. Such analyses should be conducted once more RCT results have been obtained, and the analyses in this study repeated after the publication of more data.

\section{Quality of the evidence}

Only RE-LY Study 2009 was conducted in single blinded fashion; however, since the outcome assessors were blinded, we concluded that this analysis method did not have adverse effects on the results. We assessed the risk of bias for both the primary efficacy and primary safety outcomes to be low. However, this study did not report important secondary outcomes such as MI and allcause mortality even though they were predefined in the protocol; therefore, outcome reporting bias was suspected.

We could not assess differences in the types or dosages of DOAC sufficiently. We could not obtain the results for different dosages of apixaban. It is possible that higher doses caused more serious bleeding than lower doses, but this information is hidden by combining the dosages.

To assess publication of incomplete outcome data, which is related to attrition bias, we basically adopted the ITT principle for the primary efficacy outcome and the modified ITT principle for the primary safety outcome. The ITT principle for the efficacy outcomes maintains the balance of random allocation and is generally conservative by accepting the results of noncompliance and dropouts. In contrast, safety outcomes should not be diluted by noncompliance or dropouts, making the modified ITT principle more appropriate. J-ROCKET AF Study 2012 used modified ITT for efficacy outcomes and RE-LY Study 2009 used conventional ITT for safety outcomes. We expected that the relative measure (RR) was probably similar in conventional ITT and modified ITT analyses because this review adapted an active comparator. Therefore, we considered that adherence was likely to be similar in both groups and not to be related to the efficacy and the safety.

Funding biases can also affect the results of studies. Since all of the included studies followed the pre-defined protocol, we considered that the impact, if any, was small.

Using the GRADE system, we assessed the primary efficacy outcome to be of moderate quality due to concerns with imprecision and the primary safety outcome to be of low certainty due to concerns with inconsistency and imprecision. For the secondary outcomes, we assessed the results for minor bleeding to be of low certainty due to concerns with inconsistency and imprecision, Gl bleeding, intracranial haemorrhage, and all-cause mortality to be of moderate certainty due to concerns with imprecision, respectively.

\section{Potential biases in the review process}

We performed a comprehensive search using several different databases but we cannot rule out the possibility that we may have missed several smaller studies. Further, we contacted the sponsors and performed web searches to collect data that we could not obtain from the Cochrane Kidney and Transplant Specialised Register, but there may still be a possibility that we missed some data.

\section{Agreements and disagreements with other studies or reviews}

A previous systematic review reported that DOAC were more effective than warfarin in preventing stroke and systemic embolism among AF patients regardless of kidney function, but the evidence among patients with kidney impairment were not established. Since CKD patients have an increased risk of stroke compared to the general population, preventive strategies for stroke are necessary for these patients (Lau 2016; Marinigh 2011; Masson 2015). However, clinicians hesitate to prescribe anticoagulants to CKD patients due to concerns about bleeding risks (Lau 2016). For example, dabigatran is predominantly excreted from the kidneys (Stangier 2008), so there is a risk that blood concentrations of the drug may rise.

The included original RCTs were all designed as non-inferiority studies and the data from a smaller group of participants in this review showed consistent results. Moreover, the point estimates among CKD participants were lower than among those without kidney impairment; variability (by $95 \% \mathrm{Cl}$ ) was larger because of the smaller sample size. 


\section{AUTHORS' CONCLUSIONS}

\section{Implications for practice}

DOAC are as likely as warfarin to prevent all strokes and systemic embolic events without increasing risk of major bleeding events among AF patients with kidney impairment. These findings should encourage physicians to prescribe DOAC to AF patients with CKD. Additionally, prescription of DOAC may improve quality of life because, unlike warfarin, they do not require regular monitoring or restrictions on foods or other drugs.

\section{Implications for research}

Several concerns remain and future studies should address the following points.

1. This study could not assess the effectiveness or safety of DOAC among patients with severe kidney dysfunction, such as those with $\mathrm{CrCl}<30 \mathrm{~mL} / \mathrm{min}$, especially haemodialysis patients; it is important to establish the recommendations for these patients.
2. Other subgroup analyses using baseline characteristics such as age, history of previous stroke, and stroke risk factors (assessed by $\mathrm{CHADS}_{2}$ score) should be conducted. Further, future studies should assess the impact of concomitant use of antiplatelet agents and DOAC.

3. We could not sufficiently assess the effect of DOAC on important secondary outcomes such as MI, minor bleeding and vascular death because of lack of available data. Therefore, these analyses should be repeated after the publication of more data.

4. The included studies had a maximum follow up period of 2.8 years. Future studies should assess the long-term effectiveness and safety of DOAC use.

5. Future studies should compare subtypes dosages of DOAC so as to provide clinicians with the comparative effectiveness of available alternatives.

\section{ACKNOWLEDGEMENTS}

We would like to thank the referees for their advice and feedback during the preparation of this manuscript. 


\section{R E F E R E N C E S}

\section{References to studies included in this review}

ARISTOTLE Study 2010 \{published data only\}

Al-Khatib SM, Thomas L, Wallentin L, Lopes RD, Gersh B, Garcia D, et al. Outcomes of apixaban vs. warfarin by type and duration of atrial fibrillation: results from the ARISTOTLE trial. European Heart Journal 2013;34(31):2464-71. [MEDLINE: 23594592]

Alexander JH, Levy E, Lawrence J, Hanna M, Waclawski AP, Wang J, et al. Documentation of study medication dispensing in a prospective large randomized clinical trial: experiences from the ARISTOTLE Trial. American Heart Journal 2013;166(3):559-65. [MEDLINE: 24016507]

Alexander JH, Lopes RD, Thomas L, Alings M, Atar D, Aylward P, et al. Apixaban vs. warfarin with concomitant aspirin in patients with atrial fibrillation: insights from the ARISTOTLE trial. European Heart Journal 2014;35(4):224-32. [MEDLINE: 24144788]

Avezum A, Bahit CM, Hermosillo AG, Zanetti FL, IsazaRestrepo D, Juarez-Garcia A. Apixaban versus warfarin in patients with atrial fibrillation: patient characteristics of the Latin America cohort from a multinational clinical trial [abstract]. Stroke 2015;46(Suppl 1):AWP147. [CENTRAL: $\mathrm{CN}-01067615]$

Avezum A, Lopes RD, Schulte PJ, Lanas F, Gersh BJ, Hanna M, et al. Apixaban in comparison with warfarin in patients with atrial fibrillation and valvular heart disease: Findings From the Apixaban for Reduction in Stroke and Other Thromboembolic Events in Atrial Fibrillation (ARISTOTLE) Trial. Circulation 2015;132(8):624-32. [MEDLINE: 26106009]

Avezum A, Lopes RD, Schulte PJ, Lanas F, Hanna M, Pais P. Apixaban versus warfarin in patients with atrial fibrillation and valvular heart disease: findings from the ARISTOTLE trial [abstract]. European Heart Journal 2013;34(Suppl 1):809. [CENTRAL: CN-00886584]

Bahit MC, Lopes RD, Hohnloser SH, Wojdyla D, Alexander JH, Lewis BS, et al. Apixaban in patients with atrial fibrillation and prior coronary artery disease: insights from the ARISTOTLE trial [abstract no: 13026]. Circulation 2012;126(21 Suppl 1). [EMBASE: 70956622]

Bahit MC, Lopes RD, Wojdyla DM, Hohnloser SH, Alexander JH, Lewis BS, et al. Apixaban in patients with atrial fibrillation and prior coronary artery disease: insights from the ARISTOTLE trial. International Journal of Cardiology 2013;170(2):215-20. [MEDLINE: 24192334]

Christersson C, Wallentin L, Andersson U, Alexander JH, Ansell J, De Caterina R, et al. D-dimer and risk of thromboembolic and bleeding events in patients with atrial fibrillation--observations from the ARISTOTLE trial. Journal of Thrombosis \& Haemostasis 2014;12(9):1401-12. [MEDLINE: 24942912]

De Caterina R, Andersson U, Alexander JH, Al-Khatib SM, Bahit MC, Goto S, et al. History of bleeding and outcomes with apixaban versus warfarin in patients with atrial fibrillation in the
Apixaban for Reduction in Stroke and Other Thromboembolic Events in Atrial Fibrillation trial. American Heart Journal 2016;175:175-83. [MEDLINE: 27179738]

Diener HC, Easton JD, Alings M, Bahit C, Goto S, Lewis BS. Apixaban compared with warfarin in patients with atrial fibrillation and prior stroke or TIA: a subgroup analysis of the ARISTOTLE trial [abstract]. Cerebrovascular Diseases 2012;33(Suppl 2):47. [CENTRAL: CN-00854732]

Dorian P, Kongnakorn T, Phatak H, Rublee DA, Kuznik A, Lanitis T, et al. Cost-effectiveness of apixaban vs. current standard of care for stroke prevention in patients with atrial fibrillation. European Heart Journal 2014;35(28):1897-906. [MEDLINE: 24513791]

Durheim MT, Cyr DD, Lopes RD, Thomas LE, Tsuang WM, Gersh BJ, et al. Chronic obstructive pulmonary disease in patients with atrial fibrillation: insights from the ARISTOTLE trial. International Journal of Cardiology 2016;202:589-94. [MEDLINE: 26447668]

Easton JD, Lopes RD, Bahit MC, Wojdyla DM, Granger CB, Wallentin L, et al. Apixaban compared with warfarin in patients with atrial fibrillation and previous stroke or transient ischaemic attack: a subgroup analysis of the ARISTOTLE trial. [Erratum appears in Lancet Neurol. 2012 Dec;11(12):1021]. Lancet Neurology 2012;11(6):503-11. [MEDLINE: 22572202]

Ezekowitz J, Dorian P, Granger C, Alexander J, Lopes R, Hanna M, et al. Efficacy and safety of apixaban compared to warfarin for prevention of stroke and systemic embolism in 18,201 patients with atrial fibrillation: Primary results of the ARISTOTLE trial [abstract]. Canadian Journal of Cardiology 2011;27(5 Suppl 1):S334. [EMBASE: 70608602]

Flaker G, Lopes R, Al-Khatib S, Hermosillo A, Thomas L, Zhu J, et al. Apixaban and warfarin are associated with a low risk of stroke following cardioversion for atrial fibrillation: results from the ARISTOTLE Trial [abstract no: 4048]. European Heart Journal 2012;33(Suppl 1):686. [EMBASE: 70884980]

Flaker G, Lopes RD, Al-Khatib SM, Hermosillo AG, Hohnloser SH, Tinga $B$, et al. Efficacy and safety of apixaban in patients after cardioversion for atrial fibrillation: insights from the ARISTOTLE Trial (Apixaban for Reduction in Stroke and Other Thromboembolic Events in Atrial Fibrillation). Journal of the American College of Cardiology 2014;63(11):1082-7. [MEDLINE: 24211508]

Flaker G, Lopes RD, Hylek E, Wojdyla DM, Thomas L, AlKhatib SM, et al. Amiodarone, anticoagulation, and clinical events in patients with atrial fibrillation: insights from the ARISTOTLE trial. Journal of the American College of Cardiology 2014;64(15):1541-50. [MEDLINE: 25301455]

Flaker GC, Hohnloser S, Wojdyla D, Hylek E, Garcia D, Sullivan R, et al. Apixaban is efficacious and safe in patients with atrial fibrillation using concomitant amiodarone: an analysis from the ARISTOTLE trial [abstract]. Journal of the American College of Cardiology 2013;61(10 Suppl 1):E317. [EMBASE: 71019680]

Direct oral anticoagulants versus warfarin for preventing stroke and systemic embolic events among atrial fibrillation patients with 
Garcia DA, Alexander JH, Lopes RD, Thomas L, Yang H, Ansell J, et al. Apixaban versus warfarin in patients with atrial fibrillation in relation to prior warfarin use: Insights from the ARISTOTLE trial [abstract no: 14771]. Circulation 2012;126(21 Suppl 1). [EMBASE: 70958949]

Garcia DA, Wallentin L, Lopes RD, Thomas L, Alexander JH, Hylek EM, et al. Apixaban versus warfarin in patients with atrial fibrillation according to prior warfarin use: results from the Apixaban for Reduction in Stroke and Other Thromboembolic Events in Atrial Fibrillation trial. American Heart Journal 2013;166(3):549-58. [MEDLINE: 24016506]

Goto S, Zhu J, Liu L, Oh BH, Wojdyla DM, Aylward P, et al. Efficacy and safety of apixaban compared with warfarin for stroke prevention in patients with atrial fibrillation from East Asia: a subanalysis of the Apixaban for Reduction in Stroke and Other Thromboembolic Events in Atrial Fibrillation (ARISTOTLE) Trial. American Heart Journal 2014;168(3):303-9. [MEDLINE: 25173541]

Granger CB, Alexander JH, Hanna M, Wang J, Mohan P, Lawrence J, et al. Events after discontinuation of randomized treatment at the end of the ARISTOTLE trial [abstract no: 4045]. European Heart Journal 2012;33(Suppl 1):685-6. [EMBASE: 70884977]

Granger CB, Alexander JH, McMurray JJ, Lopes RD, Hylek EM, Hanna $M$, et al. Apixaban versus warfarin in patients with atrial fibrillation. New England Journal of Medicine 2011;365(11):981-92. [MEDLINE: 21870978]

Halvorsen S, Atar D, Yang H, De Caterina R, Erol C, Garcia D, et al. Efficacy and safety of apixaban compared with warfarin according to age for stroke prevention in atrial fibrillation: observations from the ARISTOTLE trial. European Heart Journal 2014;35(28):1864-72. [MEDLINE: 24561548]

Held C, Hylek EB, Alexander JH, Hanna M, Lopes RD, Wojdyla D, et al. Risk of events in the 30 days following a major bleed with Apixaban or Warfarin - experiences from the ARISTOTLE trial [abstract]. European Heart Journal 2013;34:99. [EMBASE: 71257890]

Held C, Hylek EM, Alexander JH, Hanna M, Lopes RD, Wojdyla DM, et al. Clinical outcomes and management associated with major bleeding in patients with atrial fibrillation treated with apixaban or warfarin: insights from the ARISTOTLE trial. European Heart Journal 2015;36(20):1264-72. [MEDLINE: 25499871]

Hijazi Z, Siegbahn A, Andersson U, Granger CB, Alexander JH, Atar D, et al. High-sensitivity troponin I for risk assessment in patients with atrial fibrillation: insights from the Apixaban for Reduction in Stroke and other Thromboembolic Events in Atrial Fibrillation (ARISTOTLE) trial. Circulation 2014;129(6):625-34. [MEDLINE: 24226808]

Hijazi Z, Siegbahn A, Andersson U, Lindahl B, Granger CB, Alexander JH, et al. Comparison of cardiac troponins I and T measured with high-sensitivity methods for evaluation of prognosis in atrial fibrillation: an ARISTOTLE substudy. Clinical Chemistry 2015;61(2):368-78. [MEDLINE: 25451868]
Hijazi Z, Wallentin L, Siegbahn A, Andersson U, Alexander JH, Atar $D$, et al. High-sensitivity troponin T and risk stratification in patients with atrial fibrillation during treatment with apixaban or warfarin. Journal of the American College of Cardiology 2014;63(1):52-61. [MEDLINE: 24055845]

Hijazi Z, Wallentin L, Siegbahn A, Andersson U, Christersson C, Ezekowitz J, et al. N-terminal pro-B-type natriuretic peptide for risk assessment in patients with atrial fibrillation: insights from the ARISTOTLE Trial (Apixaban for the Prevention of Stroke in Subjects With Atrial Fibrillation). Journal of the American College of Cardiology 2013;61(22):2274-84. [MEDLINE: 23563134]

* Hohnloser SH, Hijazi Z, Thomas L, Alexander JH, Amerena J, Hanna M, et al. Efficacy of apixaban when compared with warfarin in relation to renal function in patients with atrial fibrillation: insights from the ARISTOTLE trial. European Heart Journal 2012;33(22):2821-30. [MEDLINE: 22933567]

Lopes RD, Al-Khatib SM, Wallentin L, Yang H, Ansell J, Bahit MC, et al. Efficacy and safety of apixaban compared with warfarin according to patient risk of stroke and of bleeding in atrial fibrillation: a secondary analysis of a randomised controlled trial.[Erratum appears in Lancet. 2013 Jan 19;381(9862):204]. Lancet 2012;380(9855):1749-58. [MEDLINE: 23036896]

Lopes RD, Alexander JH, Al-Khatib SM, Ansell J, Diaz R, Easton JD, et al. Apixaban for reduction in stroke and other thromboembolic events in atrial fibrillation (ARISTOTLE) trial: design and rationale. [Erratum appears in Am Heart J. 2010 Jun;159(6):1162]. American Heart Journal 2010;159(3):331-9. [MEDLINE: 20211292]

McMurray JJ, Ezekowitz JA, Lewis BS, Gersh BJ, van Diepen S, Amerena J, et al. Left ventricular systolic dysfunction, heart failure, and the risk of stroke and systemic embolism in patients with atrial fibrillation: insights from the ARISTOTLE trial. Circulation: Heart Failure 2013;6(3):451-60. [MEDLINE: 23575255]

Ogawa S, Shinohara Y, Kanmuri K. Safety and efficacy of the oral direct factor Xa inhibitor apixaban in Japanese patients with non-valvular atrial fibrillation. Circulation Journal 2011;75(8):1852-9. [MEDLINE: 21670542]

Rao MP, Halvorsen S, Wojdyla D, Thomas L, Alexander JH, Hylek EM, et al. Blood pressure control and risk of stroke or systemic embolism inpatients with atrial fibrillation: results from the apixaban for reduction in stroke and other thromboembolic events in atrial fibrillation (ARISTOTLE) trial. Journal of the American Heart Association 2015;4(12):e002015. [MEDLINE: 26627878]

Rordorf R, de Ferrari GM, Wojdyla D, De Caterina R, Thomas L, Granger CB, et al. Digoxin use is associated with higher mortality among patients with atrial fibrillation with and without heart failure: insights from the ARISTOTLE trial [abstract]. European Heart Journal 2015;36:1068. [EMBASE: 72022734]

Sandhu RK, Ezekowitz J, Andersson U, Alexander J, Granger C, Halvorsen S, et al. Body mass index and outcomes with apixaban versus warfarin in patients with atrial fibrillation in the ARISTOTLE (apixaban for reduction in stroke and other thromboembolic events in atrial fibrillation) trial [abstract].

Direct oral anticoagulants versus warfarin for preventing stroke and systemic embolic events among atrial fibrillation patients with 
Journal of the American College of Cardiology 2015;65(10 Suppl 1):A284. [EMBASE: 71833341]

Sandhu RK, Ezekowitz J, Andersson U, Alexander JH, Granger CB, Halvorsen S, et al. The 'obesity paradox' in atrial fibrillation: observations from the ARISTOTLE (Apixaban for Reduction in Stroke and Other Thromboembolic Events in Atrial Fibrillation) trial. European Heart Journal 2016;37(38):2869-78. [MEDLINE: 27071819]

Siegbahn A, Christersson C, Schollin M, Alexander JH, Horowitz J, Hylek EM, et al. Increased levels of D-dimer identify patients with atrial fibrillation at high risk for bleeding an ARISTOTLE substudy [abstract no: P553]. European Heart Journal 2012;33(Suppl 1):51. [EMBASE: 70882600]

Vinereanu D, Stevens SR, Alexander JH, Al-Khatib SM, Avezum A, Bahit MC, et al. Clinical outcomes in patients with atrial fibrillation according to sex during anticoagulation with apixaban or warfarin: a secondary analysis of a randomized controlled trial. European Heart Journal 2015;36(46):3268-75. [MEDLINE: 26371113]

Wallentin L, Lopes RD, Hanna M, Thomas L, Hellkamp A, Nepal S, et al. Efficacy and safety of apixaban compared with warfarin at different levels of predicted international normalized ratio control for stroke prevention in atrial fibrillation. Circulation 2013;127(22):2166-76. [MEDLINE: 23640971]

\section{ENGAGE AF-TIMI 48 Study 2013 \{published data only\}}

* Bohula EA, Giugliano RP, Ruff CT, Kuder JF, Murphy SA, Antman EM, et al. Impact of renal function on outcomes with edoxaban in the ENGAGE AF-TIMI 48 trial. Circulation 2016;134(1):24-36. [MEDLINE: 27358434]

Deepak KG, Shah A, Giugliano R, Ruff C, Antman E, Laura TG, et al. Cardiac structure and function and CHADS2 risk score in patients with atrial fibrillation: the effective anticoagulation with factor Xa next generation in afthrombolysis in myocardial infarction 48 (ENGAGE AF -TIMI 48) echocardiographic study [abstract]. Journal of the American College of Cardiology 2013;61(10 Suppl 1):E964. [EMBASE: 71020327]

Douketis J, Weitz J, Murphy S, Deenadayalu N, Crompton AE, Mercuri M, et al. Perioperative adverse outcomes in patients with atrial fibrillation taking edoxaban or warfarin: analysis of the ENGAGE AF-TIMI 48 trial [abstract]. Journal of the American College of Cardiology 2015;65(10 Suppl 1):A2092. [EMBASE: 71835148]

Eisen A, Giugliano RP, Ruff CT, Nordio F, Gogia HS, Awasty VR, et al. Edoxaban vs warfarin in patients with nonvalvular atrial fibrillation in the US Food and Drug Administration approval population: an analysis from the Effective Anticoagulation with Factor Xa Next Generation in Atrial Fibrillation-Thrombolysis in Myocardial Infarction 48 (ENGAGE AF-TIMI 48) trial. American Heart Journal 2016;172:144-51. [MEDLINE: 26856226]

Geller BJ, Giugliano RP, Braunwald E, Murphy SA, Hanyok JJ, Jin J, et al. Systemic, noncerebral, arterial embolism in 21,105 patients with atrial fibrillation randomized to edoxaban or warfarin: results from the Effective Anticoagulation With
Factor Xa Next Generation in Atrial Fibrillation-Thrombolysis in Myocardial Infarction Study 48 trial. American Heart Journal 2015;170(4):669-74. [MEDLINE: 26386790]

Giugliano RP, Ruff CT, Braunwald E, Murphy SA, Grip LT, Betcher JM, et al. ENGAGE AF-TIMI 48 primary results [abstract]. Circulation 2013;128(24):2711-2. [EMBASE: 71281640]

Giugliano RP, Ruff CT, Braunwald E, Murphy SA, Wiviott SD, Halperin JL, et al. Edoxaban versus warfarin in patients with atrial fibrillation. New England Journal of Medicine 2013;369(22):2093-104. [MEDLINE: 24251359]

Giugliano RP, Ruff CT, Rost NS, Silverman S, Wiviott SD, Lowe C, et al. Cerebrovascular events in 21105 patients with atrial fibrillation randomized to edoxaban versus warfarin: Effective Anticoagulation with Factor Xa Next Generation in Atrial Fibrillation-Thrombolysis in Myocardial Infarction 48. Stroke 2014;45(8):2372-8. [MEDLINE: 24947287]

Giugliano RP, Ruff CT, Wiviott SD, Murphy SA, Kappelhof JAN, Shi M, et al. Reduction in bleeding with edoxaban vs warfarin linked to lower all-cause mortality in 21,105 patients randomized in the ENGAGE AF-TIMI 48 trial [abstract]. European Heart Journal 2014;35(Suppl 1):867. [EMBASE: 71649981]

Giugliano RP, Ruff CT, Wiviott SD, Nordio F, Murphy SA, Kappelhof JA, et al. Mortality in patients with atrial fibrillation randomized to edoxaban or warfarin: Insights from the ENGAGE AF-TIMI 48 Trial. American Journal of Medicine 2016;129(8):850-7, e2. [MEDLINE: 26994510]

Gupta D, Giugliano RP, Ruff CT, Claggett B, Murphy S, Antman E, et al. The prognostic significance of cardiac structure and function in atrial fibrillation: the ENGAGE AF-TIMI 48 Echocardiographic Substudy [abstract]. European Heart Journal 2014;35(Suppl 1):1117. [EMBASE: 71650934]

Gupta DK, Giugliano RP, Ruff CT, Claggett B, Murphy S, Antman $E$, et al. The prognostic significance of cardiac structure and function in atrial fibrillation: The ENGAGE AF-TIMI 48 echocardiographic substudy. Journal of the American Society of Echocardiography 2016;29(6):537-44. [MEDLINE: 27106009]

Gupta DK, Shah AM, Giugliano RP, Ruff CT, Antman EM, Grip LT, et al. Left atrial structure and function in atrial fibrillation: ENGAGE AF-TIMI 48. European Heart Journal 2014;35(22):1457-65. [MEDLINE: 24302269]

Kato ET, Giugliano RP, Ruff CT, Koretsune Y, Yamashita T, Kiss RG, et al. Efficacy and safety of edoxaban in elderly patients with atrial fibrillation in the ENGAGE AF-TIMI 48 Trial. Journal of the American Heart Association 2016;5(5):e003432. [MEDLINE: 27207971]

Krekels EH, Niebecker R, Karlsson MO, Miller R, Shimizu T, Karlsson KE, et al. Population pharmacokinetics of edoxaban in patients with non-valvular atrial fibrillation in the ENGAGE AFTIMI 48 Study, a phase III clinical trial. Clinical Pharmacokinetics 2016;55(9):1079-90. [MEDLINE: 26951208]

Magnuson EA, Wang K, Li H, Kwong WJ, Antman EM, Ruff CT, et al. Impact of spontaneous bleeding events on health state utility in patients with atrial fibrillation: Results from 
the ENGAGE AF-TIMI 48 trial [abstract no: 314]. Circulation 2014;7(Suppl 1):A314. [EMBASE: 71669975]

Mega JL, Walker JR, Ruff CT, Vandell AG, Nordio F, Deenadayalu N, et al. Genetics and the clinical response to warfarin and edoxaban: findings from the randomised, doubleblind ENGAGE AF-TIMI 48 trial. Lancet 2015;385(9984):2280-7. [MEDLINE: 25769357]

Ruff CT, Giugliano R, Braunwald E, Morrow D, Murphy S, Deenadayalu N, et al. Relationship between dose, anti-factor Xa activity, and outcomes in patients randomized to edoxaban in the ENGAGE AF-TIMI 48 trial [abstract]. Journal of the American College of Cardiology 2014;63(12 Suppl 1):A329. [EMBASE: 71406353]

Ruff CT, Giugliano RP, Antman EM, Crugnale SE, Bocanegra T, Mercuri M, et al. Evaluation of the novel factor Xa inhibitor edoxaban compared with warfarin in patients with atrial fibrillation: Design and rationale for the Effective aNticoaGulation with factor Xa next GEneration in Atrial Fibrillation- Thrombolysis in Myocardial Infarction study 48 (ENGAGE AF-TIMI 48). American Heart Journal 2010;160(4):635-41. [MEDLINE: 20934556]

Ruff CT, Giugliano RP, Braunwald E, Mercuri M, Curt V, Betcher J, et al. Transition of patients from blinded study drug to openlabel anticoagulation: the ENGAGE AF-TIMI 48 trial. Journal of the American College of Cardiology 2014;64(6):576-84. [MEDLINE: 25104527]

Ruff CT, Giugliano RP, Braunwald E, Morrow DA, Murphy SA, Kuder JF, et al. Association between edoxaban dose, concentration, anti-Factor Xa activity, and outcomes: an analysis of data from the randomised, double-blind ENGAGE AF-TIMI 48 trial. Lancet 2015;385(9984):2288-95. [MEDLINE: 25769361]

Ruff CT, Giugliano RP, Braunwald E, Murphy SA, Brown K, Jarolim P, et al. Cardiovascular biomarker score and clinical outcomes in patients with atrial fibrillation enrolled in the ENGAGE AF-TIMI 48 trial [abstract no: P2481]. European Heart Journal 2014;35(Suppl 1):440. [EMBASE: 71648380]

Salazar DE, Mendell J, Kastrissios H, Green M, Carrothers TJ, Song $S$, et al. Modelling and simulation of edoxaban exposure and response relationships in patients with atrial fibrillation. Thrombosis \& Haemostasis 2012;107(5):925-36. [MEDLINE: 22398655]

Shimada YJ, Yamashita T, Koretsune Y, Kimura T, Abe K, Sasaki S, et al. Effects of regional differences in Asia on efficacy and safety of edoxaban compared with warfarin: insights from the ENGAGE AF-TIMI 48 trial. Circulation Journal 2015;79(12):2560-7. [MEDLINE: 26460886]

Steffel J, Giugliano RP, Braunwald E, Murphy SA, Atar D, Heidbuchel $\mathrm{H}$, et al. Edoxaban vs. warfarin in patients with atrial fibrillation on amiodarone: a subgroup analysis of the ENGAGE AF-TIMI 48 trial. European Heart Journal 2015;36(33):2239-45. [MEDLINE: 25971288]

Xu H, Ruff CT, Giugliano RP, Murphy SA, Nordio F, Patel I, et al. Concomitant use of single antiplatelet therapy with edoxaban or warfarin in patients with atrial fibrillation: analysis from the ENGAGE AF-TIMI48 Trial. Journal of the American Heart Association 2016;5(2):e002587. [MEDLINE: 26908401]

Yamashita T, Koretsune Y, Yang Y, Chen SA, Chung N, Shimada YJ, et al. Edoxaban vs. warfarin in East Asian patients with atrial fibrillation- an ENGAGE AF-TIMI 48 subanalysis. Circulation Journal 2016;80(4):860-9. [MEDLINE: 26888149]

\section{J-ROCKET AF Study 2012 \{published data only\}}

Safety/efficacy of rivaroxaban for prevention of stroke in Japanese atrial fibrillation patients - Sub-analysis of renal impairment in J-ROCKET AF [abstract]. Therapeutic Research 2012;33(7):957-8. [EMBASE: 365495775]

Chan MY, Lin M, Lucas J, Moseley A, Thompson JW, Cyr D, et al. Plasma proteomics of patients with non-valvular atrial fibrillation on chronic anti-coagulation with warfarin or a direct factor Xa inhibitor. Thrombosis \& Haemostasis 2012;108(6):1180-91. [MEDLINE: 23052711]

Delgado-Fernandez M. The J-ROCKET AF study: A matter of ethnicity or a matter of weight?. Circulation Journal 2013;77(10):2636. [EMBASE: 2013608415]

* Hori M, Kajikawa M. The J-ROCKET AF study: A matter of ethnicity or a matter of weight?. Circulation Journal 2013;77(10):2637. [MEDLINE: 23903065]

Hori M, Matsumoto M, Tanahashi N, Momomura S, Uchiyama S, Goto S, et al. J-ROCKET AF: The safety and efficacy of rivaroxaban for prevention of stroke in Japanese patients with non-valvular atrial fibrillation [abstract]. Journal of Thrombosis and Haemostasis 2011;9:20. [EMBASE: 70612436]

Hori M, Matsumoto M, Tanahashi N, Momomura S, Uchiyama S, Goto S, et al. Rivaroxaban versus warfarin in Japanese patients with nonvalvular atrial fibrillation in relation to the CHADS2 score: a subgroup analysis of the J-ROCKET AF trial. Journal of Stroke \& Cerebrovascular Diseases 2014;23(2):379-83. [MEDLINE: 23954611]

Hori M, Matsumoto M, Tanahashi N, Momomura S, Uchiyama S, Goto S, et al. Rivaroxaban vs. Warfarin in Japanese patients with non-valvular atrial fibrillation in relation to age. Circulation Journal 2014;78(6):1349-56. [MEDLINE: 24705469]

Hori M, Matsumoto M, Tanahashi N, Momomura S, Uchiyama S, Goto S, et al. Rivaroxaban vs. warfarin in Japanese patients with atrial fibrillation - the J-ROCKET AF study. Circulation Journal 2012;76(9):2104-11. [MEDLINE: 22664783]

Hori M, Matsumoto M, Tanahashi N, Momomura S, Uchiyama S, Goto S, et al. Safety and efficacy of adjusted dose of rivaroxaban in Japanese patients with non-valvular atrial fibrillation: subanalysis of J-ROCKET AF for patients with moderate renal impairment. Circulation Journal 2013;77(3):632-8. [MEDLINE: 23229461]

Kaneko M, Tanigawa T, Hashizume K, Kajikawa M, Tajiri M, Mueck W. Confirmation of model-based dose selection for a Japanese phase III study of rivaroxaban in non-valvular atrial fibrillation patients. Drug Metabolism \& Pharmacokinetics 2013;28(4):321-31. [MEDLINE: 23337693]

Direct oral anticoagulants versus warfarin for preventing stroke and systemic embolic events among atrial fibrillation patients with 
Matsumoto M, Hori M, Tanahashi N, Momomura S, Uchiyama S, Goto S, et al. Rivaroxaban versus warfarin in Japanese patients with non-valvular atrial fibrillation in relation to hypertension: A subgroup analysis of the J-ROCKET AF trial. Hypertension Research - Clinical \& Experimental 2014;37(5):457-62. [MEDLINE: 24477179]

Tanahashi N, Hori M, Matsumoto M, Momomura SI, Uchiyama S, Goto S, et al. Rivaroxaban versus warfarin in Japanese patients with nonvalvular atrial fibrillation for the secondary prevention of stroke: A subgroup analysis of J-ROCKET AF. Journal of Stroke \& Cerebrovascular Diseases 2013;22(8):1317-25. [MEDLINE: 23352688]

Tanigawa T, Kaneko M, Hashizume K, Kajikawa M, Ueda H, Tajiri M, et al. Model-based dose selection for phase III rivaroxaban study in Japanese patients with non-valvular atrial fibrillation. Drug Metabolism \& Pharmacokinetics 2013;28(1):59-70. [MEDLINE: 22813718]

Uchiyama S, Hori M, Matsumoto M, Tanahashi N, Momomura S, Goto $S$, et al. Net clinical benefit of rivaroxaban versus warfarin in Japanese patients with nonvalvular atrial fibrillation: a subgroup analysis of J-ROCKET AF. Journal of Stroke \& Cerebrovascular Diseases 2014;23(5):1142-7. [MEDLINE: 24189454]

Uchiyama S, Hori M, Matsumoto M, Tanahashi N, Momomura S, Goto $S$, et al. Net clinical benefit of rivaroxaban versus warfarin in Japanese patients with nonvalvular atrial fibrillation: a subgroup analysis of J-ROCKET AF. Journal of Stroke \& Cerebrovascular Diseases 2014;23(5):1142-7. [MEDLINE: 24189454]

\section{RE-LY Study 2009 \{published data only\}}

Bohm M, Ezekowitz MD, Connolly SJ, Eikelboom JW, Hohnloser SH, Reilly PA, et al. Changes in renal function in patients with atrial fibrillation: an analysis from the RE-LY Trial. Journal of the American College of Cardiology 2015;65(23):2481-93. [MEDLINE: 26065986]

Bytzer P, Connolly SJ, Yang S, Ezekowitz M, Formella S, Reilly PA, et al. Analysis of upper gastrointestinal adverse events among patients given dabigatran in the RE-LY trial. Clinical Gastroenterology \& Hepatology 2013;11(3):246-52. [MEDLINE: 23103906]

* Connolly SJ, Ezekowitz MD, Yusuf S, Eikelboom J, Oldgren J, Parekh A, et al. Dabigatran versus warfarin in patients with atrial fibrillation. [Erratum appears in N Engl J Med. 2010 Nov 4;363(19):1877]. New England Journal of Medicine 2009;361(12):1139-51. [MEDLINE: 19717844]

Dans AL, Connolly SJ, Wallentin L, Yang S, Nakamya J, Brueckmann M, et al. Concomitant use of antiplatelet therapy with dabigatran or warfarin in the Randomized Evaluation of Long-Term Anticoagulation Therapy (RE-LY) trial. Circulation 2013;127(5):634-40. [MEDLINE: 23271794]

Diener HC, Connolly SJ, Ezekowitz MD, Wallentin L, Reilly PA, Yang S, et al. Dabigatran compared with warfarin in patients with atrial fibrillation and previous transient ischaemic attack or stroke: a subgroup analysis of the RE-LY trial.[Erratum appears in Lancet Neurol. 2011 Jan;10(1):27]. Lancet Neurology 2010;9(12):1157-63. [MEDLINE: 21059484]

Douketis JD, Healey JS, Brueckmann M, Eikelboom JW, Ezekowitz MD, Fraessdorf M, et al. Perioperative bridging anticoagulation during dabigatran or warfarin interruption among patients who had an elective surgery or procedure. Substudy of the RE-LY trial. Thrombosis \& Haemostasis 2015;113(3):625-32. [MEDLINE: 25472710]

Douketis JD, Healey JS, Brueckmann M, Fraessdorf M, Spyropoulos AC, Wallentin L, et al. Urgent surgery or procedures in patients taking dabigatran or warfarin: analysis of perioperative outcomes from the RE-LY trial. Thrombosis Research 2016;139:77-81. [MEDLINE: 26916299]

Eikelboom JW, Wallentin L, Connolly SJ, Ezekowitz M, Healey JS, Oldgren J, et al. Risk of bleeding with 2 doses of dabigatran compared with warfarin in older and younger patients with atrial fibrillation: an analysis of the randomized evaluation of long-term anticoagulant therapy (RE-LY) trial. Circulation 2011;123(21):2363-72. [MEDLINE: 21576658]

Ezekowitz MD, Connolly S, Parekh A, Reilly PA, Varrone J, Wang S, et al. Rationale and design of RE-LY: randomized evaluation of long-term anticoagulant therapy, warfarin, compared with dabigatran. American Heart Journal 2009;157(5):805-10, 810.e1-2. [MEDLINE: 19376304]

Ezekowitz MD, Wallentin L, Connolly SJ, Parekh A, Chernick MR, Pogue J, et al. Dabigatran and warfarin in vitamin $\mathrm{K}$ antagonistnaive and -experienced cohorts with atrial fibrillation. Circulation 2010;122(22):2246-53. [MEDLINE: 21147728]

Healey JS, Eikelboom J, Douketis J, Wallentin L, Oldgren J, Yang S, et al. Periprocedural bleeding and thromboembolic events with dabigatran compared with warfarin: results from the Randomized Evaluation of Long-Term Anticoagulation Therapy (RE-LY) randomized trial.[Erratum appears in Circulation. 2012 Sep 4;126(10):e160 Note: Heidbuchle, Hein [corrected to Heidbuchel, Hein]]. Circulation 2012;126(3):343-8. [MEDLINE: 22700854]

* Hijazi Z, Hohnloser SH, Oldgren J, Andersson U, Connolly SJ, Eikelboom JW, et al. Efficacy and safety of dabigatran compared with warfarin in relation to baseline renal function in patients with atrial fibrillation: a RE-LY (Randomized Evaluation of Long-term Anticoagulation Therapy) trial analysis. Circulation 2014;129(9):961-70. [MEDLINE: 24323795]

Hijazi Z, Oldgren J, Andersson U, Connolly SJ, Ezekowitz MD, Hohnloser $\mathrm{SH}$, et al. Cardiac biomarkers are associated with an increased risk of stroke and death in patients with atrial fibrillation: a Randomized Evaluation of Long-term Anticoagulation Therapy (RE-LY) substudy. Circulation 2012;125(13):1605-16. [MEDLINE: 22374183]

Hijazi Z, Oldgren J, Andersson U, Connolly SJ, Ezekowitz MD, Hohnloser SH, et al. Importance of persistent elevation of cardiac biomarkers in atrial fibrillation: a RE-LY substudy. Heart 2014;100(15):1193-200. [MEDLINE: 24794140]

Hohnloser SH, Oldgren J, Yang S, Wallentin L, Ezekowitz M, Reilly P, et al. Myocardial ischemic events in patients with 
atrial fibrillation treated with dabigatran or warfarin in the RE-LY (Randomized Evaluation of Long-Term Anticoagulation Therapy) trial. Circulation 2012;125(5):669-76. [MEDLINE: 22215856]

Hori M, Connolly SJ, Zhu J, Liu LS, Lau CP, Pais P, et al. Dabigatran versus warfarin: effects on ischemic and hemorrhagic strokes and bleeding in Asians and non-Asians with atrial fibrillation. Stroke 2013;44(7):1891-6. [MEDLINE: 23743976]

Hori M, Fukaya T, Kleine E, Reilly PA, Ezekowitz MD, Connolly SJ, et al. Efficacy and safety of dabigatran etexilate vs. warfarin in Asian RE-LY patients according to baseline renal function or CHADS2 score. Circulation Journal 2015;79(10):2138-47. [MEDLINE: 26248573]

Majeed A, Hwang HG, Connolly SJ, Eikelboom JW, Ezekowitz MD, Wallentin L, et al. Management and outcomes of major bleeding during treatment with dabigatran or warfarin. Circulation 2013;128(21):2325-32. [MEDLINE: 24081972]

Marijon E, Le Heuzey JY, Connolly S, Yang S, Pogue J, Brueckmann $\mathrm{M}$, et al. Causes of death and influencing factors in patients with atrial fibrillation: a competing-risk analysis from the randomized evaluation of long-term anticoagulant therapy study. Circulation 2013;128(20):2192-201. [MEDLINE: 24016454]

Nagarakanti R, Ezekowitz MD, Oldgren J, Yang S, Chernick M, Aikens TH, et al. Dabigatran versus warfarin in patients with atrial fibrillation: an analysis of patients undergoing cardioversion. Circulation 2011;123(2):131-6. [MEDLINE: 21200007]

Oldgren J, Alings M, Darius H, Diener HC, Eikelboom J, Ezekowitz MD, et al. Risks for stroke, bleeding, and death in patients with atrial fibrillation receiving dabigatran or warfarin in relation to the CHADS2 score: a subgroup analysis of the RE-LY trial. Annals of Internal Medicine 2011;155(10):660-7. [MEDLINE: 22084332]

Pare G, Eriksson N, Lehr T, Connolly S, Eikelboom J, Ezekowitz MD, et al. Genetic determinants of dabigatran plasma levels and their relation to bleeding. Circulation 2013;127(13):1404-12. [MEDLINE: 23467860]

Reilly PA, Lehr T, Haertter S, Connolly SJ, Yusuf S, Eikelboom JW, et al. The effect of dabigatran plasma concentrations and patient characteristics on the frequency of ischemic stroke and major bleeding in atrial fibrillation patients: the RE-LY Trial (Randomized Evaluation of Long-Term Anticoagulation Therapy). Journal of the American College of Cardiology 2014;63(4):321-8. [MEDLINE: 24076487]

Van Spall HG, Wallentin L, Yusuf S, Eikelboom JW, Nieuwlaat R, Yang S, et al. Variation in warfarin dose adjustment practice is responsible for differences in the quality of anticoagulation control between centers and countries: an analysis of patients receiving warfarin in the randomized evaluation of long-term anticoagulation therapy (RE-LY) trial. Circulation 2012;126(19):2309-16. [MEDLINE: 23027801]

Verdecchia P, Reboldi G, Di Pasquale G, Mazzotta G, Ambrosio G, Yang S, et al. Prognostic usefulness of left ventricular hypertrophy by electrocardiography in patients with atrial fibrillation (from the Randomized Evaluation of Long-Term Anticoagulant Therapy Study). American Journal of Cardiology 2014;113(4):669-75. [MEDLINE: 24359765]

\section{ROCKET AF Study 2010 \{published data only\}}

Apostolakis S, Lane DA, Banerjee A. Letter by Apostolakis et al regarding article, "renal dysfunction as a predictor of stroke and systemic embolism in patients with nonvalvular atrial fibrillation: validation of the R2CHADS2 index in the ROCKET AF (Rivaroxaban Once-Daily, Oral, Direct Factor Xa Inhibition Compared With Vitamin K Antagonism for Prevention of Stroke and Embolism Trial in Atrial Fibrillation) and ATRIA (Anticoagulation and Risk Factors in Atrial Fibrillation) study cohorts". Circulation 2013;128(11):e171. [MEDLINE: 24019451]

Balla SR, Cyr D, Lokhnygina Y, Becker R, Berkowitz S, Breithardt $\mathrm{G}$, et al. Obesity paradox for stroke in patients with atrial fibrillation treated with rivaroxaban and warfarin in the ROCKET AF trial [abstract]. Journal of the American College of Cardiology 2014;63(12 Suppl 1):A371. [EMBASE: 71406395]

Bansilal S, Bloomgarden Z, Halperin JL, Hellkamp AS, Lokhnygina Y, Patel MR, et al. Efficacy and safety of rivaroxaban in patients with diabetes and nonvalvular atrial fibrillation: the Rivaroxaban Once-daily, Oral, Direct Factor Xa Inhibition Compared with Vitamin K Antagonism for Prevention of Stroke and Embolism Trial in Atrial Fibrillation (ROCKET AF Trial). American Heart Journal 2015;170(4):675-82. [MEDLINE: 26386791]

Breithardt G, Baumgartner H, Berkowitz SD, Hellkamp AS, Piccini JP, Lokhnygina $Y$, et al. Patients with native aortic stenosis represent a high-risk subgroup in nonvalvular atrial fibrillation-Results from ROCKET AF [abstract]. European Heart Journal 2014;35:1033. [EMBASE: 71650613]

Breithardt G, Bode C, Patel M, Becker R, Hacke W, Halperin J, et al. Comparison of rivaroxaban with warfarin for the prevention of stroke and systemic embolism in patients with atrial fibrillation: rationale and design of the ROCKET AF study [abstract]. Hamostaseologie 2010;30(1):A38. [EMBASE: 70867883]

Capucci A, Prisco D. The ROCKET AF study [Lo studio ROCKET AF]. Giornale Italiano di Cardiologia 2012;13(9):553-6. [MEDLINE: 22825339]

Fordyce CB, Hellkamp AS, Lokhnygina Y, Lindner SM, Piccini JP, Becker RC, et al. On-treatment outcomes in patients with worsening renal function with rivaroxaban compared with warfarin: insights from ROCKET AF. [Erratum appears in Circulation. 2016 Aug 23;134(8):e114; PMID: 27550973]. Circulation 2016;134(1):37-47. [MEDLINE: 27358435]

Fox KA, Kevorkian JP. ROCKET-AF: data on rivaroxaban in patients with moderate renal function impairment [abstract] [ROCKET-AF: donnees avec le rivaroxaban chez les patients avec alteration moderee de la fonction renale]. Archives des Maladies du Coeur et des Vaisseaux - Pratique 2012;18(205 Suppl 1):9-10. [EMBASE: 365094155]

Direct oral anticoagulants versus warfarin for preventing stroke and systemic embolic events among atrial fibrillation patients with 
* Fox KA, Piccini JP, Wojdyla D, Becker RC, Halperin JL, Nessel CC, et al. Prevention of stroke and systemic embolism with rivaroxaban compared with warfarin in patients with nonvalvular atrial fibrillation and moderate renal impairment. European Heart Journal 2011;32(19):2387-94. [MEDLINE: 21873708]

Girgis IG, Patel MR, Peters GR, Moore KT, Mahaffey KW, Nessel CC, et al. Population pharmacokinetics and pharmacodynamics of rivaroxaban in patients with non-valvular atrial fibrillation: results from ROCKET AF. Journal of Clinical Pharmacology 2014;54(8):917-27. [MEDLINE: 24668660]

Goodman SG, Wojdyla DM, Piccini JP, White HD, Paolini JF, Nessel CC, et al. Factors associated with major bleeding events: insights from the ROCKET AF trial (rivaroxaban oncedaily oral direct factor Xa inhibition compared with vitamin $\mathrm{K}$ antagonism for prevention of stroke and embolism trial in atrial fibrillation). Journal of the American College of Cardiology 2014;63(9):891-900. [MEDLINE: 24315894]

Goodman SG, Wojdyla DM, White HD, Piccini JP, Paolini JF, Nessel CC, et al. Predictors of major bleeding risk: Insights from the rivaroxaban once-daily oral direct factor Xa inhibition compared with vitamin $\mathrm{K}$ antagonism for prevention of stroke and embolism trial in atrial fibrillation (Rocket AF) [abstract no: 16903]. Circulation 2011;124(21 Suppl 1). [EMBASE: 70619385]

Greco C. Rivaroxaban in non valvular atrial fibrillation: subgroups analysis [Rivaroxaban nella fibrillazione atriale non valvolare: I'importanza dei sottogruppi]. Monaldi Archives for Chest Disease 2014;82(1):16-9. [MEDLINE: 25481935]

Hacke W, Hankey G. Rivaroxaban versus warfarin in patients with AF and prior cerebrovascular disease: Results from the ROCKET-AF trial [abstract]. Cerebrovascular Diseases 2011;31:17. [EMBASE: 70432150]

Halperin JL, Bloomgarden Z, Hellkamp A, Lokhnygina Y, Patel M, Becker R, et al. Rivaroxaban compared with warfarin in patients with atrial fibrillation and diabetes: A subgroup analysis of the ROCKET AF trial [abstract no: 15544]. Circulation 2012;126(21 Suppl 1). [EMBASE: 70956249]

Halperin JL, Hankey GJ, Wojdyla DM, Piccini JP, Lokhnygina Y, Patel MR, et al. Efficacy and safety of rivaroxaban compared with warfarin among elderly patients with nonvalvular atrial fibrillation in the Rivaroxaban Once Daily, Oral, Direct Factor Xa Inhibition Compared With Vitamin K Antagonism for Prevention of Stroke and Embolism Trial in Atrial Fibrillation (ROCKET AF). Circulation 2014;130(2):138-46. [MEDLINE: 24895454]

Halperin JL, Wojdyla D, Piccini JP, Lokhnygina Y, Patel MR, Breithardt G, et al. Efficacy and safety of rivaroxaban compared with warfarin among elderly patients with nonvalvular atrial fibrillation in the ROCKET AF trial [abstract no: 148]. Stroke 2012;43(2 Suppl 1). [EMBASE: 70925131]

Hankey GJ, Patel MR, Stevens SR, Becker RC, Breithardt G, Carolei A, et al. Rivaroxaban compared with warfarin in patients with atrial fibrillation and previous stroke or transient ischaemic attack: a subgroup analysis of ROCKET AF. Lancet Neurology 2012;11(4):315-22. [MEDLINE: 22402056]
Hankey GJ, Stevens S, Piccini JP, Lokhnygina Y, Mahaffey KW, Halperin JL, et al. Predictors of intracranial hemorrhage among anticoagulated patients with atrial fibrillation: Insights from the rivaroxaban once-daily oral direct factor $X A$ inhibition compared with vitamin $\mathrm{K}$ antagonism for prevention of stroke and embolism trial in atrial fibrillation (ROCKET AF) [abstract no: 152]. Stroke 2012;43(2 Suppl 1). [EMBASE: 70925135]

Hughey A, Barnes G, Gu X, Haymart B, Kline-Rogers E, Almany S, et al. Warfarin for prevention of thromboembolism in atrial fibrillation: comparison of patient characteristics and outcomes of the "Real-world" michigan anticoagulation quality improvement initiative (MAQI2) registry to the RE-LY, ROCKETAF, and ARISTOTLE trials [abstract]. Journal of the American College of Cardiology 2014;63(12 Suppl 1):A418. [EMBASE: 71406442]

Jones WS, Hellkamp AS, Halperin J, Piccini JP, Breithardt G, Singer DE, et al. Efficacy and safety of rivaroxaban compared with warfarin in patients with peripheral artery disease and non-valvular atrial fibrillation: insights from ROCKET AF. European Heart Journal 2014;35(4):242-9. [MEDLINE: 24302273]

Jones WS, Hellkamp AS, Halperin J, Piccini JP, Breithardt G, Singer DE, et al. Efficacy and safety of rivaroxaban compared with warfarin in patients with peripheral artery disease and non-valvular-atrial fibrillation: insights from ROCKET AF [abstract]. European Heart Journal 2013;34(Suppl 1):809-10. [EMBASE: 71260515]

Li HF, Zhao RL. Lack of stroke subtype information may hinder indirect comparison between the ROCKET-AF and other trials of new oral anticoagulants. Journal of the American College of Cardiology 2013;61(5):595-6. [MEDLINE: 23273400]

Mahaffey KW, Hellkamp A, Patel MR, Hannan K, Schwabe K, Nessel CC, et al. Inadequate anticoagulant therapy during end of study transition to open-label vitamin $\mathrm{K}$ antagonist therapy: experience in ROCKET AF [abstract no: 5291]. European Heart Journal 2012;33(Suppl 1):968. [EMBASE: 70886038]

Mahaffey KW, Hellkamp AS, Patel MR, Hannan KL, Schwabe K, Nessel CC, et al. End of study transition from study drug to open-label vitamin $\mathrm{K}$ antagonist therapy: the ROCKET AF experience. Circulation. Cardiovascular Quality \& Outcomes 2013;6(4):470-8. [MEDLINE: 23759472]

Mahaffey KW, Stevens SR, White HD, Nessel CC, Goodman SG, Piccini JP, et al. Ischaemic cardiac outcomes in patients with atrial fibrillation treated with vitamin $\mathrm{K}$ antagonism or factor Xa inhibition: results from the ROCKET AF trial. European Heart Journal 2014;35(4):233-41. [MEDLINE: 24132190]

Mahaffey KW, White HD, Nessel CC, Goodman SG, Piccini JP, Patel MR, et al. Ischemic cardiac outcomes in patients with AF treated with vitamin $\mathrm{K}$ antagonism or factor Xa inhibition: Results from the ROCKET AF Trial [abstract no: 13482]. Circulation 2011;124(21 Suppl 1). [EMBASE: 70621217]

Mahaffey KW, Wojdyla D, Hankey GJ, White HD, Nessel CC, Piccini JP, et al. Clinical outcomes with rivaroxaban in patients transitioned from vitamin $\mathrm{K}$ antagonist therapy: a subgroup analysis of a randomized trial.[Summary for patients in Ann 
Intern Med. 2013 Jun 18;158(12):I-28; PMID: 23778921]. Annals of Internal Medicine 2013;158(12):861-8. [MEDLINE: 23778903]

Minar E. Presentation of the ROCKET AF study on the occasion of the Annual Congress of the American Heart Association. November 15, 2010, Chicago [abstract] [Prasentation der ROCKET-AF-studie anlasslich des Jahreskongresses der American Heart Association 15. November 2010, Chicago]. Zeitschrift fur Gefassmedizin 2010;7(4):18-9. [EMBASE: 360213615]

Nessel C, Mahaffey K, Piccini J, Pan G, Patel M, Becker R, et al. Incidence and outcomes of gastrointestinal hemorrhage in patients with atrial fibrillation treated with rivaroxaban or warfarin: Results from the ROCKET AF trial [abstract]. Chest 2012;142(4 Suppl 1):84A. [EMBASE: 71072421]

Patel M, Becker R, Breithardt G, Hacke W, Halperin J, Hankey G, et al. Rationale and design of the ROCKET AF study: Comparison of rivaroxaban with warfarin for the prevention of stroke and systemic embolism in patients with atrial fibrillation [abstract]. European Heart Journal 2009;30(Suppl 1):705. [EMBASE: 70355859]

Patel MR, Hellkamp AS, Lokhnygina Y, Piccini JP, Zhang Z, Mohanty $S$, et al. Outcomes of discontinuing rivaroxaban compared with warfarin in patients with nonvalvular atrial fibrillation: analysis from the ROCKET AF trial (Rivaroxaban Once-Daily, Oral, Direct Factor Xa Inhibition Compared With Vitamin K Antagonism for Prevention of Stroke and Embolism Trial in Atrial Fibrillation). Journal of the American College of Cardiology 2013;61(6):651-8. [MEDLINE: 23391196]

Patel MR, Mahaffey KW, Garg J, Pan G, Singer DE, Hacke W, et al. Rivaroxaban versus warfarin in nonvalvular atrial fibrillation. New England Journal of Medicine 2011;365(10):883-91. [MEDLINE: 21830957]

Piccini JP, Garg J, Patel MR, Lokhnygina Y, Goodman SG, Becker RC, et al. Management of major bleeding events in patients treated with rivaroxaban versus warfarin: Results from the ROCKET AF trial [abstract]. Circulation 2013;128(22 Suppl 1). [EMBASE: 71337075]

Piccini JP, Garg J, Patel MR, Lokhnygina Y, Goodman SG, Becker RC, et al. Management of major bleeding events in patients treated with rivaroxaban vs. warfarin: results from the ROCKET AF trial. European Heart Journal 2014;35(28):1873-80. [MEDLINE: 24658769]

Piccini JP, Harrell F, Lokhnygina Y, Wang J, Oppenheimer L, Patel MR, et al. Relationship between center time in therapeutic range and comparative treatment effect of rivaroxaban and warfarin: results from the ROCKET AF trial [abstract no: 5293]. European Heart Journal 2012;33(Suppl 1):968-9. [EMBASE: 70886040]

Piccini JP, Hellkamp AS, Lokhnygina Y, Patel MR, Harrell FE, Singer $D E$, et al. Relationship between time in therapeutic range and comparative treatment effect of rivaroxaban and warfarin: results from the ROCKET AF trial. Journal of the American Heart Association 2014;3(2):e000521. [MEDLINE: 24755148]
Piccini JP, Stevens S, Lokhnygina Y, Patel M, Singer D, Halperin J, et al. Outcomes following cardioversion and atrial fibrillation ablation in patients treated with rivaroxaban and warfarin in the ROCKET AF trial [abstract no: 19281]. Circulation 2012;126(21 Suppl 1). [EMBASE: 70958434]

Piccini JP, Stevens S, Patel MR, Singer DE, Breithardt G, Hankey GJ, et al. Independent predictors of mortality in patients with non-valvular atrial fibrillation: results from ROCKET AF [abstract]. European Heart Journal 2012;33(Suppl 1):56-7. [EMBASE: 70882618]

Piccini JP, Stevens SR, Chang Y, Singer DE, Lokhnygina Y, Go AS, et al. Renal dysfunction as a predictor of stroke and systemic embolism in patients with nonvalvular atrial fibrillation: validation of the R2CHADS2 index in the ROCKET AF. Circulation 2013;127(2):224-32. [EMBASE: 368158325]

Piccini JP, Stevens SR, Chang Y, Singer DE, Lokhnygina Y, Go AS, et al. Response to letter regarding article, "renal dysfunction as a predictor of stroke and systemic embolism in patients with nonvalvular atrial fibrillation: validation of the R2CHADS2 index in the ROCKET AF (Rivaroxaban OnceDaily, Oral, Direct Factor Xa Inhibition Compared With Vitamin K Antagonism for Prevention of Stroke and Embolism Trial in Atrial Fibrillation) and ATRIA (Anticoagulation and Risk Factors in Atrial Fibrillation) study cohorts". Circulation 2013;128(11):e172-3. [MEDLINE: 24019452]

Piccini JP, Stevens SR, Lokhnygina Y, Patel MR, Halperin JL, Singer DE, et al. Outcomes after cardioversion and atrial fibrillation ablation in patients treated with rivaroxaban and warfarin in the ROCKET AF trial. Journal of the American College of Cardiology 2013;61(19):1998-2006. [MEDLINE: 23500298]

Piccini JP, Stevens SR, Patel MR, Mahaffey KW, Paolini JF, Nessel CC, et al. Renal dysfunction is a potent predictor of stroke and systemic embolism among individuals with atrial fibrillation: results from the Rocket AF trial [abstract no: 17137]. Circulation 2011;124(21 Suppl 1). [EMBASE: 70619386]

Pokorney SD, Piccini JP, Stevens SR, Patel MR, Pieper KS, Halperin JL, et al. Cause of death and predictors of all-cause mortality in anticoagulated patients with nonvalvular atrial fibrillation: data from ROCKET AF. Journal of the American Heart Association 2016;4(3):e002197. [MEDLINE: 26955859]

ROCKET AF Study Investigators. Rivaroxaban-once daily, oral, direct factor $\mathrm{Xa}$ inhibition compared with vitamin $\mathrm{K}$ antagonism for prevention of stroke and Embolism Trial in Atrial Fibrillation: rationale and design of the ROCKET AF study. American Heart Journal 2010;159(3):340-7. [MEDLINE: 20211293]

Rasty S, Soliman W, Taheri R. Comparative efficacy and safety analysis of atrial fibrillaion patients treated with dabigatran in RE-LY study (Chads 2 score of 3 or greater) versus rivaroxaban in ROCKET-AF [abstract]. Value in Health 2012;15(7):A362. [EMBASE: 70916436]

Sherwood MW, Douketis JD, Patel MR, Piccini JP, Hellkamp AS, Lokhnygina $Y$, et al. Outcomes of temporary interruption of rivaroxaban compared with warfarin in patients with nonvalvular atrial fibrillation: results from the rivaroxaban once daily, oral, direct factor Xa inhibition compared with vitamin 
$\mathrm{K}$ antagonism for prevention of stroke and embolism trial in atrial fibrillation (ROCKET AF). Circulation 2014;129(18):1850-9. [MEDLINE: 24552831]

Sherwood MW, Jones S, Cyr D, Becker R, Berkowitz S, Washam J, et al. The use of dual antiplatelet therapy and patient outcomes in those undergoing $\mathrm{PCl}$ in the ROCKET AF trial [abstract]. Journal of the American College of Cardiology 2014;63(12 Suppl 1):A1724. [EMBASE: 71407748]

Sherwood MW, Nessel CC, Hellkamp AS, Mahaffey KW, Piccini JP, Suh EY, et al. Gastrointestinal bleeding in patients with atrial fibrillation treated with rivaroxaban or warfarin: ROCKET AF trial. Journal of the American College of Cardiology 2015;66(21):2271-81. [MEDLINE: 26610874]

Singer DE, Hellkamp AS, Halperin JL, Mahaffey KW, Becker RC, Breithardt G, et al. Individual and regional determinants of time in therapeutic range among patients randomized to warfarin in the ROCKET AF trial of rivaroxaban [abstract no: 16169]. Circulation 2011;124(21 Suppl 1). [EMBASE: 70621620]

Singer DE, Hellkamp AS, Piccini JP, Mahaffey KW, Lokhnygina Y, Pan G, et al. Impact of global geographic region on time in therapeutic range on warfarin anticoagulant therapy: data from the ROCKET AF clinical trial. Journal of the American Heart Association 2013;2(1):e000067. [MEDLINE: 23525418]

Spencer RJ, Amerena JV. Rivaroxaban in the prevention of stroke and systemic embolism in patients with non-valvular atrial fibrillation: clinical implications of the ROCKET AF Trial and its subanalyses. American Journal of Cardiovascular Drugs 2015;15(6):395-401. [MEDLINE: 26062914]

Steinberg B, Hellkamp A, Lokhnygina Y, Halperin J, Breithardt G, Passman R, et al. Use and outcomes of antiarrhythmic therapy in patients with atrial fibrillation receiving oral anticoagulation: results from the ROCKET AF trial [abstract]. Journal of the American College of Cardiology 2014;63(12 Suppl 1):A327. [EMBASE: 71406351]

Steinberg BA, Hellkamp AS, Lokhnygina Y, Halperin JL, Breithardt G, Passman R, et al. Use and outcomes of antiarrhythmic therapy in patients with atrial fibrillation receiving oral anticoagulation: results from the ROCKET AF trial. Heart Rhythm 2014;11(6):925-32. [MEDLINE: 24833235]

Steinberg BA, Hellkamp AS, Lokhnygina Y, Patel MR, Breithardt G, Hankey GJ, et al. Higher risk of death and stroke in patients with persistent vs. paroxysmal atrial fibrillation: results from the ROCKET-AF Trial. European Heart Journal 2015;36(5):288-96. [MEDLINE: 25209598]

Steinberg BA, Hellkamp AS, Lokhnygina Y, Patel MR, Breithardt G, Singer DE, et al. Higher risk of death and stroke in patients with persistent versus paroxysmal atrial fibrillation: results from the ROCKET AF trial [abstract]. European Heart Journal 2014;35:866. [EMBASE: 71649978]

Tiefenbacher CP. ROCKET AF. Herz 2011;36(2):149-50. [EMBASE: 21424349]

Uguccioni M, Napoletano C. Critical issues in megatrials on new oral anticoagulants. Rocket AF: Applying results to low risk patients [Questioni aperte nei grandi trial clinici sui nuovi anticoagulanti orali lo studio ROCKET-AF: trasferibilita dei risultati nei soggetti a basso rischio]. Monaldi Archives for Chest Disease 2013;80(1):3-6. [MEDLINE: 23923584]

Van Diepen S, Hellkamp AS, Patel MR, Becker RC, Breithard G, Halperin JL, et al. Rivaroxaban is associated with a reduced risk of thromboembolic events and hemorrhagic stroke in patient with heart failure: insights from ROCKET AF [abstract no: 14365]. Circulation 2012;126(21 Suppl 1). [EMBASE: 70958827]

Washam JB, Stevens SR, Lokhnygina Y, Halperin JL, Breithardt G, Singer DE, et al. Digoxin use in patients with atrial fibrillation is associated with adverse cardiac outcomes: results from the ROCKET AF trial [abstract]. European Heart Journal 2014;35:867. [EMBASE: 71649980]

Wong KS, Hu DY, Oomman A, Tan RS, Patel MR, Singer DE, et al. Rivaroxaban for stroke prevention in East Asian patients from the ROCKET AF trial. Stroke 2014;45(6):1739-47. [MEDLINE: 24763930]

van Diepen S, Hellkamp AS, Patel MR, Becker RC, Breithardt G, Hacke W, et al. Efficacy and safety of rivaroxaban in patients with heart failure and nonvalvular atrial fibrillation: insights from ROCKET AF. Circulation: Heart Failure 2013;6(4):740-7. [MEDLINE: 23723250]

\section{References to studies excluded from this review}

Caluwé 2016 \{published data only\}

Caluwe R, Pyfferoen L, De Boeck K, De Vriese AS. The effects of vitamin $\mathrm{K}$ supplementation and vitamin $\mathrm{K}$ antagonists on progression of vascular calcification: ongoing randomized controlled trials. Clinical Kidney Journal 2016;9(2):273-9. [MEDLINE: 26985380]

\section{Eriksson 2003a \{published data only\}}

Eriksson UG, Johansson S, Attman PO, Mulec H, Frison L, Fager $\mathrm{G}$, et al. Influence of severe renal impairment on the pharmacokinetics and pharmacodynamics of oral ximelagatran and subcutaneous melagatran. Clinical Pharmacokinetics 2003;42(8):743-53. [MEDLINE: 12846595]

\section{Koretsune 2015 \{published data only\}}

Koretsune Y, Yamashita T, Kimura T, Fukuzawa M, Abe K, Yasaka M. Short-term safety and plasma concentrations of edoxaban in Japanese patients with non-valvular atrial fibrillation and severe renal impairment. Circulation Journal 2015;79(7):1486-95. [MEDLINE: 25925842]

\section{Murray 2004 \{published data only\}}

Murray PT, Reddy BV, Grossman EJ, Hammes MS, Trevino S, Ferrell J, et al. A prospective comparison of three argatroban treatment regimens during hemodialysis in end-stage renal disease. Kidney International 2004;66(6):2446-53. [MEDLINE: 15569338] 


\section{References to ongoing studies}

\section{X-NOAC Study 2015 \{published data only\}}

Suzuki M, Fukamizu S, Oyama J, Mizukami A, Matsumura A, Hashimoto $Y$, et al. Rationale and design of the efficacy of rivaroxaban on renal function in patients with non-valvular atrial fibrillation and chronic kidney disease: the X-NOAC study. International Journal of Cardiology 2015;188:52-3. [MEDLINE: 25889327]

\section{Additional references}

\section{Alonso 2011}

Alonso A, Lopez FL, Matsushita K, Loehr LR, Agarwal SK, Chen LY, et al. Chronic kidney disease is associated with the incidence of atrial fibrillation: the Atherosclerosis Risk in Communities (ARIC) study. Circulation 2011;123(25):2946-53. [MEDLINE: 21646496]

\section{Bruins Slot 2013}

Bruins Slot KM, Berge E. Factor Xa inhibitors versus vitamin $\mathrm{K}$ antagonists for preventing cerebral or systemic embolism in patients with atrial fibrillation. Cochrane Database of Systematic Reviews 2013, Issue 8. [DOI: 10.1002/14651858.CD008980.pub2]

\section{Dahal 2016}

Dahal K, Kunwar S, Rijal J, Schulman P, Lee J. Stroke, major bleeding, and mortality outcomes in warfarin users with atrial fibrillation and chronic kidney disease: a meta-analysis of observational studies. Chest 2016;149(4):951-9. [MEDLINE: 26378611]

\section{EHRA-EACTS 2010}

European Heart Rhythm Association, European Association for Cardio-Thoracic Surgery, Camm AJ, Kirchhof P, Lip GY, Schotten $\mathrm{U}$, et al. Guidelines for the management of atrial fibrillation: the Task Force for the Management of Atrial Fibrillation of the European Society of Cardiology (ESC). [Erratum appears in Europace. $2011 \mathrm{Jul}$;13(7):1058 Note: Dosage error in article text]. Europace 2010;12(10):1360-420. [MEDLINE: 20876603]

\section{EMA 2014}

European Medicines Agency. Product-information requirements. 2014. www.ema.europa.eu/ema/index.jsp? curl=pages/regulation/general/general_content_000199.jsp (accessed 9 August 2017).

\section{Eriksson 2011}

Eriksson BI, Quinlan DJ, Eikelboom JW. Novel oral factor Xa and thrombin inhibitors in the management of thromboembolism. Annual Review of Medicine 2011;62:41-57. [MEDLINE: 21226611]

\section{FDA 2014}

US Food, Drug Administration. 2014 Safety alerts for Muman medical products. www.wayback.archiveit.org/7993/20170111132857/http://www.fda.gov/ Safety/MedWatch/SafetyInformation/ SafetyAlertsforHumanMedicalProducts/ucm380008.htm (accessed 9 August 2017).

\section{Gage 2001}

Gage BF, Waterman AD, Shannon W, Boechler M, Rich MW, Radford MJ. Validation of clinical classification schemes for predicting stroke: results from the National Registry of Atrial Fibrillation. JAMA 2001;285(22):2864-70. [MEDLINE: 11401607]

\section{Go 2001}

Go AS, Hylek EM, Phillips KA, Chang Y, Henault LE, Selby JV, et al. Prevalence of diagnosed atrial fibrillation in adults: national implications for rhythm management and stroke prevention: the AnTicoagulation and Risk Factors in Atrial Fibrillation (ATRIA) Study. JAMA 2001;285(18):2370-5. [MEDLINE: 11343485]

\section{Go 2009}

Go AS, Fang MC, Udaltsova N, Chang Y, Pomernacki NK, Borowsky L, et al. Impact of proteinuria and glomerular filtration rate on risk of thromboembolism in atrial fibrillation: the anticoagulation and risk factors in atrial fibrillation (ATRIA) study. Circulation 2009;119(10):1363-9. [MEDLINE: 19255343]

\section{GRADE 2008}

Guyatt GH, Oxman AD, Vist GE, Kunz R, Falck-Ytter Y, AlonsoCoello $P$, et al. GRADE: an emerging consensus on rating quality of evidence and strength of recommendations. $B M J$ 2008;336(7650):924-6. [MEDLINE: 18436948]

\section{Hart 2007}

Hart RG, Pearce LA, Aguilar MI. Meta-analysis: antithrombotic therapy to prevent stroke in patients who have nonvalvular atrial fibrillation. Annals of Internal Medicine 2007;146(12):857-67. [MEDLINE: 17577005]

\section{Health Canada 2017}

Health Canada. First Nations and Inuit Health. www.canada.ca/ en/health-canada/services/first-nations-inuit-health.html (accessed 9 August 2017).

\section{Higgins 2003}

Higgins JP, Thompson SG, Deeks JJ, Altman DG. Measuring inconsistency in meta-analyses. BMJ 2003;327(7414):557-60. [MEDLINE: 12958120]

\section{Higgins 2011}

Higgins JP, Green S (editors). Cochrane Handbook for Systematic Reviews of Interventions Version 5.1.0 [updated March 2011]. The Cochrane Collaboration, 2011. Available from www.cochrane-handbook.org.

\section{KDIGO 2012}

National Kidney Foundation. KDIGO 2012 clinical practice guideline for the evaluation and management of chronic kidney disease. Kidney International - Supplement 2013;3(1):1-150. [DOI: 10.1038/kisup.2012.73]

\section{Lau 2016}

Lau YC, Proietti M, Guiducci E, Blann AD, Lip GY. Atrial fibrillation and thromboembolism in patients with chronic kidney disease. Journal of the American College of Cardiology 2016;68(13):1452-64. [MEDLINE: 27659468] 


\section{Levey 2006}

Levey AS, Coresh J, Greene T, Stevens LA, Zhang YL, Hendriksen $\mathrm{S}$, et al. Using standardized serum creatinine values in the modification of diet in renal disease study equation for estimating glomerular filtration rate. [Erratum appears in Ann Intern Med. 2008 Oct 7;149(7):519]. Annals of Internal Medicine 2006;145(4):247-54. [MEDLINE: 16908915]

\section{Levey 2009}

Levey AS, Stevens LA, Schmid CH, Zhang YL, Castro AF 3rd, Feldman $\mathrm{HI}$, et al. A new equation to estimate glomerular filtration rate.[Erratum appears in Ann Intern Med. 2011 Sep 20;155(6):408]. Annals of Internal Medicine 2009;150(9):604-12. [MEDLINE: 19414839]

\section{Liu 2015}

Liu G, Long M, Hu X, Hu CH, Liao XX, Du ZM, et al. Effectiveness and safety of warfarin in dialysis patients with atrial fibrillation: a meta-analysis of observational studies. Medicine 2015;94(50):e2233. [MEDLINE: 26683937]

\section{Marinigh 2011}

Marinigh R, Lane DA, Lip GY. Severe renal impairment and stroke prevention in atrial fibrillation: implications for thromboprophylaxis and bleeding risk. Journal of the American College of Cardiology 2011;57(12):1339-48. [MEDLINE: 21414530]

\section{Masson 2015}

Masson P, Webster AC, Hong M, Turner R, Lindley RI, Craig JC. Chronic kidney disease and the risk of stroke: a systematic review and meta-analysis. Nephrology Dialysis Transplantation 2015;30(7):1162-9. [MEDLINE: 25681099]

\section{Miller 2012}

Miller CS, Grandi SM, Shimony A, Filion KB, Eisenberg MJ. Meta-analysis of efficacy and safety of new oral anticoagulants (dabigatran, rivaroxaban, apixaban) versus warfarin in patients with atrial fibrillation. American Journal of Cardiology 2012;110(3):453-60. [MEDLINE: 22537354]

\section{Mitchell 2013}

Mitchell SA, Simon TA, Raza S, Jakouloff D, Orme ME, Lockhart I, et al. The efficacy and safety of oral anticoagulants in warfarinsuitable patients with nonvalvular atrial fibrillation: systematic review and meta-analysis. Clinical \& Applied Thrombosis/ Hemostasis 2013;19(6):619-31. [MEDLINE: 23698729]

\section{Nelson 2012}

Nelson SE, Shroff GR, Li S, Herzog CA. Impact of chronic kidney disease on risk of incident atrial fibrillation and subsequent survival in Medicare patients. Journal of the American Heart Association 2012;1(4):e002097. [MEDLINE: 23130165]

\section{Ng 2013}

Ng KP, Edwards NC, Lip GY, Townend JN, Ferro CJ. Atrial fibrillation in CKD: balancing the risks and benefits of anticoagulation. American Journal of Kidney Diseases 2013;62(3):615-32. [MEDLINE: 23746378]

\section{Olsen 2012}

Olesen JB, Lip GY, Kamper AL, Hommel K, Køber L, Lane DA, et al. Stroke and bleeding in atrial fibrillation with chronic kidney disease.[Erratum appears in N Engl J Med. 2012 Dec 6;367(23):2262]. New England Journal of Medicine 2012;367(7):625-35. [MEDLINE: 22894575]

\section{Reinecke 2013}

Reinecke H, Engelbertz C, Schabitz WR. Preventing stroke in patients with chronic kidney disease and atrial fibrillation: benefit and risks of old and new oral anticoagulants. Stroke 2013;44(10):2935-41. [MEDLINE: 24008579]

\section{Schünemann 2011a}

Schünemann HJ, Oxman AD, Higgins JP, Vist GE, Glasziou P, Guyatt GH. Chapter 11: Presenting results and 'Summary of findings' tables. In: Higgins JP, Green S (editors). Cochrane Handbook for Systematic Reviews of Interventions Version 5.1.0 [updated March 2011]. The Cochrane Collaboration, 2011. Available from www.cochrane-handbook.org.

\section{Schünemann 2011b}

Schünemann HJ, Oxman AD, Higgins JP, Deeks JJ, Glasziou P, Guyatt GH. Chapter 12: Interpreting results and drawing conclusions. In: Higgins JP, Green S (editors). Cochrane Handbook for Systematic Reviews of Interventions Version 5.1.0 [updated March 2011]. The Cochrane Collaboration, 2011. Available from www.cochrane-handbook.org.

\section{Soliman 2010}

Soliman EZ, Prineas RJ, Go AS, Xie D, Lash JP, Rahman M, et al. Chronic kidney disease and prevalent atrial fibrillation: the Chronic Renal Insufficiency Cohort (CRIC). [Erratum appears in Am Heart J. 2010 Dec;160(6):1190], [Erratum appears in Am Heart J. 2011 Oct;162(4):794]. American Heart Journal 2010;159(6):1102-07. [MEDLINE: 20569726]

\section{Stangier 2008}

Stangier J, Stähle H, Rathgen K, Fuhr R. Pharmacokinetics and pharmacodynamics of the direct oral thrombin inhibitor dabigatran in healthy elderly subjects. Clinical Pharmacokinetics 2008;47(1):47-59. [MEDLINE: 18076218]

\section{Stewart 2001}

Stewart S, Hart CL, Hole DJ, McMurray JJ. Population prevalence, incidence, and predictors of atrial fibrillation in the Renfrew/Paisley study. Heart 2001;86(5):516-21. [MEDLINE: 11602543]

\section{Watson 2009}

Watson T, Shantsila E, Lip GY. Mechanisms of thrombogenesis in atrial fibrillation: Virchow's triad revisited. Lancet 2009;373(9658):155-66. [MEDLINE: 19135613]

\section{References to other published versions of this review \\ Kimachi 2014}

Kimachi M, Furukawa TA, Kimachi K, Goto Y, Fukuhara S. New oral anticoagulants versus warfarin for preventing stroke and systemic embolic events among atrial fibrillation patients 
with chronic kidney disease. Cochrane Database of Systematic Reviews 2014, Issue 11. [DOI: 10.1002/14651858.CD011373]

* Indicates the major publication for the study

CHARACTERISTICS OF STUDIES

Characteristics of included studies [ordered by study ID]

ARISTOTLE Study 2010

\begin{tabular}{|c|c|}
\hline Methods & $\begin{array}{l}\text { - Study design: double-blind, double-dummy RCT } \\
\text { - Study duration: } 19 \text { December to } 2 \text { April } 2010 \\
\text { - Median duration of study follow-up: } 1.8 \text { years }\end{array}$ \\
\hline Participants & $\begin{array}{l}\text { - Countries: Australia, China, Hong Kong, India, Japan, Malaysia, Philippines, Singapore, South Korea, } \\
\text { Taiwan, Austria, Belgium, Czech Republic, Denmark, Finland, France, Germany, Hungary, Israel, Italy, } \\
\text { Netherlands, Norway, Poland, Romania, Russia, South Africa, Spain, Sweden, Switzerland, Turkey, UK, } \\
\text { Ukraine, Argentina, Brazil, Chile, Colombia, Mexico, Peru, Puerto Rico, Canada, USA } \\
\text { - Setting: multicentre } \\
\text { - Patients with non-valvular AF; moderate kidney impairment }(25 \leq \mathrm{CrCl}<50 \mathrm{~mL} / \mathrm{min}) \text {; aged } \geq 21 \text { years, } \\
\text { and at least one additional risk factors for stroke; age } \geq 75 \text { years; previous stroke, TIA or systemic em- } \\
\text { bolic event; symptomatic heart failure within previous } 3 \text { months or left ventricular ejection fraction of } \\
\text { no more than } 40 \% \text {; DM; hypertension requiring pharmacologic treatment } \\
\text { - Number: treatment group (1502); control group (1515) } \\
\text { - Relevant health status: participants } \\
\text { - Mean age } \pm \text { SD: } 77.6 \pm 7.1 \text { years } \\
\text { - Sex (M/F): } 1408 / 1609 \\
\text { - Exclusion criteria: AF due to a reversible cause; moderate or severe mitral stenosis; conditions other } \\
\text { than AF that required anticoagulation (e.g. a prosthetic heart valve); stroke within the previous } 7 \text { days; } \\
\text { need for aspirin at a dose of }>165 \mathrm{mg} / \mathrm{d} \text { or for both aspirin and clopidogrel; severe kidney insufficiency } \\
\text { (SCr }>221 \mu \mathrm{mol} / \mathrm{L} \text { or calculated } \mathrm{CrCl}<25 \mathrm{~mL} / \mathrm{min} \text { ) }\end{array}$ \\
\hline
\end{tabular}

Interventions Treatment group

- Oral apixaban: either $2.5 \mathrm{mg}$ or $5 \mathrm{mg}$ twice/d, with dosage determined according to whether participants satisfied two or more of the following criteria: (i) age of at least 80 years; (ii) body weight of no more than $60 \mathrm{~kg}$; or (iii) $\mathrm{SCr} \geq 133 \mu \mathrm{mol} / \mathrm{L}$

Control group

- Oral warfarin: dose-adjusted (target INR 2.0 to 3.0 )

\begin{tabular}{ll}
\hline Outcomes & All strokes and systemic embolic events \\
& - All-cause mortality \\
& - Major bleeding \\
\hline Notes & Intracranial haemorrhage \\
\hline
\end{tabular}

\section{Risk of bias}

\begin{tabular}{lll}
\hline Bias & Authors' judgement & Support for judgement \\
\hline $\begin{array}{l}\text { Random sequence genera- } \\
\text { tion (selection bias) }\end{array}$ & Low risk & $\begin{array}{l}\text { Participants were randomly assigned to treatment groups according to the } \\
\text { stratification by clinical site and prior VKA use, and the possibility that this } \\
\text { method give the influence on the results was low }\end{array}$ \\
\hline $\begin{array}{l}\text { Allocation concealment } \\
\text { (selection bias) }\end{array}$ & Low risk & $\begin{array}{l}\text { Allocation was concealed because participants were assigned to each group } \\
\text { using the Interactive Voice Response System }\end{array}$ \\
\hline
\end{tabular}

Direct oral anticoagulants versus warfarin for preventing stroke and systemic embolic events among atrial fibrillation patients with 
ARISTOTLE Study 2010 (Continued)
Blinding of participants
Low risk
Double-blind, double-dummy design and personnel (perfor- mance bias)
All outcomes

\begin{tabular}{|c|c|c|}
\hline $\begin{array}{l}\text { Blinding of outcome as- } \\
\text { sessment (detection bias) } \\
\text { All outcomes }\end{array}$ & Low risk & $\begin{array}{l}\text { Efficacy and safety outcomes were adjudicated on the basis of prespecified cri- } \\
\text { teria by a clinical events committee whose members were unaware of study } \\
\text { group assignments }\end{array}$ \\
\hline
\end{tabular}

Incomplete outcome data Unclear risk
(attrition bias)

Primary efficacy outcome was analysed in ITT population. Primary safety out-

All outcomes come was analysed in modified ITT population including all randomised patients who received least one dose of the study drug and included all events from receipt of the study drug until 2 days after the last dose of the drug. It has unclear risk because the number of participants that discontinued during study was reported, but the reason was unclear

\begin{tabular}{lll}
\hline $\begin{array}{l}\text { Selective reporting (re- } \\
\text { porting bias) }\end{array}$ & Low risk & All predefined efficacy and safety outcomes were reported \\
\hline Other bias & High risk & The study was funded by Bristol-Myers Squibb and Pfizer \\
\hline
\end{tabular}

\section{ENGAGE AF-TIMI 48 Study 2013}

$\begin{array}{ll}\text { Methods } & \text { - Study design: double-blind, double-dummy RCT } \\ \text { - Study duration: } 19 \text { November } 2008 \text { to } 22 \text { November } 2010 \\ \text { - Median duration of study follow-up: } 2.8 \text { years }\end{array}$

Participants

- Countries: USA, Canada, Argentina, Brazil, Chile, Colombia, Mexico, Peru, Guatemala, Belgium, Finland, France, Germany, Greece, Israel, Italy, Netherlands, Norway, Portugal, Spain, Sweden, Switzerland, Turkey, UK, Denmark, Bulgaria, Croatia, Czech Republic, Estonia, Hungary, Poland, Romania, Russia, Serbia and Montenegro, Slovakia, Ukraine, Australia, China, India, Korea, New Zealand, Philippines, South Africa, Taiwan, Thailand, Japan

- Relevant health status: participants aged $\geq 21$ years with non-valvular AF, moderate kidney impairment $(30 \leq \mathrm{CrCl}<50 \mathrm{~mL} / \mathrm{min})$; a score of 2 or higher on the $\mathrm{CHADS}_{2}$ risk assessment

- Setting: multicentre

- Number: treatment group (1379); control group (1361)

- Median age (IQR): 79 years ( 75 to 83 )

- $\operatorname{Sex}(\mathrm{M} / \mathrm{F}): 1260 / 1480$

- Exclusion criteria: AF due to a reversible disorder; an estimated $\mathrm{CrCl}<30 \mathrm{~mL} / \mathrm{min}$; a high risk of bleeding; use of dual antiplatelet therapy; moderate-to severe mitral stenosis; other indications for anticoagulation therapy; acute coronary syndromes, coronary revascularization, or stroke within 30 days before randomisation; an inability to adhere to study procedures

\begin{tabular}{ll}
\hline Interventions & Treatment group \\
& - Oral edoxaban: $30 \mathrm{mg} / \mathrm{d}$ \\
& Control group \\
& - Oral warfarin: dose-adjusted (target INR 2.0 to 3.0) \\
\hline Outcomes & All strokes and systemic embolic events \\
& - MI \\
& All-cause mortality \\
- Major bleeding
\end{tabular}

Direct oral anticoagulants versus warfarin for preventing stroke and systemic embolic events among atrial fibrillation patients with 


\author{
ENGAGE AF-TIMI 48 Study 2013 (Continued) \\ - Minor bleeding \\ - Gl bleeding \\ - Intracranial haemorrhage

Notes $\quad$ Funding source: Daiichi Sankyo Pharma Development

\title{
Risk of bias
}

\begin{tabular}{|c|c|c|}
\hline Bias & Authors' judgement & Support for judgement \\
\hline $\begin{array}{l}\text { Random sequence genera- } \\
\text { tion (selection bias) }\end{array}$ & Low risk & $\begin{array}{l}\text { Participants were randomly assigned to treatment groups with the use of a } \\
\text { central, 24-horur, interactive, computerized response system }\end{array}$ \\
\hline $\begin{array}{l}\text { Allocation concealment } \\
\text { (selection bias) }\end{array}$ & Low risk & $\begin{array}{l}\text { Allocation was concealed because participants were assigned to each group } \\
\text { using a central, 24-horur, interactive, computerized response system }\end{array}$ \\
\hline $\begin{array}{l}\text { Blinding of participants } \\
\text { and personnel (perfor- } \\
\text { mance bias) } \\
\text { All outcomes }\end{array}$ & Low risk & Double-blind, double-dummy design \\
\hline $\begin{array}{l}\text { Blinding of outcome as- } \\
\text { sessment (detection bias) } \\
\text { All outcomes }\end{array}$ & Low risk & $\begin{array}{l}\text { Efficacy and safety outcomes were adjudicated by an independent clinical } \\
\text { end-point committee whose members were not aware of study group assign- } \\
\text { ments }\end{array}$ \\
\hline $\begin{array}{l}\text { Incomplete outcome data } \\
\text { (attrition bias) } \\
\text { All outcomes }\end{array}$ & Unclear risk & $\begin{array}{l}\text { Primary efficacy outcome was reported in both ITT and modified ITT popula- } \\
\text { tion. Primary safety outcome was analysed in modified ITT population. The } \\
\text { number of participants that discontinued during study was reported, but the } \\
\text { reason was unclear }\end{array}$ \\
\hline $\begin{array}{l}\text { Selective reporting (re- } \\
\text { porting bias) }\end{array}$ & Low risk & All predefined efficacy and safety outcomes were reported \\
\hline Other bias & High risk & The study was funded by Daiichi Sankyo Pharma Development \\
\hline
\end{tabular}

\section{J-ROCKET AF Study 2012}

$\begin{array}{ll}\text { Methods } & \text { Study design: double-blind, double-dummy RCT } \\ \text { - Study duration: } 8 \text { June } 82007 \text { to } 19 \text { January } 2010 \\ \text { - Median duration of study follow-up: } 2.5 \text { years }\end{array}$

\begin{tabular}{|c|c|}
\hline Participants & $\begin{array}{l}\text { - Country: Japan } \\
\text { - Setting: Multicentre } \\
\text { - Participants with non-valvular AF, moderate kidney impairment }(30 \leq \mathrm{CrCl}<50 \mathrm{~mL} / \mathrm{min}) \text {; aged } \geq 20 \\
\text { years, and at least one additional risk factors: a history of prior ischaemic stroke, TIA, or non-CNS } \\
\text { systemic embolism, or had } \geq 2 \text { of the following risk factors for thromboembolism, congestive heart } \\
\text { failure and/or left ventricular ejection fraction } \leq 35 \% \text {, hypertension, age } \geq 75 \text { years, or DM } \\
\text { - Number: treatment group (141); control group (143) } \\
\text { - Median age, IQR (years): treatment group ( } 78,74 \text { to } 81) \text {, control group }(78,75 \text { to } 82) \\
\text { - Sex(M/F): treatment group (105/36); control group (95/48) } \\
\text { - Exclusion criteria: } \mathrm{CrCl}<30 \mathrm{~mL} / \mathrm{min}\end{array}$ \\
\hline
\end{tabular}

Interventions Treatment group

- Oral rivaroxaban: $10 \mathrm{mg} / \mathrm{d}$

Direct oral anticoagulants versus warfarin for preventing stroke and systemic embolic events among atrial fibrillation patients with 
J-ROCKET AF Study 2012 (Continued)

\section{Control group}

- Oral warfarin: dose-adjusted (target INR 2.0 to 3.0 for age $<70$ and 1.6 to 2.6 to patients for age $\geq 70$ )

\begin{tabular}{ll}
\hline Outcomes & All strokes and systemic embolic events (not shown because of the result from modified ITT analysis) \\
- Major bleeding \\
- Minor bleeding \\
- Intracranial haemorrhage \\
\hline Notes
\end{tabular}

Risk of bias

\begin{tabular}{|c|c|c|}
\hline Bias & Authors' judgement & Support for judgement \\
\hline $\begin{array}{l}\text { Random sequence genera- } \\
\text { tion (selection bias) }\end{array}$ & Unclear risk & $\begin{array}{l}\text { Study was described as randomised, method of randomisation was not report- } \\
\text { ed }\end{array}$ \\
\hline $\begin{array}{l}\text { Allocation concealment } \\
\text { (selection bias) }\end{array}$ & Unclear risk & Insufficient information to permit judgement \\
\hline $\begin{array}{l}\text { Blinding of participants } \\
\text { and personnel (perfor- } \\
\text { mance bias) } \\
\text { All outcomes }\end{array}$ & Low risk & Double-blind, double-dummy \\
\hline $\begin{array}{l}\text { Blinding of outcome as- } \\
\text { sessment (detection bias) } \\
\text { All outcomes }\end{array}$ & Low risk & $\begin{array}{l}\text { Efficacy and safety outcomes were adjudicated on the basis of prespecified cri- } \\
\text { teria by an independent clinical endpoint committee whose members were } \\
\text { unaware of study group assignments }\end{array}$ \\
\hline $\begin{array}{l}\text { Incomplete outcome data } \\
\text { (attrition bias) } \\
\text { All outcomes }\end{array}$ & Unclear risk & $\begin{array}{l}\text { Primary efficacy endpoints were analysed in the per-protocol population } \\
\text { whose were ITT patients with no major protocol violation. Primary safety end- } \\
\text { points were analysed in modified ITT population. The number of participants } \\
\text { that discontinued during study was reported, but the reason was unclear }\end{array}$ \\
\hline $\begin{array}{l}\text { Selective reporting (re- } \\
\text { porting bias) }\end{array}$ & Low risk & All predefined efficacy and safety outcomes were reported \\
\hline Other bias & High risk & $\begin{array}{l}\text { The study was funded by the Bayer Healthcare Pharmaceuticals Japanese sub- } \\
\text { sidiary, Bayer Yakuhin }\end{array}$ \\
\hline
\end{tabular}

\section{RE-LY Study 2009}

$\begin{array}{ll}\text { Methods } & \text { - Study design: parallel RCT } \\ & \text { - Study duration: } 22 \text { December } 2005 \text { to } 15 \text { March } 2009 \\ & \text { - Median duration of study follow-up: } 2.0 \text { years }\end{array}$

Participants

- Country: Taiwan, Colombia, Mexico, Peru, Romania, India, Russia, Brazil, China, Korea, Greece, Thailand, Malaysia, Poland, Japan, South Africa, France, Slovakia, Portugal, Israel, Czech Republic, Philippines, Bulgaria, Hungary, Hong Kong, Turkey, Belgium, Austria, USA, Spain, Germany, Switzerland, Singapore, Argentina, Netherlands, Norway, Canada, Italy, Ukraine, UK, Denmark, Australia, Finland, Sweden

- Setting: multicentre

- Relevant health status: participants with non-valvular AF, moderate kidney impairment $(30 \leq \mathrm{CrCl}<$ $50 \mathrm{~mL} / \mathrm{min}$ ); aged $\geq 18$ years, and at least one of the following risk factors for stroke; previous stroke or TIA, a left ventricular ejection fraction of less than $40 \%$, New York Heart Association class II or higher

Direct oral anticoagulants versus warfarin for preventing stroke and systemic embolic events among atrial fibrillation patients with 
RE-LY Study 2009 (Continued)

heart-failure symptoms within 6 months before screening, and an age of at least 75 years or an age of 65 to 74 years plus DM, hypertension, or coronary artery disease

- Number: treatment group (2428); control group (1126)

- Mean age \pm SD: $75.2 \pm 7.2$ years

- $\operatorname{Sex}(\mathrm{M} / \mathrm{F}): 1803 / 1571$

- Exclusion criteria: presence of a severe heart-valve disorder; stroke within 14 days or severe stroke within 6 months before screening; a condition that increased the risk of haemorrhage; $\mathrm{CrCl}<30 \mathrm{~mL}$ / min; active liver disease; pregnancy

\begin{tabular}{ll}
\hline Interventions & Treatment group \\
- Oral dabigatran: $110 \mathrm{mg}$ or $150 \mathrm{mg}$ twice daily \\
Control group \\
- Oral warfarin: dose-adjusted (target INR 2.0 to 3.0) \\
\hline - All strokes and systemic embolic events \\
- All-cause mortality \\
- Major bleeding (not included in this review because of the result from conventional ITT analysis) \\
analysis) \\
\hline - Funding source: Boehringer Ingelheim Pharmaceuticals
\end{tabular}

\section{Risk of bias}

\begin{tabular}{lll}
\hline Bias & Authors' judgement & Support for judgement \\
\hline $\begin{array}{l}\text { Random sequence genera- } \\
\text { tion (selection bias) }\end{array}$ & Low risk & $\begin{array}{l}\text { Participants were randomly assigned to treatment groups with means of a } \\
\text { central, interactive, automated telephone system }\end{array}$ \\
\hline $\begin{array}{l}\text { Allocation concealment } \\
\text { (selection bias) }\end{array}$ & Low risk & $\begin{array}{l}\text { Allocation was concealed because participants were assigned to each group } \\
\text { using a central, interactive, automated telephone system }\end{array}$ \\
\hline $\begin{array}{l}\text { Blinding of participants } \\
\text { and personnel (perfor- } \\
\text { mance bias) } \\
\text { All outcomes }\end{array}$ & Unclear risk & $\begin{array}{l}\text { Dabigatran was administered in a blinded fashion, but warfarin was adminis- } \\
\text { tered in an unblinded fashion. But we judged that incomplete blinding didn't } \\
\text { give influence for the outcomes, because the outcomes were objective mea- } \\
\text { sures and the outcome assessors were blinded }\end{array}$ \\
\hline
\end{tabular}

\begin{tabular}{lll}
\hline $\begin{array}{l}\text { Blinding of outcome as- } \\
\text { sessment (detection bias) } \\
\text { All outcomes }\end{array}$ & Low risk & $\begin{array}{l}\text { Each primary and secondary outcome event was adjudicated by two indepen- } \\
\text { dent investigators who were unaware of the treatment assignments }\end{array}$ \\
\hline $\begin{array}{l}\text { Incomplete outcome data } \\
\text { (attrition bias) } \\
\text { All outcomes }\end{array}$ & Unclear risk & $\begin{array}{l}\text { All outcomes were analyses in the ITT population. The information about dis- } \\
\text { continuation during study was unclear }\end{array}$ \\
\hline $\begin{array}{l}\text { Selective reporting (re- } \\
\text { porting bias) }\end{array}$ & Low risk & All predefined efficacy and safety outcomes were reported \\
\hline Other bias & High risk & The study was funded by Boehringer Ingelheim Pharmaceuticals \\
\hline
\end{tabular}


ROCKET AF Study 2010 (Continued)

- Study duration: 18 December 2006 to 17 June 2009

- Median duration of study follow-up: 1.9 years

Participants

Interventions

Treatment group

- Oral rivaroxaban: $15 \mathrm{mg} / \mathrm{d}$

Control group

- Oral warfarin: dose-adjusted (target INR 2.0 to 3.0 )
- Countries: Australia, China, Hong Kong, India, Korea, Malaysia, New Zealand, Philippines, Singapore, Taiwan, Thailand, Bulgaria, Czech Republic, Greece, Hungary, Lithuania, Poland, Romania, Russia, Turkey, Ukraine, Argentina, Brazil, Chile, Colombia, Mexico, Panama, Peru, Venezuela, Canada, USA, Austria, Belgium, Denmark, Finland, France, Germany, Israel, Italy, Netherlands, Norway, South Africa, Spain, Sweden, Switzerland, UK

- Setting: multicentre

- Participants with non-valvular AF, moderate kidney impairment $(30 \leq \mathrm{CrCl}<50 \mathrm{~mL} / \mathrm{min})$; aged $\geq 18$ years, and a score of 2 or higher on the $\mathrm{CHADS}_{2}$ risk assessment

- Number: treatment group (1474); control group (1476)

- Median age, IQR (years): treatment group (79; 75 to 82 ); control group (79, 75 to 83 )

- Sex (M/F): treatment group (663/811); control group (651/825)

- Exclusion criteria: cardiovascular-related conditions; haemorrhage risk-related criteria; any stroke within 14 days before randomisation; TIA within 3 days before randomisation; indication for anticoagulant therapy for a condition other than AF; anaemia at the screening visit; pregnancy or breastfeeding; calculated $\mathrm{CrCl}<30 \mathrm{~mL} / \mathrm{min}$; known significant liver disease

\begin{tabular}{ll}
\hline Outcomes & All strokes and systemic embolic events \\
& - Major bleeding \\
& Gl bleeding \\
& Intracranial haemorrhage \\
\hline Notes & Funding sources: Johnson \& Johnson Pharmaceutical Research \& Development L.L.C. (Raritan, NJ) \\
& and Bayer HealthCare Pharmaceuticals (Berlin, Germany) \\
\hline
\end{tabular}

\section{Risk of bias}

\begin{tabular}{|c|c|c|}
\hline Bias & Authors' judgement & Support for judgement \\
\hline $\begin{array}{l}\text { Random sequence genera- } \\
\text { tion (selection bias) }\end{array}$ & Low risk & $\begin{array}{l}\text { Participants were randomly assigned to treatment groups with the use of a } \\
\text { central 24-hour, computerized, automated voice-response system }\end{array}$ \\
\hline $\begin{array}{l}\text { Allocation concealment } \\
\text { (selection bias) }\end{array}$ & Low risk & $\begin{array}{l}\text { Allocation was concealed because participants were assigned to each group } \\
\text { using a central 24-hour, computerised, automated voice-response system }\end{array}$ \\
\hline $\begin{array}{l}\text { Blinding of participants } \\
\text { and personnel (perfor- } \\
\text { mance bias) } \\
\text { All outcomes }\end{array}$ & Low risk & Double-blind, double-dummy design \\
\hline $\begin{array}{l}\text { Blinding of outcome as- } \\
\text { sessment (detection bias) } \\
\text { All outcomes }\end{array}$ & Low risk & $\begin{array}{l}\text { Efficacy and safety outcomes were adjudicated by an independent clinical } \\
\text { end-point committee whose members were unaware of study group assign- } \\
\text { ments }\end{array}$ \\
\hline $\begin{array}{l}\text { Incomplete outcome data } \\
\text { (attrition bias) } \\
\text { All outcomes }\end{array}$ & Unclear risk & $\begin{array}{l}\text { Primary efficacy outcome was reported in both ITT and modified ITT popula- } \\
\text { tion. Primary and secondary safety outcome was analysed in the modified ITT } \\
\text { population }\end{array}$ \\
\hline
\end{tabular}

Direct oral anticoagulants versus warfarin for preventing stroke and systemic embolic events among atrial fibrillation patients with 
ROCKET AF Study 2010 (Continued)

\begin{tabular}{|c|c|c|}
\hline $\begin{array}{l}\text { Selective reporting (re- } \\
\text { porting bias) }\end{array}$ & Low risk & $\begin{array}{l}\text { All outcomes were analyses in the ITT population. The number of participants } \\
\text { that discontinued during study was reported, but the reason was unclear }\end{array}$ \\
\hline Other bias & High risk & $\begin{array}{l}\text { The study was funded by Johnson \& Johnson Pharmaceutical Research \& De- } \\
\text { velopment L.L.C. (Raritan, NJ) and Bayer HealthCare Pharmaceuticals (Berlin, } \\
\text { Germany) }\end{array}$ \\
\hline
\end{tabular}

AF - atrial fibrillation; CNS - central nervous system; $\mathrm{CrCl}$ - creatinine clearance; DM - diabetes mellitus; GI - gastrointestinal; INR international normalised ratio; IQR - interquartile range; ITT - intention to treat; M/F - male/female; RCT - randomised controlled trial; SCr - serum creatinine; SD - standard deviation; TIA - transient ischaemic attack

Characteristics of excluded studies [ordered by study ID]

\begin{tabular}{ll}
\hline Study & Reason for exclusion \\
\hline Caluwé 2016 & Wrong intervention: rivaroxaban versus rivaroxaban plus vitamin K2 versus vitamin K antagonist \\
\hline Eriksson 2003a & Pharmacokinetic/pharmacodynamic RCT of ximelagatran and melagatran \\
\hline Koretsune 2015 & Pharmacokinetic/pharmacodynamic RCT of 3 treatment regimens of edoxaban \\
\hline Murray 2004 & Pharmacokinetic/pharmacodynamic cross-over RCT of 3 treatment regimens of argatroban \\
\hline
\end{tabular}

$\mathrm{RCT}$ - randomised controlled trial

Characteristics of ongoing studies [ordered by study ID]

\section{X-NOAC Study 2015}

Trial name or title

Efficacy of rivaroxaban on renal function in patients with non-valvular atrial fibrillation and chronic kidney disease: The X-NOAC study

\begin{tabular}{ll}
\hline Methods & Parallel RCT (1:1) \\
\hline Participants & Non-valvular AF patients with eGFR $<30$ and $<89 \mathrm{~mL} / \mathrm{min} / 1.73 \mathrm{~m}^{2}$ \\
& $\begin{array}{l}\text { Randomisation factors were age }(<75 \text { years or } \geq 75 \text { years), gender, anticoagulation pretreatment } \\
\text { (none or warfarin), and the CHADS } 2 \text { score }(<2 \text { or } \geq 2 \text { ). The total sample size is } 160 \text { patients }\end{array}$
\end{tabular}

Treatment group

- Oral rivaroxaban: $15 \mathrm{mg}$ once daily after a meal. In addition, in cases where the $\mathrm{CrCl}$ was 30 to 49 $\mathrm{mL} / \mathrm{min}, 10 \mathrm{mg}$ was given orally once daily after a meal

Control group

- Warfarin: dose was adjusted such that PT-INR would become 2.0 to 3.0 in patients aged $<70$ years or 1.6 to 2.6 in those aged $\geq 70$ years

\begin{tabular}{ll}
\hline Outcomes & $\begin{array}{l}\text { The primary endpoint is the change in urinary albumin excretion, and the secondary endpoints } \\
\text { are changes in endothelial cell function, blood coagulation/fibrinolysis, inflammation, and kidney } \\
\text { function three months after registration }\end{array}$ \\
\hline Starting date & Not reported \\
\hline Contact information & Makoto Suzuki, Department of Cardiology, Kameda Medical centre, 929 Higashi-chou, Kamo- \\
gawa-city, Chiba 296-8602, Japan.
\end{tabular}

Direct oral anticoagulants versus warfarin for preventing stroke and systemic embolic events among atrial fibrillation patients with 
X-NOAC Study 2015 (Continued)

$$
\text { macmed33@gmail.com }
$$

Notes

AF - atrial fibrillation; eGFR - estimated glomerular filtration rate; RCT - randomised controlled trial

\section{DATA AND ANALYSES}

Comparison 1. Direct oral anticoagulants versus warfarin

\begin{tabular}{|c|c|c|c|c|}
\hline Outcome or subgroup title & No. of studies & $\begin{array}{l}\text { No. of partici- } \\
\text { pants }\end{array}$ & Statistical method & Effect size \\
\hline $\begin{array}{l}1 \text { All strokes and systemic } \\
\text { embolic events }\end{array}$ & 5 & 12545 & Risk Ratio (M-H, Random, 95\% Cl) & $0.81[0.65,1.00]$ \\
\hline 2 Ischaemic stroke & 4 & 8991 & Risk Ratio (M-H, Random, 95\% Cl) & $1.01[0.75,1.36]$ \\
\hline 3 Haemorrhagic stroke & 4 & 8991 & Risk Ratio (M-H, Random, 95\% Cl) & $0.52[0.28,0.97]$ \\
\hline 4 Major bleeding & 5 & 12521 & Risk Ratio (M-H, Random, 95\% Cl) & $0.79[0.59,1.04]$ \\
\hline 5 Myocardial infarction & 1 & 2740 & Risk Ratio (M-H, Random, 95\% Cl) & $0.92[0.45,1.90]$ \\
\hline 6 Minor bleeding & 2 & 3012 & Risk Ratio (M-H, Random, 95\% Cl) & $0.97[0.58,1.61]$ \\
\hline 7 Gastrointestinal bleeding & 2 & 5678 & Risk Ratio (M-H, Random, 95\% Cl) & $1.40[0.97,2.01]$ \\
\hline 8 Intracranial haemorrhage & 5 & 12521 & Risk Ratio (M-H, Random, 95\% Cl) & $0.43[0.27,0.69]$ \\
\hline 9 All-cause mortality & 4 & 9595 & Risk Ratio (M-H, Random, 95\% Cl) & $0.91[0.78,1.05]$ \\
\hline
\end{tabular}

Analysis 1.1. Comparison 1 Direct oral anticoagulants versus warfarin, Outcome 1 All strokes and systemic embolic events.

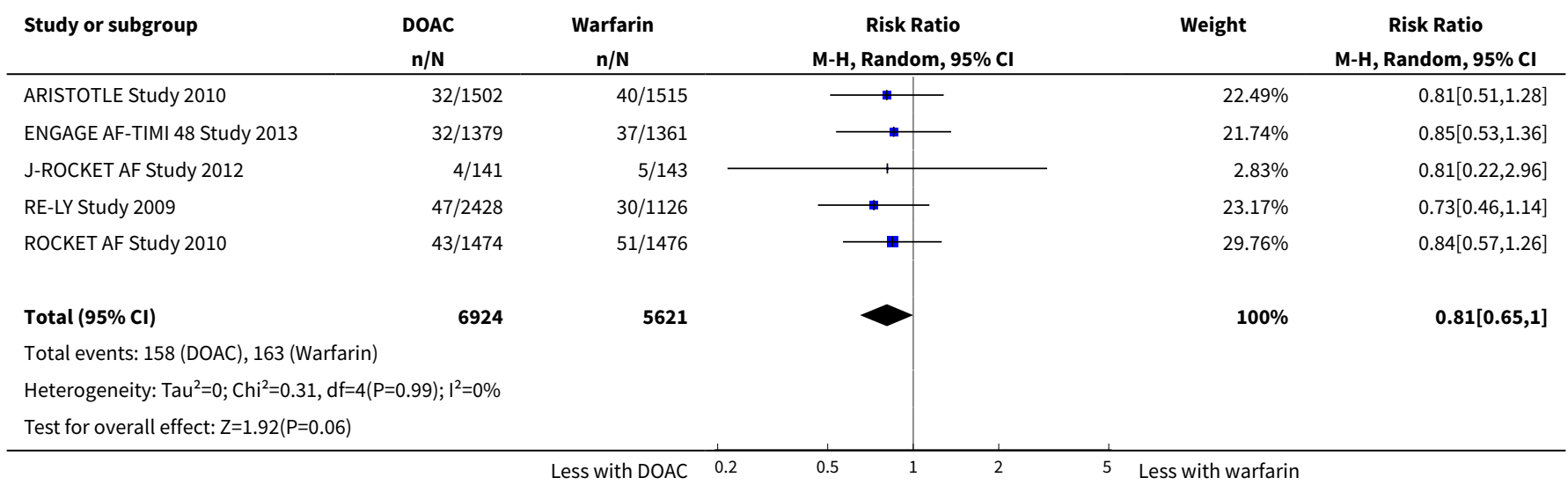


Analysis 1.2. Comparison 1 Direct oral anticoagulants versus warfarin, Outcome 2 Ischaemic stroke.

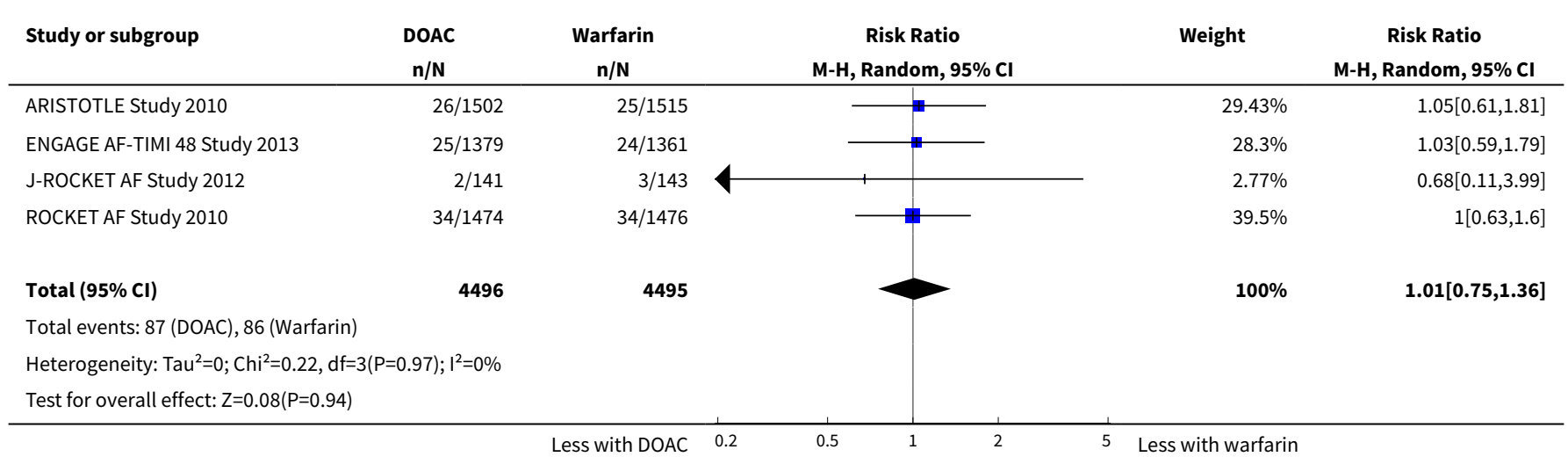

Analysis 1.3. Comparison 1 Direct oral anticoagulants versus warfarin, Outcome 3 Haemorrhagic stroke.

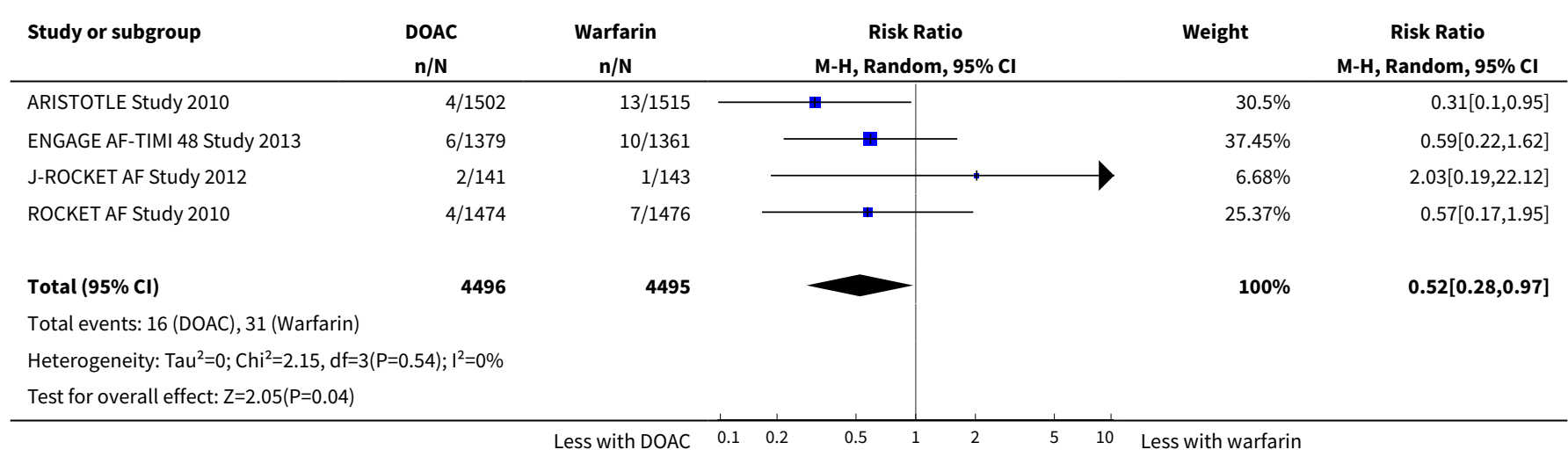

Analysis 1.4. Comparison 1 Direct oral anticoagulants versus warfarin, Outcome 4 Major bleeding.

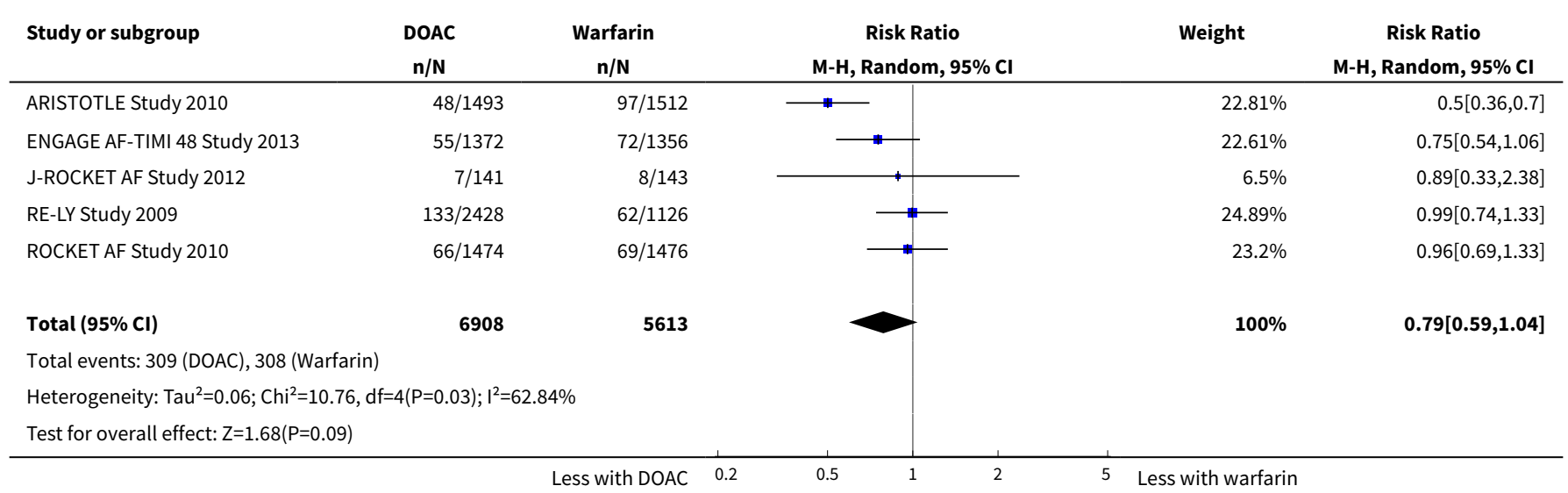


Analysis 1.5. Comparison 1 Direct oral anticoagulants versus warfarin, Outcome 5 Myocardial infarction.

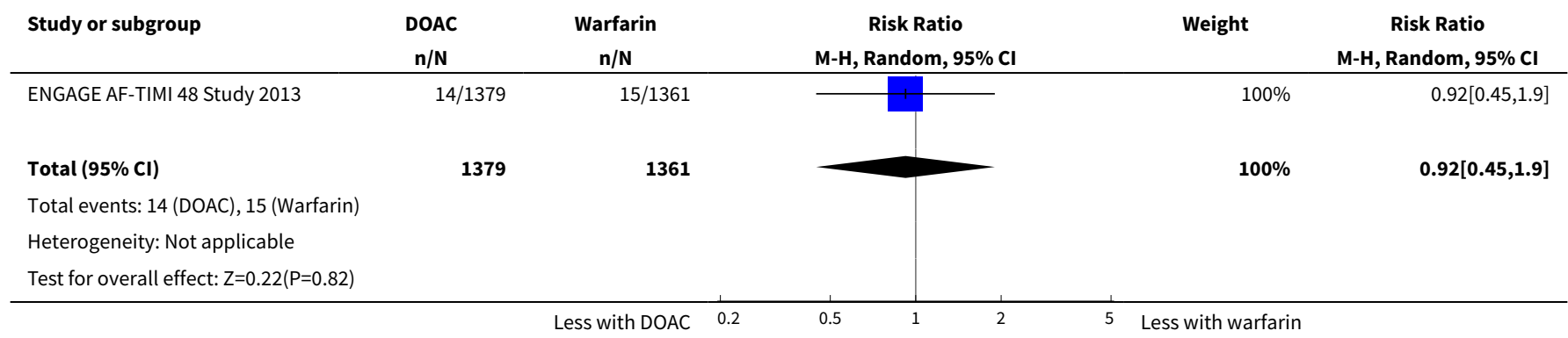

Analysis 1.6. Comparison 1 Direct oral anticoagulants versus warfarin, Outcome 6 Minor bleeding.

\begin{tabular}{|c|c|c|c|c|c|}
\hline Study or subgroup & $\begin{array}{c}\text { DOAC } \\
n / N\end{array}$ & $\begin{array}{c}\text { Warfarin } \\
\mathrm{n} / \mathrm{N}\end{array}$ & $\begin{array}{c}\text { Risk Ratio } \\
\text { M-H, Random, } 95 \% \mathrm{CI}\end{array}$ & Weight & $\begin{array}{c}\text { Risk Ratio } \\
\text { M-H, Random, } 95 \% \mathrm{Cl}\end{array}$ \\
\hline ENGAGE AF-TIMI 48 Study 2013 & $67 / 1372$ & $86 / 1356$ & 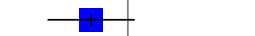 & $55.85 \%$ & $0.77[0.56,1.05]$ \\
\hline J-ROCKET AF Study 2012 & $32 / 141$ & $25 / 143$ & 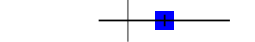 & $44.15 \%$ & $1.3[0.81,2.07]$ \\
\hline Total $(95 \% \mathrm{Cl})$ & 1513 & 1499 & & $100 \%$ & $0.97[0.58,1.61]$ \\
\hline \multicolumn{6}{|c|}{ Total events: 99 (DOAC), 111 (Warfarin) } \\
\hline \multicolumn{6}{|c|}{ Heterogeneity: $\operatorname{Tau}^{2}=0.1 ; \mathrm{Chi}^{2}=3.33, \mathrm{df}=1(\mathrm{P}=0.07) ; 1^{2}=70 \%$} \\
\hline \multicolumn{6}{|c|}{ Test for overall effect: $Z=0.12(P=0.91)$} \\
\hline & & DOAC & 0.5 & th warfarin & \\
\hline
\end{tabular}

Analysis 1.7. Comparison 1 Direct oral anticoagulants versus warfarin, Outcome 7 Gastrointestinal bleeding.

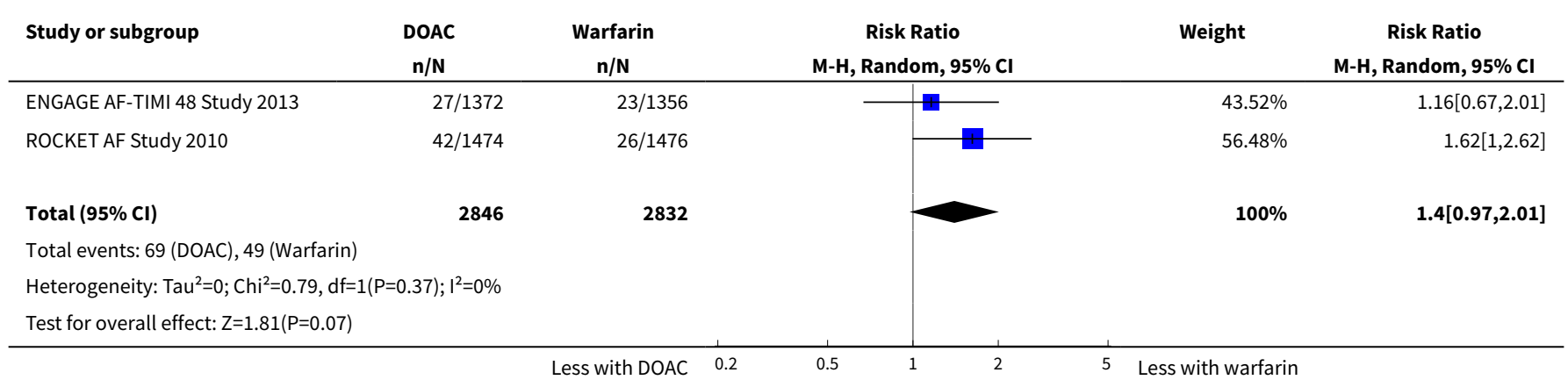

Analysis 1.8. Comparison 1 Direct oral anticoagulants versus warfarin, Outcome 8 Intracranial haemorrhage.

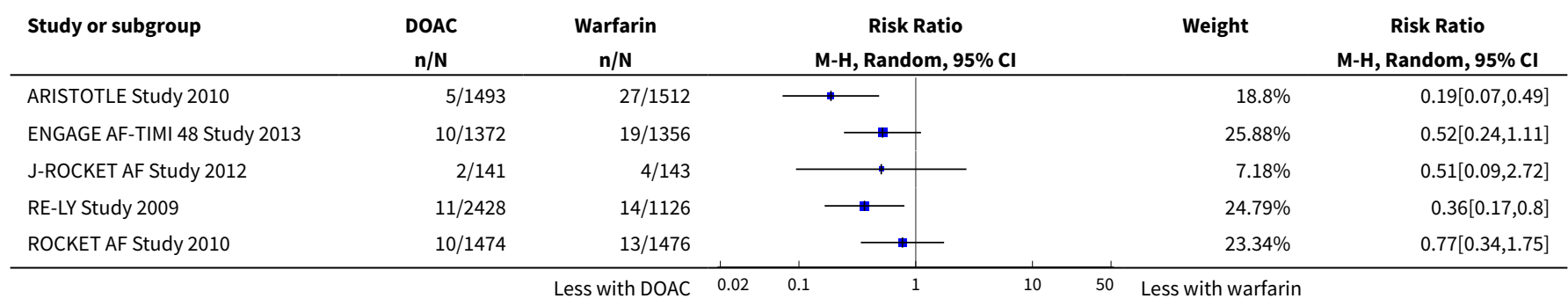




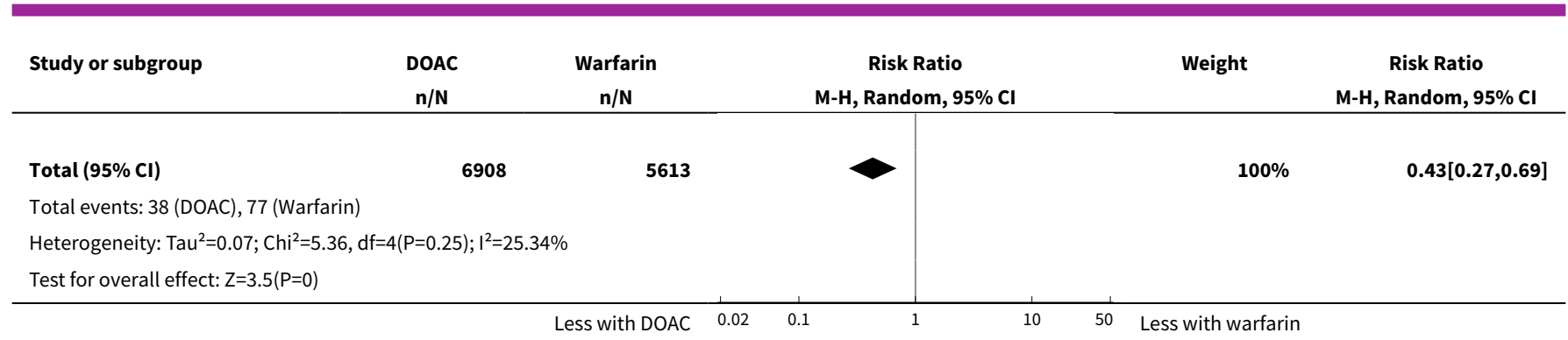

Analysis 1.9. Comparison 1 Direct oral anticoagulants versus warfarin, Outcome 9 All-cause mortality.

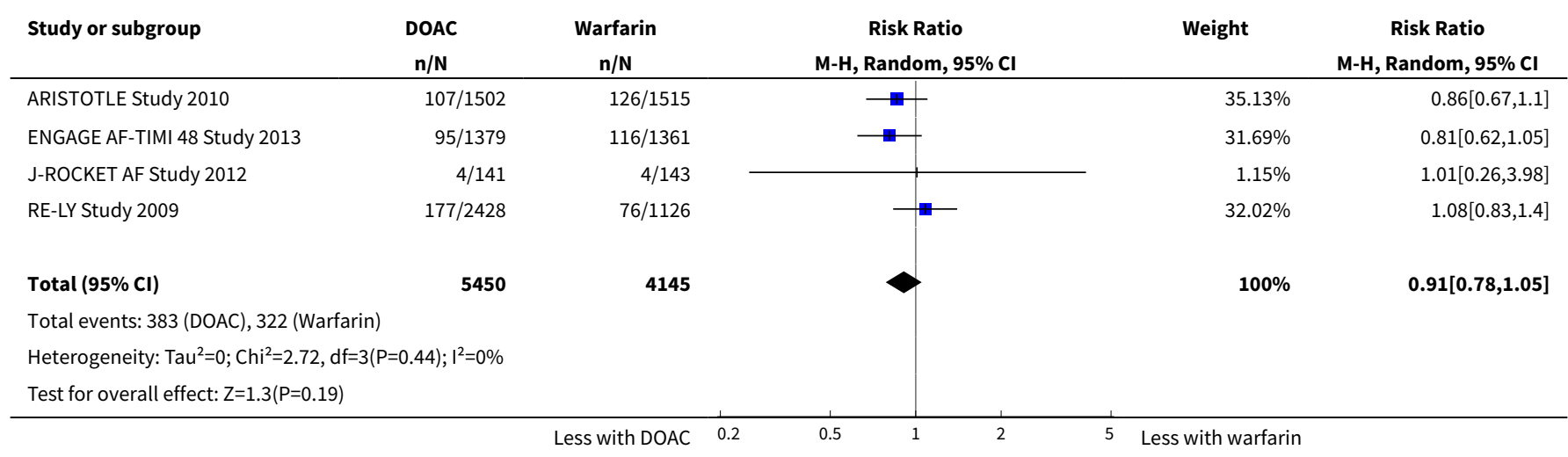

Comparison 2. Direct oral anticoagulants versus warfarin: subgroup analysis for participants with $\mathrm{CrCl} 30$ to $50 \mathrm{~mL}$ $\min$

\begin{tabular}{lllll}
\hline Outcome or subgroup title & No. of studies & $\begin{array}{l}\text { No. of partici- } \\
\text { pants }\end{array}$ & Statistical method & Effect size \\
\hline $\begin{array}{l}1 \text { All strokes and systemic embol- } \\
\text { ic events }\end{array}$ & 5 & 12155 & Risk Ratio (M-H, Random, 95\% Cl) & $0.82[0.66,1.02]$ \\
\hline \begin{tabular}{l} 
2 Major bleeding \\
\hline
\end{tabular} & 5 & 12132 & Risk Ratio (M-H, Random, 95\% Cl) & $0.80[0.62,1.03]$ \\
\hline
\end{tabular}

Analysis 2.1. Comparison 2 Direct oral anticoagulants versus warfarin: subgroup analysis for participants with $\mathrm{CrCl} 30$ to $50 \mathrm{~mL} / \mathrm{min}$, Outcome 1 All strokes and systemic embolic events.

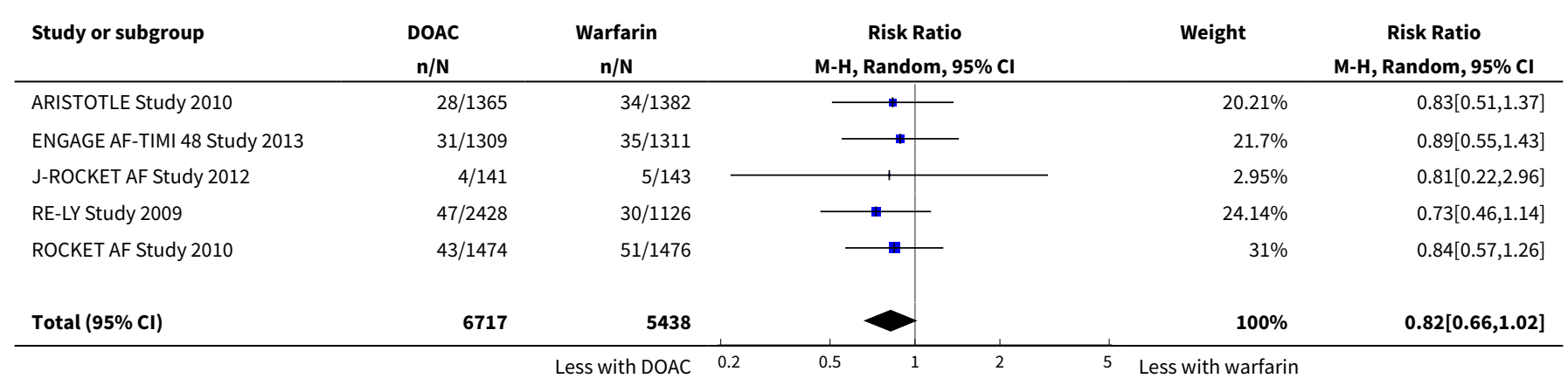




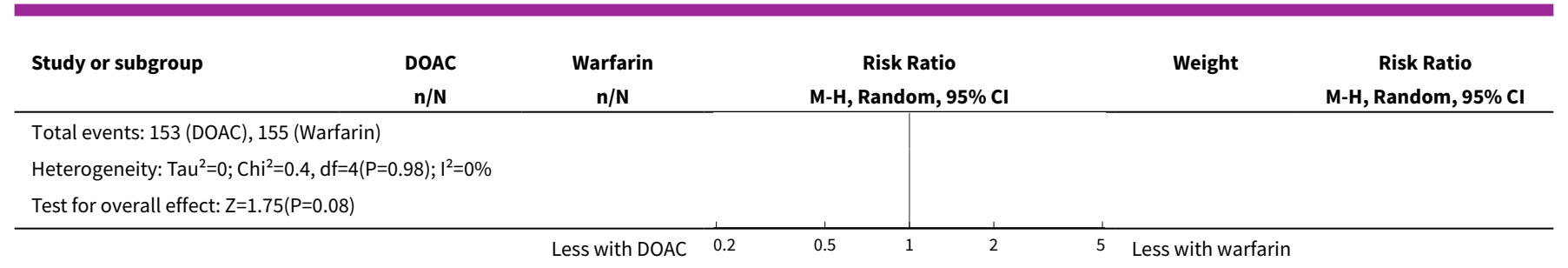

Analysis 2.2. Comparison 2 Direct oral anticoagulants versus warfarin: subgroup analysis for participants with $\mathrm{CrCl} 30$ to $50 \mathrm{~mL} / \mathrm{min}$, Outcome 2 Major bleeding.

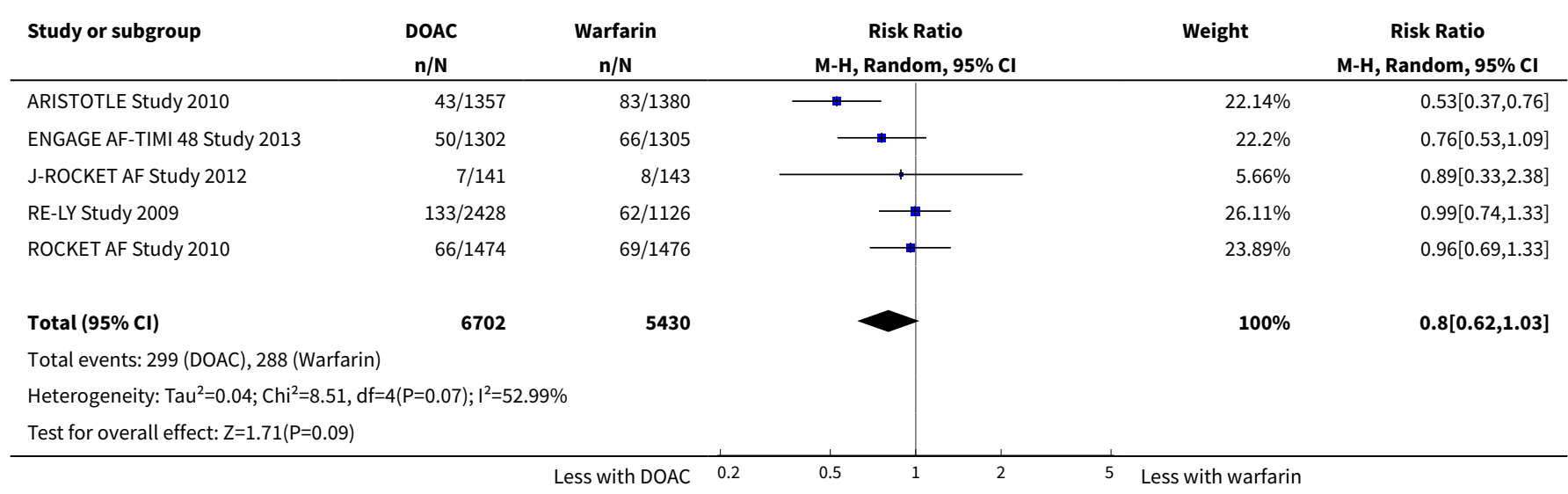

Comparison 3. Direct oral anticoagulants versus warfarin: subgroup analysis for participants with $\mathrm{CrCl} 15$ to $30 \mathrm{~mL}$ $\min$

\begin{tabular}{lllll}
\hline Outcome or subgroup title & No. of studies & $\begin{array}{l}\text { No. of partici- } \\
\text { pants }\end{array}$ & Statistical method & Effect size \\
\hline $\begin{array}{l}1 \text { All strokes and systemic embol- } \\
\text { ic events }\end{array}$ & 2 & 390 & Risk Ratio (M-H, Random, 95\% Cl) & $0.68[0.23,2.00]$ \\
\hline \begin{tabular}{l}
2 Major bleeding \\
\hline
\end{tabular} & 1 & 268 & Risk Ratio (M-H, Random, 95\% Cl) & $0.30[0.11,0.80]$ \\
\hline
\end{tabular}

Analysis 3.1. Comparison 3 Direct oral anticoagulants versus warfarin: subgroup analysis for participants with $\mathrm{CrCl} 15$ to $30 \mathrm{~mL} / \mathrm{min}$, Outcome 1 All strokes and systemic embolic events.

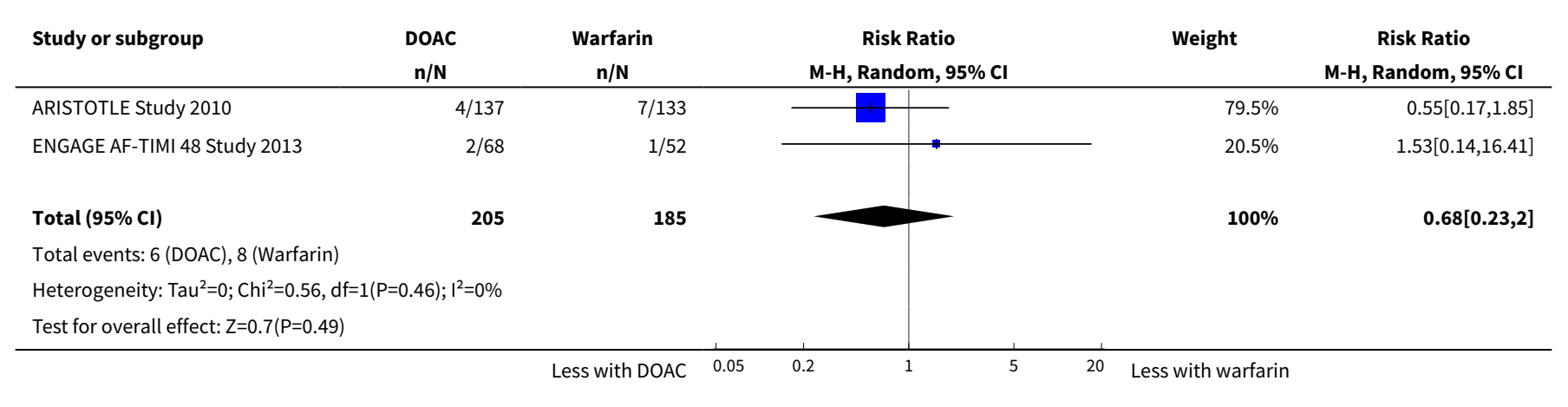


Analysis 3.2. Comparison 3 Direct oral anticoagulants versus warfarin: subgroup analysis for participants with $\mathrm{CrCl} 15$ to $30 \mathrm{~mL} / \mathrm{min}$, Outcome 2 Major bleeding.

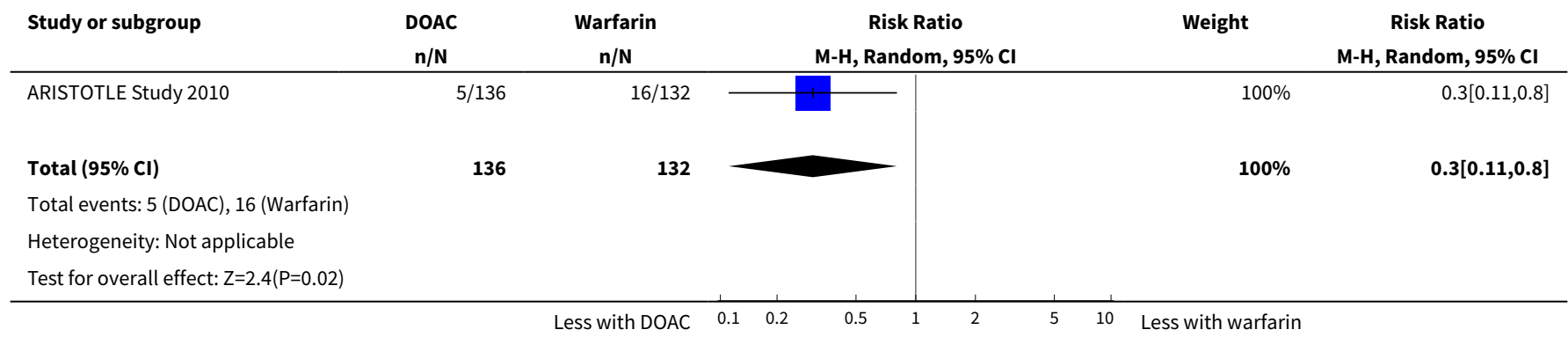

Comparison 4. Direct oral anticoagulants versus warfarin: subgroup analysis for different doses of DOAC

\begin{tabular}{lllll}
\hline Outcome or subgroup title & No. of studies & $\begin{array}{l}\text { No. of partici- } \\
\text { pants }\end{array}$ & Statistical method & Effect size \\
\hline $\begin{array}{l}1 \text { All strokes and systemic em- } \\
\text { bolic events }\end{array}$ & 5 & 12545 & Risk Ratio (M-H, Random, 95\% Cl) & $0.81[0.65,1.00]$ \\
\hline 2 Major bleeding & 5 & 12521 & Risk Ratio (M-H, Random, 95\% Cl) & $0.81[0.63,1.03]$ \\
\hline 3 All-cause mortality & 4 & 9595 & Risk Ratio (M-H, Random, 95\% Cl) & $0.91[0.78,1.05]$ \\
\hline
\end{tabular}

Analysis 4.1. Comparison 4 Direct oral anticoagulants versus warfarin: subgroup analysis for different doses of DOAC, Outcome 1 All strokes and systemic embolic events.

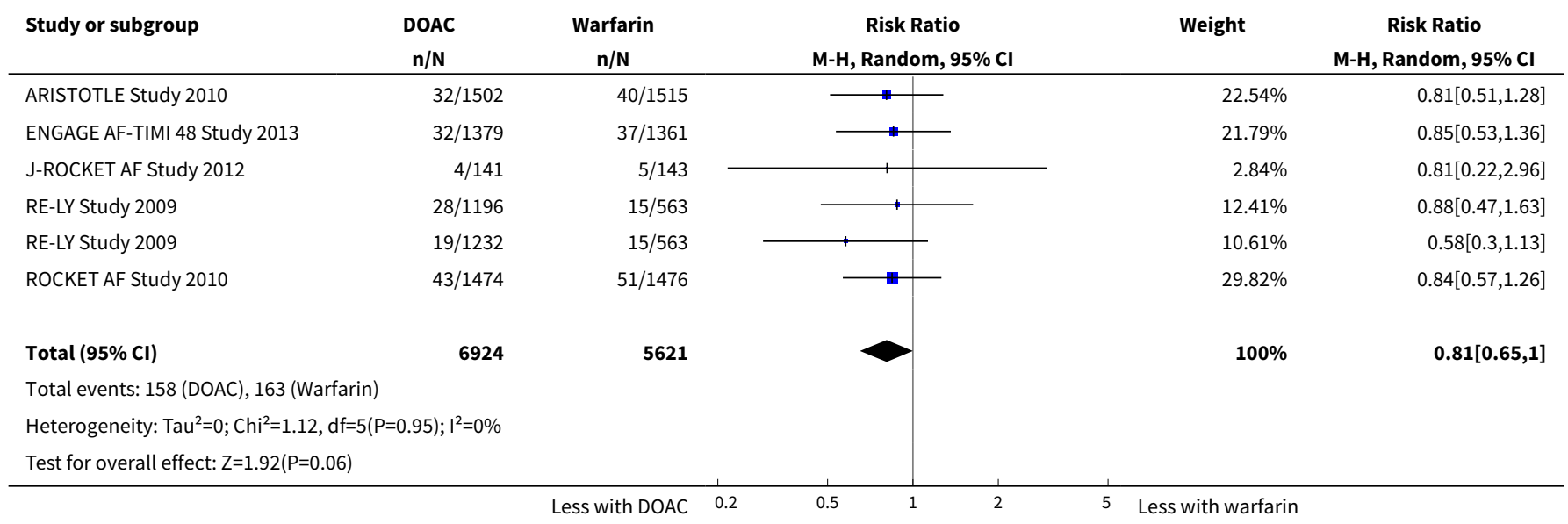


Analysis 4.2. Comparison 4 Direct oral anticoagulants versus warfarin: subgroup analysis for different doses of DOAC, Outcome 2 Major bleeding.

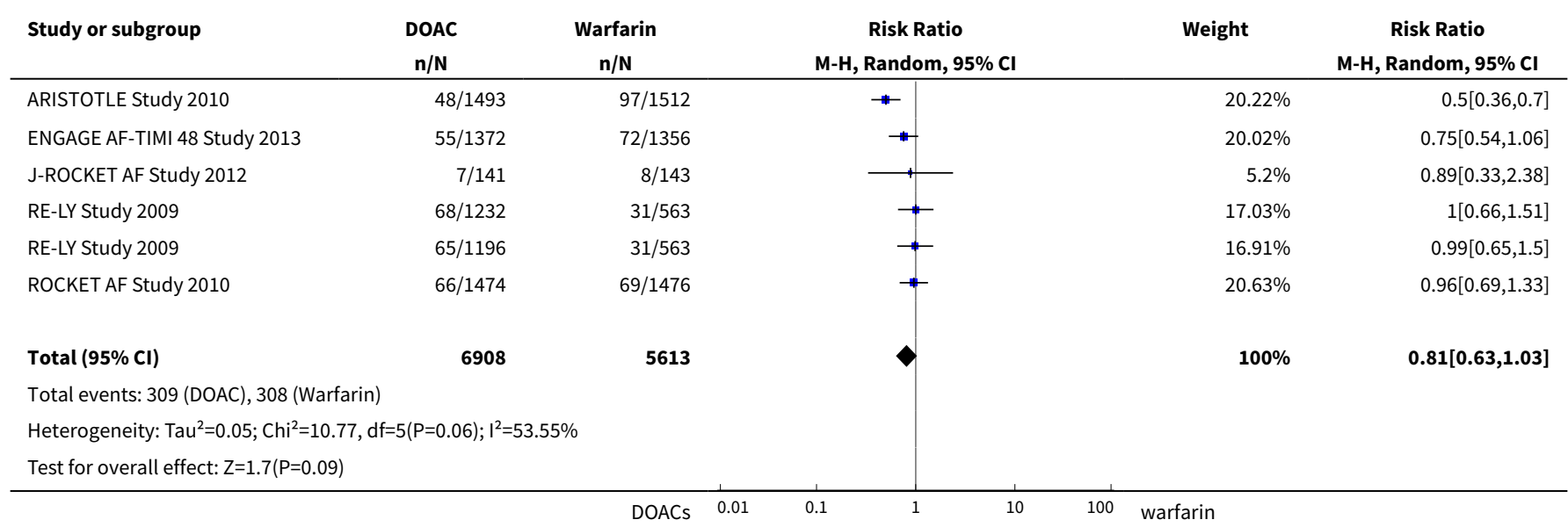

Analysis 4.3. Comparison 4 Direct oral anticoagulants versus warfarin: subgroup analysis for different doses of DOAC, Outcome 3 All-cause mortality.

\begin{tabular}{|c|c|c|c|c|c|}
\hline Study or subgroup & $\begin{array}{c}\text { DOAC } \\
n / N\end{array}$ & $\begin{array}{c}\text { Warfarin } \\
n / N\end{array}$ & $\begin{array}{c}\text { Risk Ratio } \\
\text { M-H, Random, 95\% Cl }\end{array}$ & Weight & $\begin{array}{c}\text { Risk Ratio } \\
\text { M-H, Random, 95\% Cl }\end{array}$ \\
\hline ARISTOTLE Study 2010 & $107 / 1502$ & $126 / 1515$ & $\longrightarrow+$ & $35.14 \%$ & $0.86[0.67,1.1]$ \\
\hline ENGAGE AF-TIMI 48 Study 2013 & $95 / 1379$ & $116 / 1361$ & 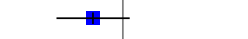 & $31.7 \%$ & $0.81[0.62,1.05]$ \\
\hline J-ROCKET AF Study 2012 & $4 / 141$ & $4 / 143$ & & $1.15 \%$ & $1.01[0.26,3.98]$ \\
\hline RE-LY Study 2009 & $83 / 1232$ & $38 / 563$ & - & $15.67 \%$ & $1[0.69,1.45]$ \\
\hline RE-LY Study 2009 & $94 / 1196$ & $38 / 563$ & 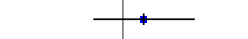 & $16.33 \%$ & $1.16[0.81,1.67]$ \\
\hline Total $(95 \% \mathrm{Cl})$ & 5450 & 4145 & & $100 \%$ & $0.91[0.78,1.05]$ \\
\hline \multicolumn{6}{|c|}{ Total events: 383 (DOAC), 322 (Warfarin) } \\
\hline \multicolumn{6}{|c|}{ Heterogeneity: $\mathrm{Tau}^{2}=0 ; \mathrm{Chi}^{2}=3.06, \mathrm{df}=4(\mathrm{P}=0.55) ; \mathrm{I}^{2}=0 \%$} \\
\hline \multicolumn{6}{|c|}{ Test for overall effect: $Z=1.3(P=0.19)$} \\
\hline
\end{tabular}

\section{Comparison 5. Direct oral anticoagulants versus warfarin: adverse events}

\begin{tabular}{llllll}
\hline $\begin{array}{l}\text { Outcome or sub- } \\
\text { group title }\end{array}$ & No. of studies & $\begin{array}{l}\text { No. of partici- } \\
\text { pants }\end{array}$ & Statistical method & Effect size \\
\hline 1 Epistaxis & 2 & 3234 & Risk Difference $(\mathrm{M}-\mathrm{H}$, Random, $95 \% \mathrm{Cl})$ & $-0.05[-0.22,0.11]$ \\
\hline 2 Nasopharyngitis & 2 & 3234 & Risk Difference (M-H, Random, 95\% Cl) & $0.03[-0.06,0.11]$ \\
\hline 3 Diarrhoea & 2 & 3234 & Risk Difference (M-H, Random, 95\% Cl) & $0.01[-0.04,0.06]$ \\
\hline $\begin{array}{l}4 \text { Upper respiratory } \\
\text { tract inflammation }\end{array}$ & 2 & 3234 & Risk Difference (M-H, Random, 95\% Cl) & $-0.01[-0.02,0.01]$ \\
\hline 5 Back pain & 2 & & Risk Difference (M-H, Random, 95\% Cl) & $-0.02[-0.05,0.01]$ \\
\hline
\end{tabular}

Direct oral anticoagulants versus warfarin for preventing stroke and systemic embolic events among atrial fibrillation patients with 40 chronic kidney disease (Review)

Copyright @ 2017 The Cochrane Collaboration. Published by John Wiley \& Sons, Ltd. 


\begin{tabular}{lllll}
\hline $\begin{array}{l}\text { Outcome or sub- } \\
\text { group title }\end{array}$ & No. of studies & $\begin{array}{l}\text { No. of partici- } \\
\text { pants }\end{array}$ & Statistical method & Effect size \\
\hline 6 Cardiac failure & 2 & 3234 & Risk Difference (M-H, Random, 95\% Cl) & $-0.01[-0.03,0.01]$ \\
\hline
\end{tabular}

\section{Analysis 5.1. Comparison 5 Direct oral anticoagulants versus warfarin: adverse events, Outcome 1 Epistaxis.}

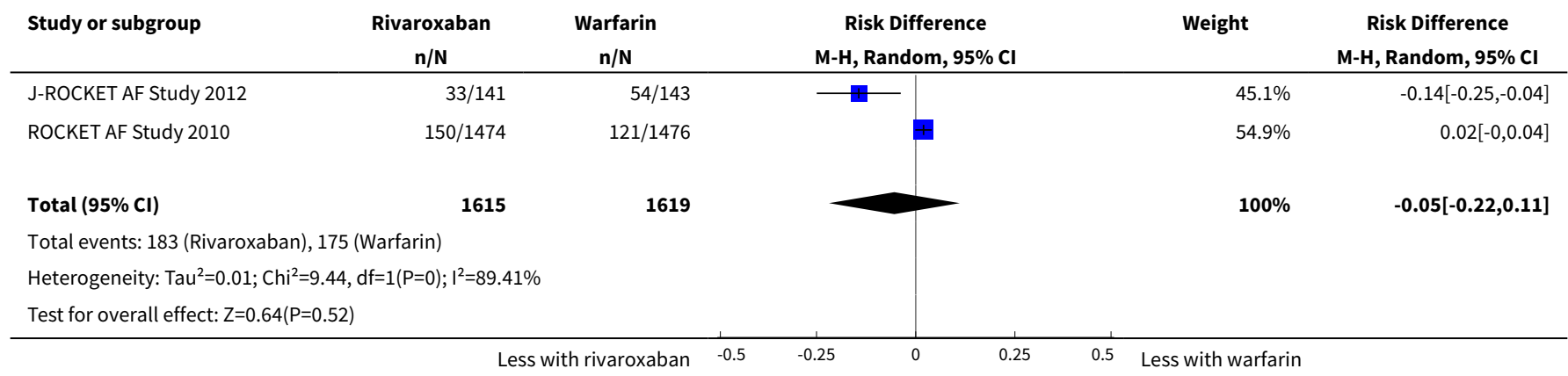

Analysis 5.2. Comparison 5 Direct oral anticoagulants versus warfarin: adverse events, Outcome 2 Nasopharyngitis.

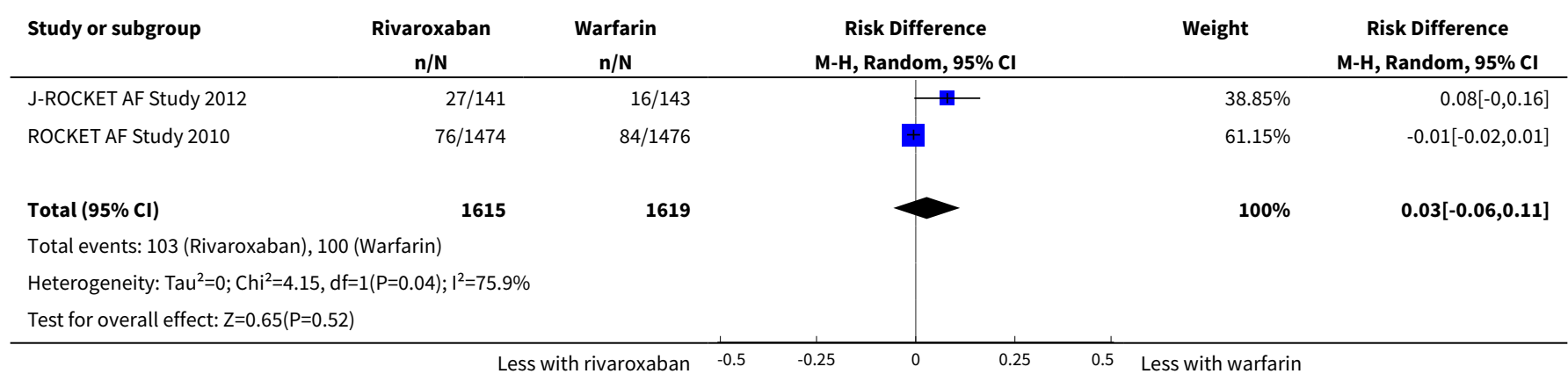

\section{Analysis 5.3. Comparison 5 Direct oral anticoagulants versus warfarin: adverse events, Outcome 3 Diarrhoea.}

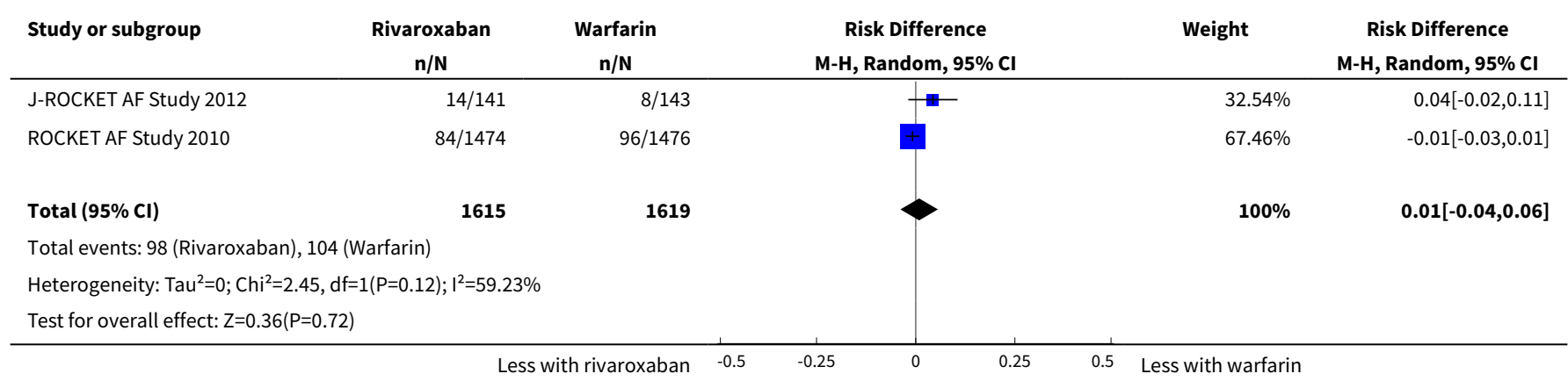


Analysis 5.4. Comparison 5 Direct oral anticoagulants versus warfarin: adverse events, Outcome 4 Upper respiratory tract inflammation.

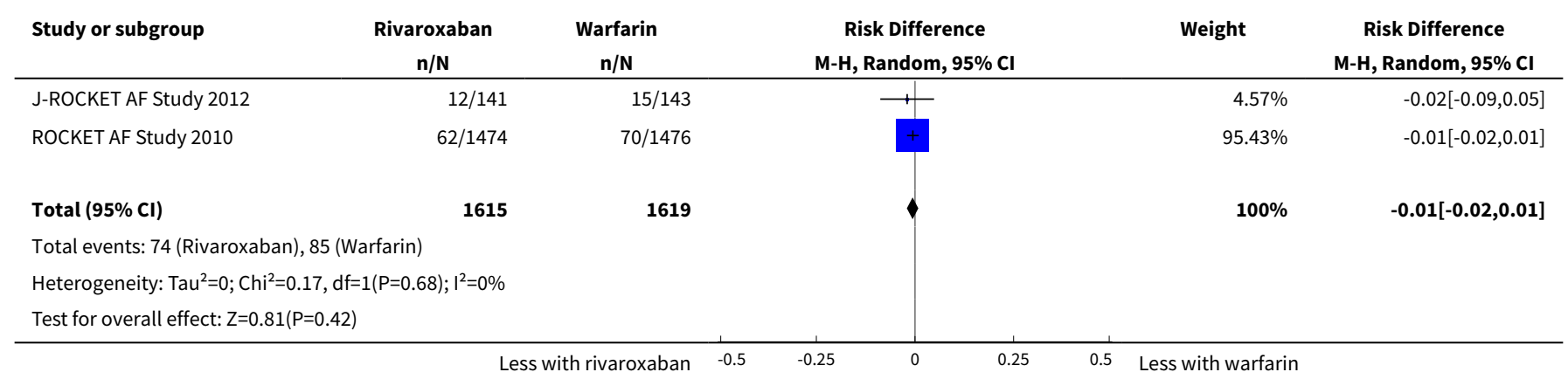

Analysis 5.5. Comparison 5 Direct oral anticoagulants versus warfarin: adverse events, Outcome 5 Back pain.

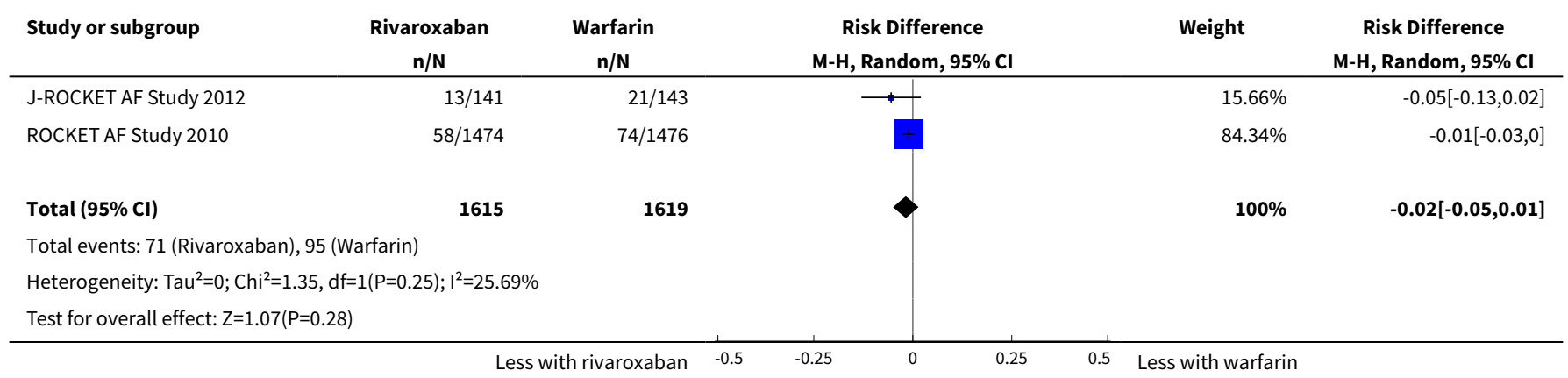

Analysis 5.6. Comparison 5 Direct oral anticoagulants versus warfarin: adverse events, Outcome 6 Cardiac failure.

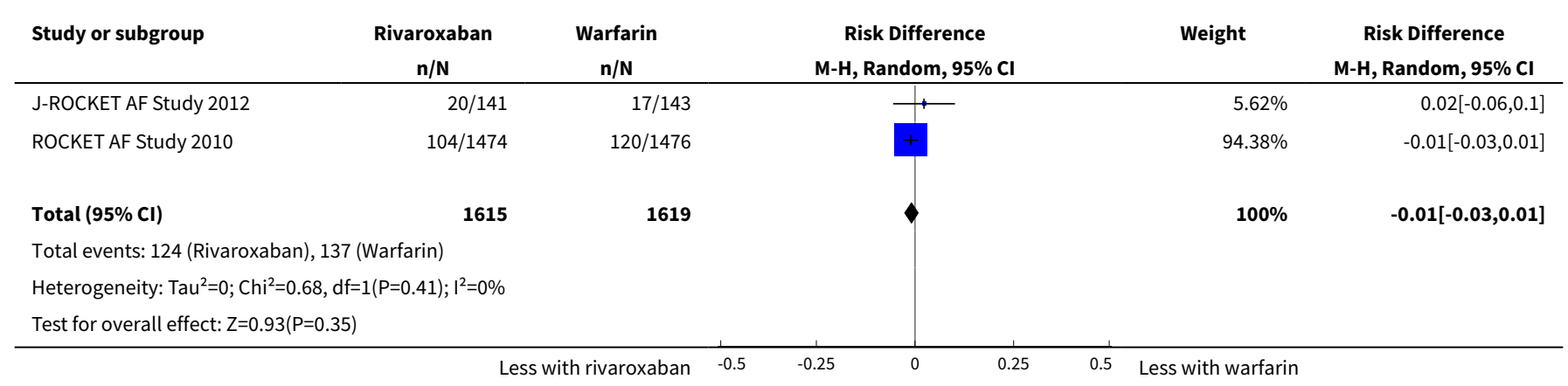

Comparison 6. Direct oral anticoagulants versus warfarin: fixed-effect model

\begin{tabular}{lllll}
\hline Outcome or subgroup title & No. of studies & $\begin{array}{l}\text { No. of partici- } \\
\text { pants }\end{array}$ & Statistical method & Effect size \\
\hline $\begin{array}{l}1 \text { All strokes and systemic embol- } \\
\text { ic events }\end{array}$ & 5 & 12545 & Risk Ratio (M-H, Fixed, 95\% Cl) & $0.81[0.65,1.01]$ \\
\hline
\end{tabular}

Direct oral anticoagulants versus warfarin for preventing stroke and systemic embolic events among atrial fibrillation patients with 


\begin{tabular}{lllll}
\hline Outcome or subgroup title & No. of studies & $\begin{array}{l}\text { No. of partici- } \\
\text { pants }\end{array}$ & Statistical method & Effect size \\
\hline 2 Major bleeding & 5 & 12521 & Risk Ratio (M-H, Fixed, 95\% Cl) & $0.79[0.67,0.92]$ \\
\hline
\end{tabular}

Analysis 6.1. Comparison 6 Direct oral anticoagulants versus warfarin: fixed-effect model, Outcome 1 All strokes and systemic embolic events.

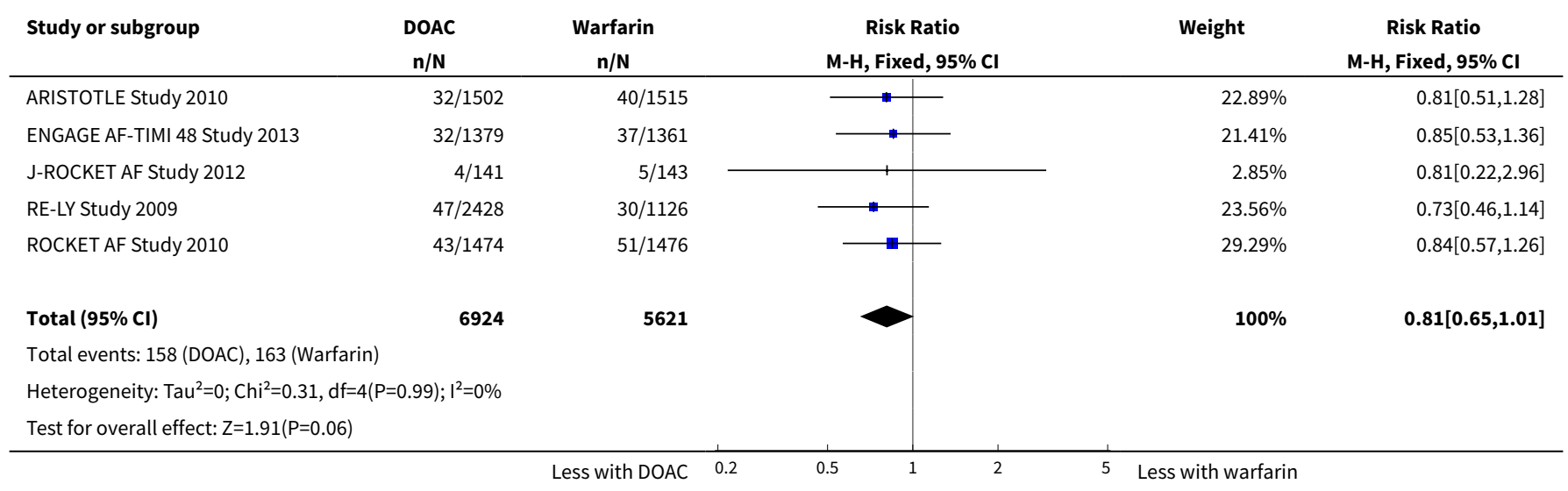

\section{Analysis 6.2. Comparison 6 Direct oral anticoagulants versus} warfarin: fixed-effect model, Outcome 2 Major bleeding.

\begin{tabular}{|c|c|c|c|c|c|}
\hline Study or subgroup & $\begin{array}{c}\text { DOAC } \\
n / N\end{array}$ & $\begin{array}{c}\text { Warfarin } \\
\text { n/N }\end{array}$ & $\begin{array}{r}\text { R } \\
M-H, F \\
\end{array}$ & Weight & $\begin{array}{c}\text { Risk Ratio } \\
\text { M-H, Fixed, 95\% Cl }\end{array}$ \\
\hline ARISTOTLE Study 2010 & $48 / 1493$ & $97 / 1512$ & $\longrightarrow$ & $29.17 \%$ & $0.5[0.36,0.7]$ \\
\hline ENGAGE AF-TIMI 48 Study 2013 & $55 / 1372$ & $72 / 1356$ & $\longrightarrow$ & $21.92 \%$ & $0.75[0.54,1.06]$ \\
\hline J-ROCKET AF Study 2012 & $7 / 141$ & $8 / 143$ & & $2.4 \%$ & $0.89[0.33,2.38]$ \\
\hline RE-LY Study 2009 & $133 / 2428$ & $62 / 1126$ & & $25.64 \%$ & $0.99[0.74,1.33]$ \\
\hline ROCKET AF Study 2010 & $66 / 1474$ & $69 / 1476$ & & $20.87 \%$ & $0.96[0.69,1.33]$ \\
\hline Total $(95 \% \mathrm{CI})$ & 6908 & 5613 & & $100 \%$ & $0.79[0.67,0.92]$ \\
\hline \multicolumn{6}{|c|}{ Total events: 309 (DOAC), 308 (Warfarin) } \\
\hline \multicolumn{6}{|c|}{ Heterogeneity: $\operatorname{Tau}^{2}=0 ; \mathrm{Chi}^{2}=10.76, \mathrm{df}=4(\mathrm{P}=0.03) ; \mathrm{I}^{2}=62.84 \%$} \\
\hline \multicolumn{6}{|l|}{ Test for overall effect: $Z=2.95(P=0)$} \\
\hline
\end{tabular}

\section{ADDITIONAL TABLES}

Table 1. Recommendation of major regulatory agencies

\begin{tabular}{lllll}
\hline & Dabigatran & Apixaban & Rivaroxaban & Edoxaban \\
\hline EMA 2014 & $\begin{array}{llll}150 \mathrm{mg} \text { twice daily for CKD } \\
\text { stage G3 (CrCl } 30 \text { to } 50 \mathrm{~mL} /\end{array}$ & $\begin{array}{l}2.5 \mathrm{mg} \text { twice daily in patients with at } \\
\text { least two of the following characteris- } \\
\text { tics: }\end{array}$ & $\begin{array}{l}15 \text { mg daily for CKD } \\
\text { stage G3 and G4 (Cr- } \\
\text { Cl 15 to } 50 \mathrm{~mL} / \mathrm{min})\end{array}$ & $\begin{array}{l}30 \mathrm{mg} \text { once daily } \\
\text { for CKD stage G3 }\end{array}$ \\
\hline
\end{tabular}

Direct oral anticoagulants versus warfarin for preventing stroke and systemic embolic events among atrial fibrillation patients with 
Table 1. Recommendation of major regulatory agencies (Continued)

$$
\begin{array}{ll}
\text { No recommendation for } & \text { - age } \geq 80 \text { years } \\
\text { CKD stage G4 } & \text { - body weight } \leq 60 \mathrm{~kg} \\
& -\mathrm{SCr}>1.5 \mathrm{mg} / \mathrm{dL}
\end{array}
$$

\begin{tabular}{|c|c|c|c|c|}
\hline FDA 2014 & $\begin{array}{l}150 \mathrm{mg} \text { twice daily for CKD } \\
\text { stage } \mathrm{G} 3(\mathrm{CrCl}>30 \mathrm{~mL} / \mathrm{min}) \\
75 \mathrm{mg} \text { twice daily for } \mathrm{CKD} \\
\text { stage } \mathrm{G} 4(\mathrm{CrCl} 15 \text { to } 30 \mathrm{~mL} / \\
\text { min) }\end{array}$ & $\begin{array}{l}2.5 \mathrm{mg} \text { twice daily in patients with at } \\
\text { least two of the following characteris- } \\
\text { tics: } \\
\text { - age } \geq 80 \text { years } \\
\text { - body weight } \leq 60 \mathrm{~kg} \\
\text { - } \mathrm{SCr}>1.5 \mathrm{mg} / \mathrm{dL}\end{array}$ & $\begin{array}{l}15 \text { mg daily for CKD } \\
\text { stage } \mathrm{G} 3 \text { and } \mathrm{G} 4(\mathrm{Cr}- \\
\mathrm{Cl} 15 \text { to } 50 \mathrm{~mL} / \mathrm{min})\end{array}$ & $\begin{array}{l}30 \mathrm{mg} \text { once daily } \\
\text { for CKD stage } \mathrm{G} 3 \\
\text { and } \mathrm{G} 4(\mathrm{CrCl} 15 \\
\text { to } 50 \mathrm{~mL} / \mathrm{min})\end{array}$ \\
\hline $\begin{array}{l}\text { Health Canada } \\
2017\end{array}$ & $\begin{array}{l}110 \text { or } 150 \text { mg twice daily } \\
\text { for CKD stage } \mathrm{G} 3 \text { ( } \mathrm{CrCl} 30 \text { to } \\
50 \mathrm{~mL} / \mathrm{min}) \\
\text { No recommendation for } \\
\text { CKD stage } \mathrm{G} 4\end{array}$ & $\begin{array}{l}2.5 \mathrm{mg} \text { twice daily in patients with at } \\
\text { least two of the following characteris- } \\
\text { tics: } \\
\text { - age } \geq 80 \text { years } \\
\text { - body weight } \leq 60 \mathrm{~kg} \\
\text { - } \mathrm{SCr}>1.5 \mathrm{mg} / \mathrm{dL}\end{array}$ & $\begin{array}{l}15 \mathrm{mg} \text { daily for CKD } \\
\text { stage } \mathrm{G} 3(\mathrm{CrCl} 30 \text { to } \\
50 \mathrm{~mL} / \mathrm{min}) \\
\text { No recommenda- } \\
\text { tion for } \mathrm{CKD} \text { stage } \\
\mathrm{G} 4\end{array}$ & $\begin{array}{l}30 \mathrm{mg} \text { once dai- } \\
\text { ly for CKD stage } \\
\mathrm{G} 3(\mathrm{CrCl} 30 \text { to } 50 \\
\mathrm{mL} / \mathrm{min})\end{array}$ \\
\hline
\end{tabular}

and $\mathrm{G} 4(\mathrm{CrCl} 15$

to $50 \mathrm{~mL} / \mathrm{min}$ )

\begin{tabular}{|c|c|}
\hline Database & Search terms \\
\hline CENTRAL & 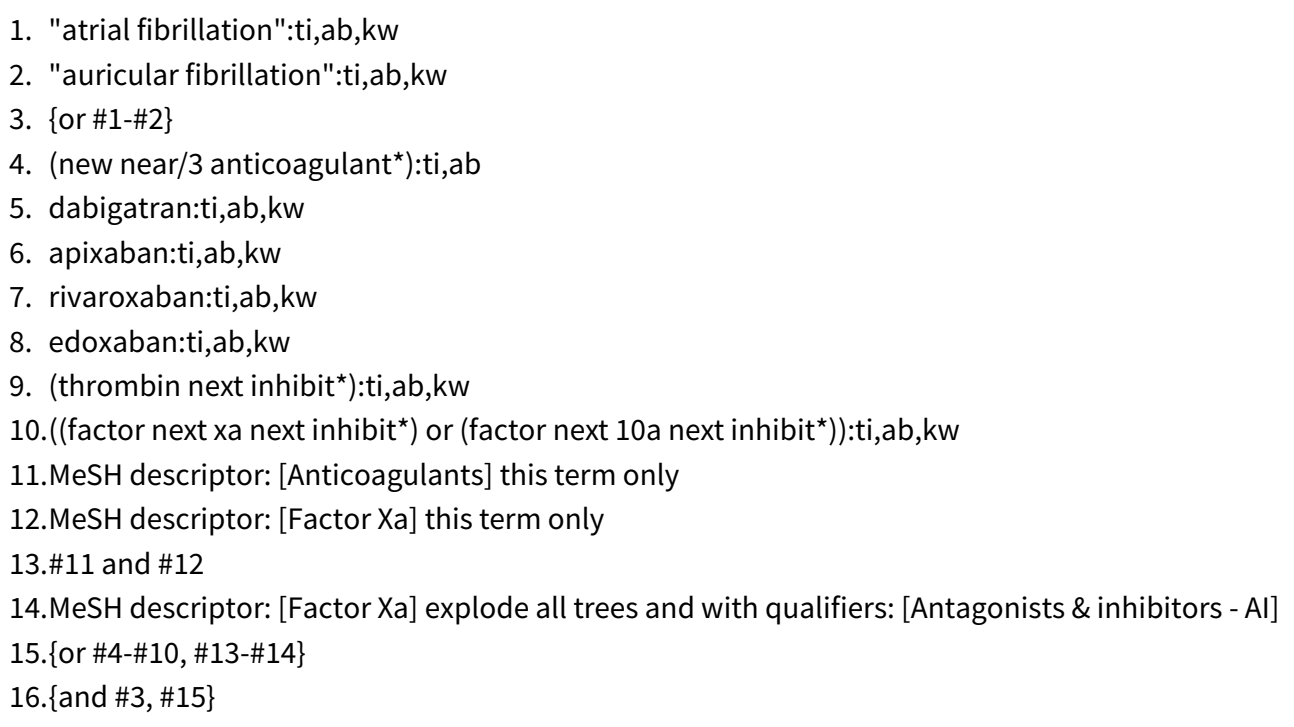 \\
\hline MEDLINE & $\begin{array}{l}\text { 1. Atrial Fibrillation/ } \\
\text { 2. atrial fibrillation.tw. } \\
\text { 2. auricular fihrillation }\end{array}$ \\
\hline
\end{tabular}

CKD - chronic kidney disease; $\mathrm{CrCl}$ - creatinine clearance; $\mathrm{SCr}$ - serum creatinine

\section{APPENDICES}

\section{Appendix 1. Electronic search strategies}




\author{
4. or/1-3 \\ 5. (new adj3 anticoagulant $\left.{ }^{\star}\right)$.tw. \\ 6. dabigatran.tw,rn. \\ 7. apixaban.tw,rn. \\ 8. rivaroxaban.tw,rn. \\ 9. edoxaban.tw,rn. \\ 10.direct thrombin inhibit*.tw. \\ 11.Anticoagulants/ and Factor $\mathrm{Xa} /$ \\ 12.factor xa inhibit ${ }^{\star}$.tw. \\ 13.Factor Xa/ai \\ 14.or/5-13 \\ 15 .and $/ 4,14$
}

EMBASE
1. exp heart atrium fibrillation/
2. atrial fibrillation.tw.
3. auricular fibrillation.tw.
4. or/1-3
5. (new adj3 anticoagulant ${ }^{\star}$ ).tw.
6. dabigatran/
7. apixaban/
8. rivaroxaban/
9. edoxaban/
10.dabigatran.tw.
11.apixaban.tw.
12.rivaroxaban.tw.
13.edoxaban.tw.
14.exp blood clotting factor 10a inhibitor/
15.exp thrombin inhibitor/
16.direct thrombin inhibit*.tw.
17.factor Xa inhibit*.tw.
18.or/5-17
19.and/4,18

\title{
Appendix 2. Risk of bias assessment tool
}

\begin{tabular}{ll}
\hline Potential source of bias & Assessment criteria \\
\hline $\begin{array}{l}\text { Random sequence genera- } \\
\text { tion }\end{array}$ & $\begin{array}{l}\text { Low risk of bias: Random number table; computer random number generator; coin tossing; shuf- } \\
\text { fling cards or envelopes; throwing dice; drawing of lots; minimization (minimization may be imple- } \\
\text { mented without a random element, and this is considered to be equivalent to being random). }\end{array}$ \\
\cline { 2 - 2 } $\begin{array}{l}\text { Selection bias (biased alloca- } \\
\text { inadequate generation of a } \\
\text { randomised sequence }\end{array}$ & $\begin{array}{l}\text { High risk of bias: Sequence generated by odd or even date of birth; date (or day) of admission; se- } \\
\text { quence generated by hospital or clinic record number; allocation by judgement of the clinician; by } \\
\text { preference of the participant; based on the results of a laboratory test or a series of tests; by avail- } \\
\text { ability of the intervention. }\end{array}$ \\
\cline { 2 - 3 } & $\begin{array}{l}\text { Unclear: Insufficient information about the sequence generation process to permit judgement. } \\
\text { Allocation concealment }\end{array}$ \\
$\begin{array}{l}\text { Low risk of bias: Randomisation method described that would not allow investigator/participant to } \\
\text { know or influence intervention group before eligible participant entered in the study (e.g. central } \\
\text { allocation, including telephone, web-based, and pharmacy-controlled, randomisation; sequential- }\end{array}$ \\
\hline
\end{tabular}

Direct oral anticoagulants versus warfarin for preventing stroke and systemic embolic events among atrial fibrillation patients with 
(Continued)

Selection bias (biased allocation to interventions) due to inadequate concealment of allocations prior to assignment ly numbered drug containers of identical appearance; sequentially numbered, opaque, sealed envelopes).

High risk of bias: Using an open random allocation schedule (e.g. a list of random numbers); assignment envelopes were used without appropriate safeguards (e.g. if envelopes were unsealed or non-opaque or not sequentially numbered); alternation or rotation; date of birth; case record number; any other explicitly unconcealed procedure.

Unclear: Randomisation stated but no information on method used is available.

\section{Blinding of participants and personnel}

Performance bias due to knowledge of the allocated interventions by participants and personnel during the study
Low risk of bias: No blinding or incomplete blinding, but the review authors judge that the outcome is not likely to be influenced by lack of blinding; blinding of participants and key study personnel ensured, and unlikely that the blinding could have been broken.

High risk of bias: No blinding or incomplete blinding, and the outcome is likely to be influenced by lack of blinding; blinding of key study participants and personnel attempted, but likely that the blinding could have been broken, and the outcome is likely to be influenced by lack of blinding.

Unclear: Insufficient information to permit judgement

\section{Blinding of outcome assess- ment}

Detection bias due to knowledge of the allocated interventions by outcome assessors.
Low risk of bias: No blinding of outcome assessment, but the review authors judge that the outcome measurement is not likely to be influenced by lack of blinding; blinding of outcome assessment ensured, and unlikely that the blinding could have been broken.

High risk of bias: No blinding of outcome assessment, and the outcome measurement is likely to be influenced by lack of blinding; blinding of outcome assessment, but likely that the blinding could have been broken, and the outcome measurement is likely to be influenced by lack of blinding.

Unclear: Insufficient information to permit judgement

\section{Incomplete outcome data}

Attrition bias due to amount, nature or handling of incomplete outcome data.
Low risk of bias: No missing outcome data; reasons for missing outcome data unlikely to be related to true outcome (for survival data, censoring unlikely to be introducing bias); missing outcome data balanced in numbers across intervention groups, with similar reasons for missing data across groups; for dichotomous outcome data, the proportion of missing outcomes compared with observed event risk not enough to have a clinically relevant impact on the intervention effect estimate; for continuous outcome data, plausible effect size (difference in means or standardized difference in means) among missing outcomes not enough to have a clinically relevant impact on observed effect size; missing data have been imputed using appropriate methods.

High risk of bias: Reason for missing outcome data likely to be related to true outcome, with either imbalance in numbers or reasons for missing data across intervention groups; for dichotomous outcome data, the proportion of missing outcomes compared with observed event risk enough to induce clinically relevant bias in intervention effect estimate; for continuous outcome data, plausible effect size (difference in means or standardized difference in means) among missing outcomes enough to induce clinically relevant bias in observed effect size; 'as-treated' analysis done with substantial departure of the intervention received from that assigned at randomisation; potentially inappropriate application of simple imputation.

Unclear: Insufficient information to permit judgement

\section{Selective reporting}

Reporting bias due to selective outcome reporting
Low risk of bias: The study protocol is available and all of the study's pre-specified (primary and secondary) outcomes that are of interest in the review have been reported in the pre-specified way; the study protocol is not available but it is clear that the published reports include all expected outcomes, including those that were pre-specified (convincing text of this nature may be uncommon).

High risk of bias: Not all of the study's pre-specified primary outcomes have been reported; one or more primary outcomes is reported using measurements, analysis methods or subsets of the data (e.g. subscales) that were not pre-specified; one or more reported primary outcomes were not prespecified (unless clear justification for their reporting is provided, such as an unexpected adverse 
effect); one or more outcomes of interest in the review are reported incompletely so that they cannot be entered in a meta-analysis; the study report fails to include results for a key outcome that would be expected to have been reported for such a study.

Unclear: Insufficient information to permit judgement

\section{Other bias}

-Funding bias
Low risk of bias: The trial was independently funded by a government organization or universities etc.

High risk of bias: The trial was funded by the commercial support and we are sure that there is an important risk of bias.

Unclear: The trial did not declare its funding source, or the trial was funded by the commercial support and we are not sure whether there is an important risk of bias.

\section{CONTRIBUTIONS OF AUTHORS}

1. Drafted the protocol: MK, TAF, KK, YG, S Fukuhara

2. Study selection: $M K, K K, Y G$

3. Extracted data from studies: MK, KK, YG

4. Entered data into RevMan: MK, KK

5. Carried out the analysis: MK, KK, YG

6. Interpreted the analysis: MK TAF, KK, YG, S Fukuma, S Fukuhara

7. Drafted the final review: MK, TAF, KK, YG,

8. Disagreement resolution: MK, TAF

9. Updated the review: MK

\section{DECLARATIONS OF INTEREST}

- Miho Kimachi: none known

- Toshiaki Furukawa has received lecture fees from Eli Lilly, Janssen, Meiji, Mitsubishi-Tanabe, MSD and Pfizer. He has received royalties from Igaku-Shoin and Nihon Bunka Kagaku-sha publishers. He has received research support from Mitsubishi-Tanabe and Mochida. These funds are not related to the production of this review.

- Kimihiko Kimachi: none known

- Yoshihito Goto: none known

- Shingo Fukuma: none known

- Shunichi Fukuhara: none known

\section{DIFFERENCES BETWEEN PROTOCOLANDREVIEW}

We changed the terms "NOACs (New oral anticoagulants)" to "DOAC (direct oral anticoagulants)" in accordance with the recommendation of the International Society on Thrombosis and Haemostasis (ISTH). In the original protocol, we intended to distinguish the effect of DOAC on two efficacy primary outcomes: all strokes and systemic embolic events. However, all included studies reported composite outcomes for all strokes, including ischaemic and haemorrhagic stroke and systemic embolic events; we therefore assessed these as one composite outcome.

\section{INDEX TERMS}

\section{Medical Subject Headings (MeSH)}

Administration, Oral; Anticoagulants [adverse effects] [*therapeutic use]; Antithrombins [adverse effects] [therapeutic use]; Atrial Fibrillation [ ${ }^{\star}$ complications]; Dabigatran [adverse effects] [therapeutic use]; Embolism [ ${ }^{\star}$ prevention \& control]; Hemorrhage [chemically induced] [epidemiology]; Pyrazoles [adverse effects] [therapeutic use]; Pyridines [adverse effects] [therapeutic use]; Pyridones [adverse effects] [therapeutic use]; Randomized Controlled Trials as Topic; Renal Insufficiency, Chronic [ ${ }^{\star}$ complications]; Rivaroxaban [adverse effects] [therapeutic use]; Stroke [ ${ }^{*}$ prevention \& control]; Thiazoles [adverse effects] [therapeutic use]; Warfarin [adverse effects] [therapeutic use] 


\section{MeSH check words}

Humans 